\title{
Assessment of Fission Product Cross-Section Data for Burnup Credit Applications
}

December 2007

\author{
Prepared by \\ L. C. Leal \\ H. Derrien \\ M. E. Dunn \\ D. E. Mueller
}

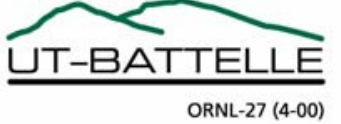




\section{DOCUMENT AVAILABILITY}

Reports produced after January 1, 1996, are generally available free via the U.S. Department of Energy (DOE) Information Bridge.

Web site http://www.osti.gov/bridge

Reports produced before January 1, 1996, may be purchased by members of the public from the following source.

National Technical Information Service

5285 Port Royal Road

Springfield, VA 22161

Telephone 703-605-6000 (1-800-553-6847)

TDD 703-487-4639

Fax 703-605-6900

E-mail info@ntis.gov

Web site http://www.ntis.gov/support/ordernowabout.htm

Reports are available to DOE employees, DOE contractors, Energy Technology Data Exchange (ETDE) representatives, and International Nuclear Information System (INIS) representatives from the following source.

Office of Scientific and Technical Information

P.O. Box 62

Oak Ridge, TN 37831

Telephone 865-576-8401

Fax 865-576-5728

E-mail reports@osti.gov

Web site http://www.osti.gov/contact.html

This report was prepared as an account of work sponsored by an agency of the United States Government. Neither the United States Government nor any agency thereof, nor any of their employees, makes any warranty, express or implied, or assumes any legal liability or responsibility for the accuracy, completeness, or usefulness of any information, apparatus, product, or process disclosed, or represents that its use would not infringe privately owned rights. Reference herein to any specific commercial product, process, or service by trade name, trademark, manufacturer, or otherwise, does not necessarily constitute or imply its endorsement, recommendation, or favoring by the United States Government or any agency thereof. The views and opinions of authors expressed herein do not necessarily state or reflect those of the United States Government or any agency thereof. 


\title{
ASSESSMENT OF FISSION PRODUCT CROSS-SECTION DATA FOR BURNUP CREDIT APPLICATIONS
}

\author{
L. C. Leal \\ H. Derrien \\ M. E. Dunn \\ D. E. Mueller
}

Date Published: December 2007

\author{
Prepared by \\ OAK RIDGE NATIONAL LABORATORY \\ Oak Ridge, Tennessee 37831-6283 \\ managed by \\ UT-BATTELLE, LLC \\ for the \\ U.S. DEPARTMENT OF ENERGY \\ under contract DE-AC05-00OR22725
}





\section{CONTENTS}

Page

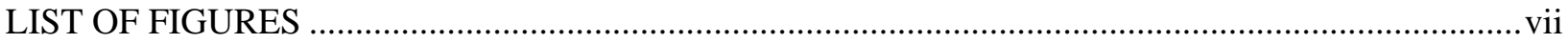

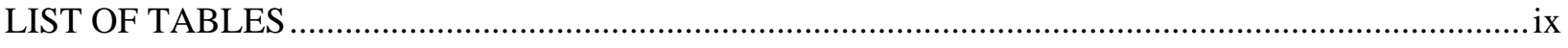

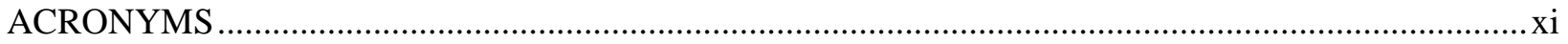

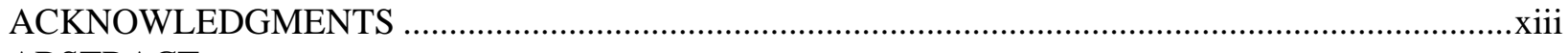

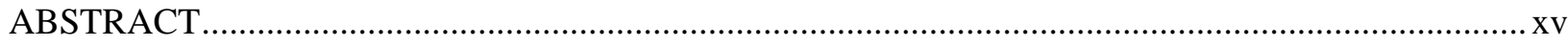

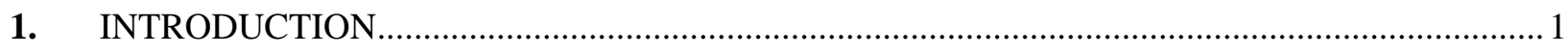

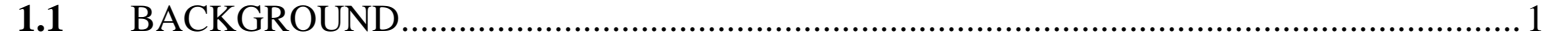

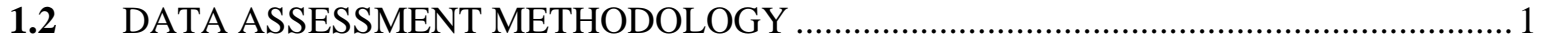

1.3 TYPICAL BURNUP-CREDIT MODEL USED IN DATA ASSESSMENT . .........................

1.4 COMPARISON WITH PREVIOUS DATA ASSESSMENT STUDIES .............................. 4

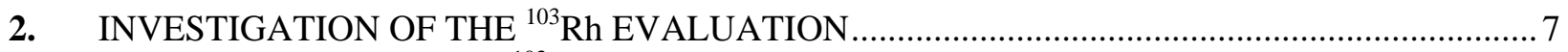

2.1 COMPARISON OF ${ }^{103} \mathrm{Rh}$ ENDF, JENDL, AND JEFF EVALUATIONS ............................ 7

2.2 COMPARISON OF THE ${ }^{103}$ Rh ENDF EVALUATION WITH

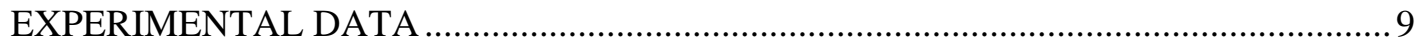

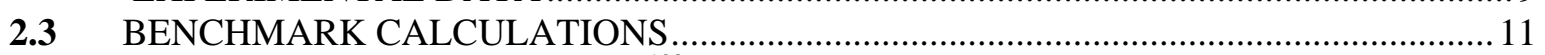

2.4 SENSITIVITY ANALYSIS FOR ${ }^{103}$ Rh IN A BURNUP CREDIT APPLICATION ...........12

$2.5 \quad$ ASSESSMENT SUMMARY AND RECOMMENDATIONS FOR ${ }^{103} \mathrm{Rh} \ldots \ldots \ldots \ldots \ldots \ldots \ldots . . . \ldots 13$

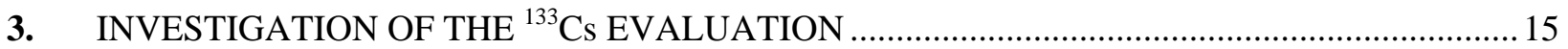

3.1 COMPARISON OF ${ }^{133}$ Cs ENDF, JENDL, AND JEFF EVALUATIONS .........................15

3.2 COMPARISONS OF THE ${ }^{133}$ CS JEFF EVALUATION WITH

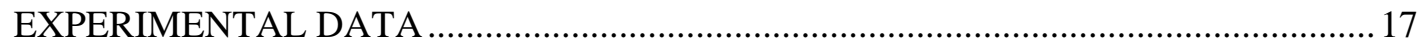

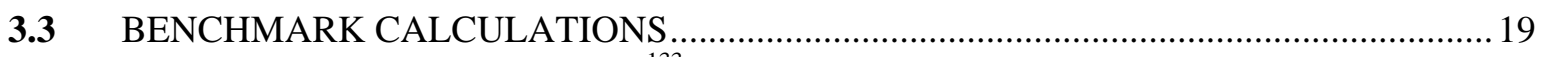

3.4 SENSITIVITY ANALYSIS FOR ${ }^{133}$ CS IN A BURNUP CREDIT APPLICATION ............19

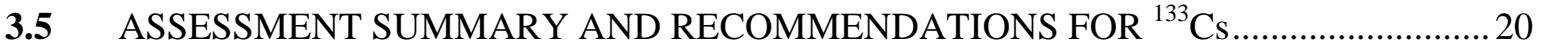

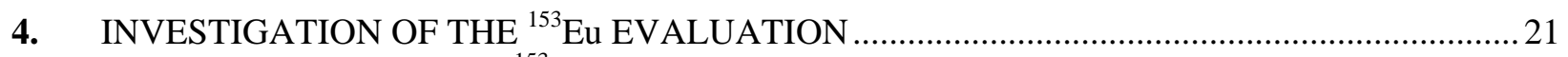

4.1 COMPARISON OF ${ }^{153}$ Eu ENDF, JENDL, AND JEFF EVALUATIONS...........................21

4.2 COMPARISON OF THE ${ }^{153}$ EU ENDF EVALUATION WITH

EXPERIMENTAL DATA

4.3 BENCHMARK CALCULATIONS

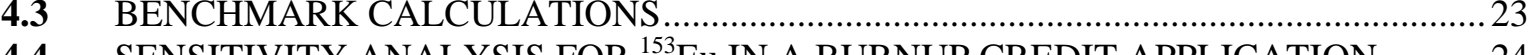

4.4 SENSITIVITY ANALYSIS FOR ${ }^{153}$ EU IN A BURNUP CREDIT APPLICATION ...........24

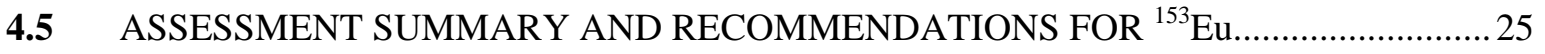

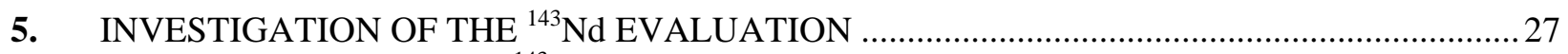

5.1 COMPARISON OF ${ }^{143}$ Nd ENDF, JENDL, AND JEFF EVALUATIONS .........................27

5.2 COMPARISONS OF THE ${ }^{143}$ Nd ENDF EVALUATION WITH

EXPERIMENTAL DATA.

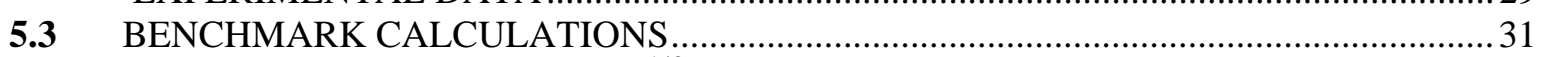

5.4 SENSITIVITY ANALYSIS FOR ${ }^{143}$ Nd IN A BURNUP CREDIT APPLICATION ...........32

$5.5 \quad$ ASSESSMENT SUMMARY AND RECOMMENDATIONS FOR ${ }^{143} \mathrm{Nd}$......................... 33

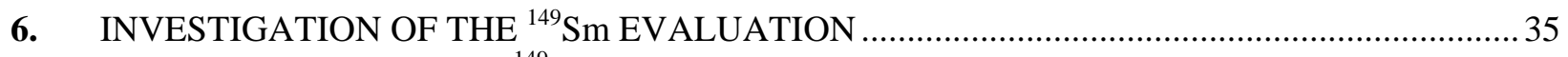

6.1 COMPARISON OF ${ }^{149}$ Sm ENDF, JENDL, AND JEFF EVALUATIONS ...........................35 


\section{CONTENTS (continued)}

Page

6.2 COMPARISONS OF THE ${ }^{149}$ Sm ENDF EVALUATION WITH EXPERIMENTAL DATA.

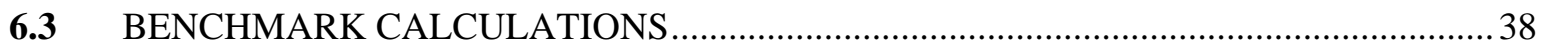

6.4 SENSITIVITY ANALYSIS FOR ${ }^{149} S \mathrm{Sm}$ IN A BURNUP CREDIT APPLICATION ...........39

6.5 ASSESSMENT SUMMARY AND RECOMMENDATIONS FOR ${ }^{149}{ }^{S m}$......................... 39

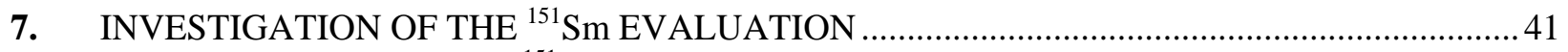

7.1 COMPARISON OF ${ }^{151}$ Sm ENDF, JENDL, AND JEFF EVALUATIONS......................... 41

7.2 COMPARISONS OF THE ${ }^{151}$ SM ENDF EVALUATION WITH EXPERIMENTAL DATA.

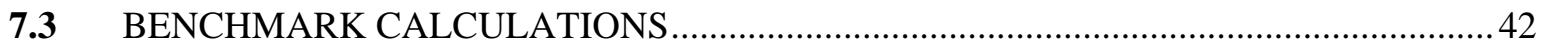

7.4 SENSITIVITY ANALYSIS FOR ${ }^{151}$ Sm IN A BURNUP CREDIT APPLICATION ...........43

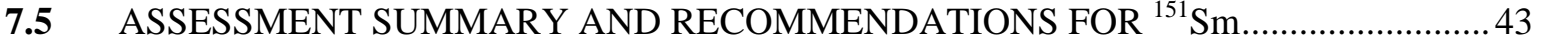

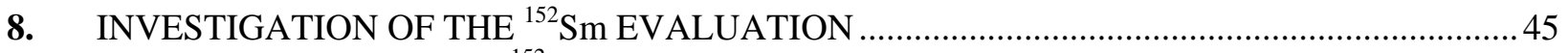

8.1 COMPARISON OF ${ }^{152} 2$ Sm ENDF, JENDL, AND JEFF EVALUATIONS........................ 45

8.2 COMPARISONS OF THE ${ }^{152}$ Sm ENDF EVALUATION WITH

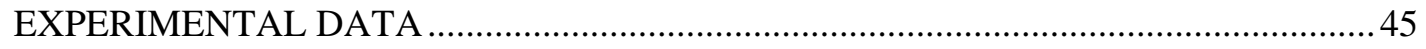

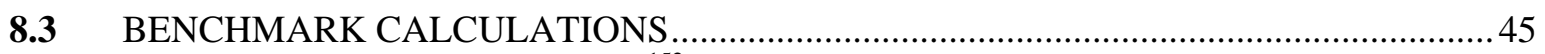

8.4 SENSITIVITY ANALYSIS FOR ${ }^{152}$ Sm IN A BURNUP CREDIT APPLICATION .......... 45

$8.5 \quad$ ASSESSMENT SUMMARY AND RECOMMENDATIONS FOR ${ }^{152}$ Sm.......................46

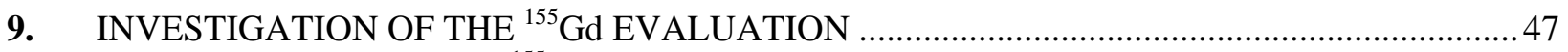

9.1 COMPARISON OF ${ }^{155}$ Gd ENDF, JENDL AND JEFF EVALUATIONS ...........................47

9.2 COMPARISONS OF THE ${ }^{155}$ Gd ENDF EVALUATION WITH

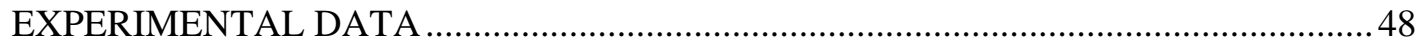

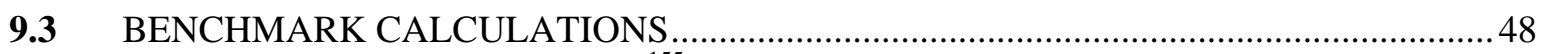

9.4 SENSITIVITY ANALYSIS FOR ${ }^{155}$ Gd IN A BURNUP CREDIT APPLICATION ..........49

9.5 ASSESSMENT SUMMARY AND RECOMMENDATIONS FOR ${ }^{155}$ Gd ..........................49

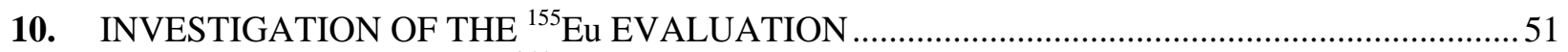

10.1 COMPARISON OF ${ }^{155}$ Eu ENDF, JENDL, AND JEFF EVALUATIONS.........................51

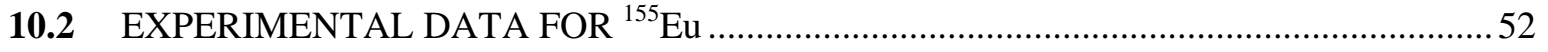

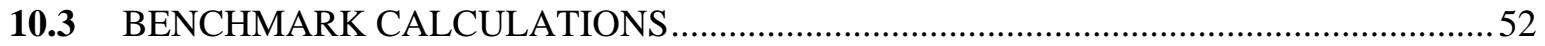

10.4 SENSITIVITY ANALYSIS FOR ${ }^{I 55}$ Eu IN A BURNUP CREDIT APPLICATION ............52

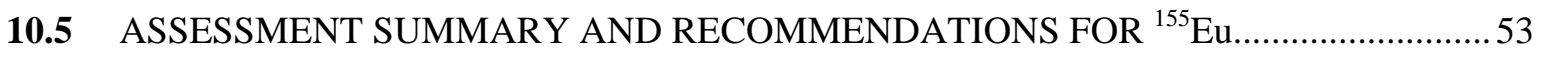

11. CONCLUSION AND RECOMMENDATIONS .................................................................... 55

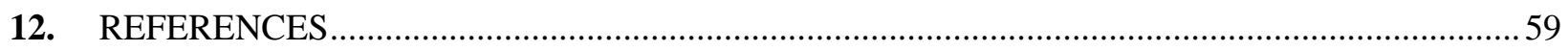




\section{LIST OF FIGURES}

Figure $\quad$ Page

Fig. 1. Comparison of the ENDF (o) and JENDL ( $\square$ ) total cross sections for ${ }^{103}$ Rh.......................... 7

Fig. 2. Comparison of the ENDF (o) and JENDL ( $\square$ ) total cross sections from 3 to $200 \mathrm{eV}$

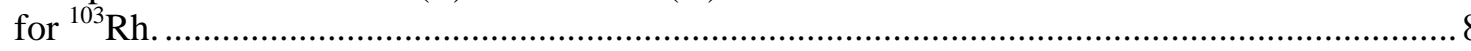

Fig. 3. Comparison of the ENDF (o) and JENDL ( $\square$ ) capture cross sections from 3 to $50 \mathrm{eV}$

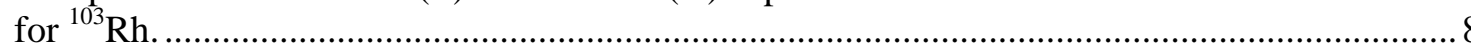

Fig. 4. Comparison of the ENDF (-) total cross section with the experimental data

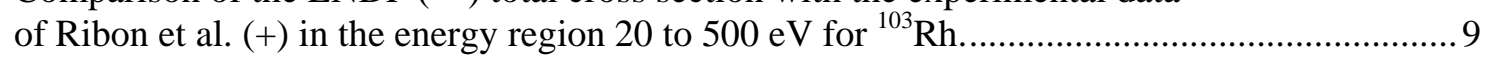

Fig. 5. Comparison of the ENDF (-) capture cross section with the experimental data

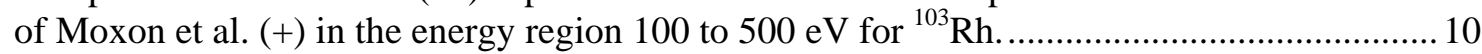

Fig. 6. Comparison of the ENDF (-) capture cross section with the experimental data

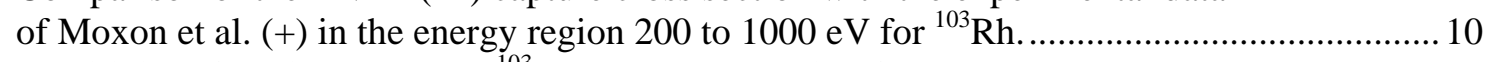

Fig. 7. Sensitivity of the keffective to the ${ }^{\mathrm{Ius}} \mathrm{Rh}$ total cross section for the GBC-32 model.........................13

Fig. 8. Comparison of the total cross sections for ${ }^{133}$ Cs in the ENDF ( $\square$ ). JEFF $(\star$ ).

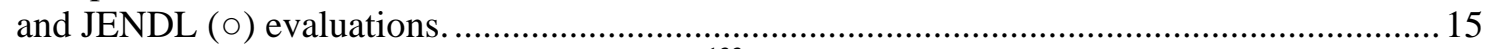

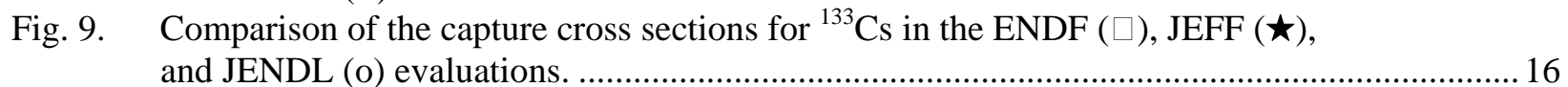

Fig. 10. Comparison of the total cross sections for ${ }^{133} \mathrm{Cs}$ in the ENDF ( $\square$ ). JEFF $(\star$ ).

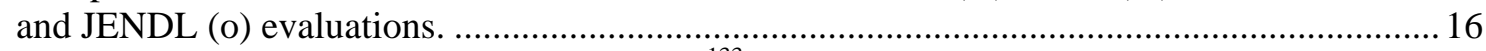

Fig. 11. Comparison of the capture cross sections for ${ }^{133} \mathrm{Cs}$ in the ENDF ( $\square$ ), JEFF ( $\star$ ). and JENDL (o) evaluations. ............................................................................................ 17

Fig. 12. Comparison of the experimental total cross section of Landon et al. and Hickman

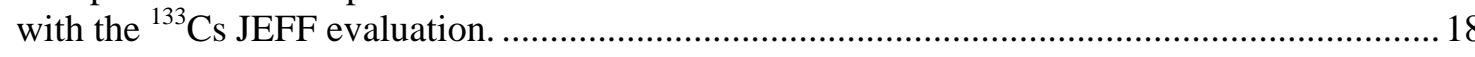

Fig. 13. Comparison of the experimental total cross section of Harvey et al. and the total cross section calculated with JEFF evaluation for ${ }^{133}$ Cs.

Fig. 14. Comparison of the experimental total cross sections of Harvey et al. data (top plot) and Garg et al. data (bottom plot) with cross section calculated with the JEFF evaluation for ${ }^{133} \mathrm{Cs}$.

Fig. 15. Sensitivity of the k ${ }_{\text {effective }}$ to the ${ }^{133}$ Cs total cross section for the GBC-32 model.......................20

Fig. 16. Comparison of the ENDF total (bottom plot) and capture (upper plot) cross section

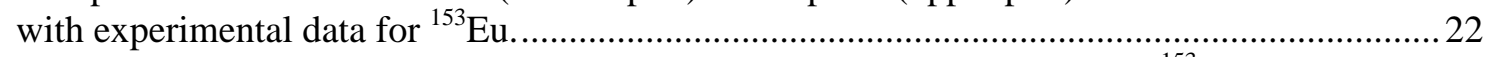

Fig. 17. Comparison of the ENDF capture cross section with experimental data for ${ }^{153}$ Eu. .................22

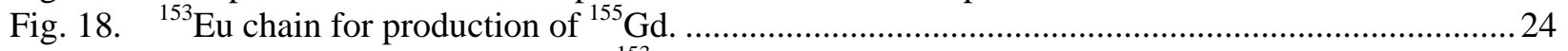

Fig. 19. Sensitivity of the keffective to the ${ }^{153}$ Eu total cross section for the GBC-32 model. ......................25

Fig. 20. Comparison of the ENDF (*), JENDL (+), and JEFF $(\times)$ capture cross sections from $10^{-3}$ to $10 \mathrm{eV}$ for ${ }^{143} \mathrm{Nd}$.

Fig. 21. Comparison of the ENDF (*), JENDL $(+)$, and JEFF $(\times)$ capture cross sections from 10 to $200 \mathrm{eV}$ for ${ }^{143} \mathrm{Nd}$.

Fig. 22. Comparison of the ENDF (*), JENDL $(+)$, and JEFF $(\times)$ capture cross sections from 500 to $1000 \mathrm{eV}$ for ${ }^{143} \mathrm{Nd}$.

Fig. 23. Comparison of the experimental total $(*)$, capture (+), and scattering $(\times)$ cross sections with the ENDF data from 0.02 to $10 \mathrm{eV}$ for ${ }^{143} \mathrm{Nd}$.

Fig. 24. Comparison of the experimental total cross sections (o) and calculations carried out with ENDF evaluation (-) for ${ }^{143} \mathrm{Nd}(60$ to $200 \mathrm{eV})$... 


\section{LIST OF FIGURES (continued)}

Figure

Page

Fig. 25. Comparison of the experimental total cross sections (o) and calculations carried out with ENDF evaluation (-) for ${ }^{143} \mathrm{Nd}(200$ to $500 \mathrm{eV})$...

Fig. 26. Comparison of the experimental total cross sections (o) and calculations carried out with ENDF evaluation (-) for ${ }^{143} \mathrm{Nd}(500$ to $1000 \mathrm{eV})$...

Fig. 27. Sensitivity of the keffective to the ${ }^{143} \mathrm{Nd}$ total cross section for the GBC-32 model.......................33

Fig. 28. Comparison of the total cross sections for ${ }^{149} \mathrm{Sm}$ from $10^{-5}$ to $0.4 \mathrm{eV}$ for the ENDF (+). $\operatorname{JEFF}(\times)$, and JENDL $(*)$ evaluations. .

Fig. 29. Comparison of the capture cross sections for ${ }^{149} \mathrm{Sm}$ from $10^{-5}$ to $0.4 \mathrm{eV}$ for the ENDF (+). JEFF $(\times)$, and JENDL $(*)$ evaluations.

Fig. 30. Comparison of the total cross sections for ${ }^{149} S m$ from $0.4 \mathrm{eV}$ to $10 \mathrm{eV}$ for the ENDF (+). JEFF $(\times)$, and JENDL $(*)$ evaluations. .

Fig. 31. Comparison of the capture cross sections for ${ }^{149} \mathrm{Sm}$ from $0.4 \mathrm{eV}$ to $10 \mathrm{eV}$ for the ENDF (+).

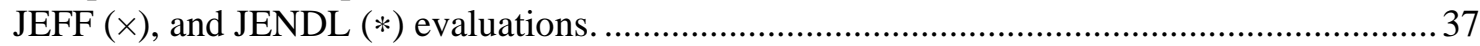

Fig. 32. Comparison of the experimental total cross section of Ohno et al. with the ENDF ${ }^{149} \mathrm{Sm}$ evaluation

等

Fig. 33. Sensitivity of the keffective to the ${ }^{149}$ Sm total cross section for the GBC-32 model. ...................... 39

Fig. 34. Comparison of the capture cross sections for ${ }^{151} \mathrm{Sm}$ from $10^{-5}$ to $10 \mathrm{eV}$ for the ENDF (+).

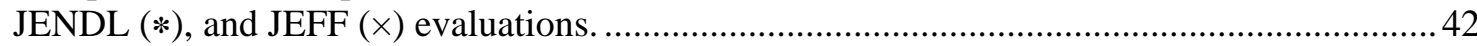

Fig. 35. Comparison of the experimental total cross section of Kirouac et al. with the 151 Sm ENDF

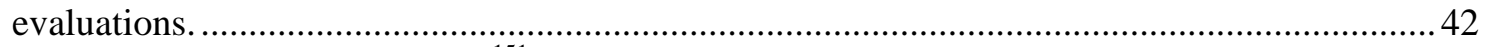

Fig. 36. Sensitivity of the keffective to the ${ }^{151}$ Sm total cross section for the GBC-32 model....................43

Fig. 37. Sensitivity of the keffective to the ${ }^{152}$ Sm total cross section for the GBC-32 model. .................... 46

Fig. 38. Comparison of the capture cross sections for ${ }^{155} \mathrm{Gd}$ from $10^{-5}$ to $5 \mathrm{eV}$ for the ENDF (+) and JENDL (*).

Fig. 39. Comparison of the experimental total cross section of Moller et al. with the ${ }^{155}$ Gd ENDF

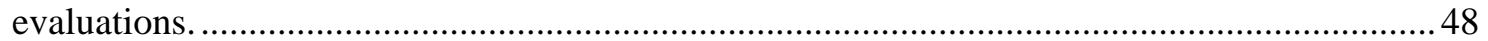

Fig. 40. Sensitivity of the $\mathrm{k}_{\text {effective }}$ to the ${ }^{15 \mathrm{~s}} \mathrm{Gd}$ total cross section for the GBC-32 model..................... 49

Fig. 41. Comparison of the capture cross sections for ${ }^{155}$ Eu from $10^{-5}$ to $4 \mathrm{eV}$ for the ENDF (+) and JENDL $(*)$.

Fig. 42. Sensitivity of the keffective to the ${ }^{155}$ Eu total cross section for the GBC-32 model. .....................53 


\section{LIST OF TABLES}

Table

$\underline{\text { Page }}$

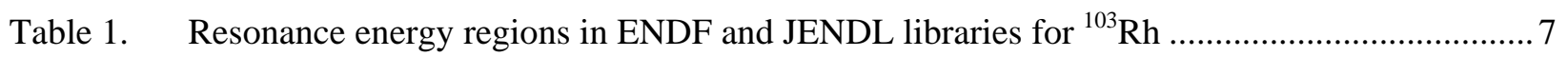

Table 2. $\quad$ Results of k effective $_{\text {e }}$ calculated with the MCNP and SCALE codes ..........................................11

Table 3. Calculation-to-experiment ratios of sample reactivity worth for ${ }^{\mathrm{IO}} \mathrm{Rh}$ in the Minerve experiments. The energetic contribution of the incident neutron spectrum to the ${ }^{103} \mathrm{Rh}$ capture reaction rate is also shown.

Table 4. $\quad$ Resonance energy regions in ENDF, JENDL, and JEFF libraries for ${ }^{133}$ Cs..........................15

Table 5. $\quad$ Resonance energy regions in ENDF, JENDL, and JEFF libraries for ${ }^{153} \mathrm{Eu}$.........................21

Table 6. Calculation-to-experiment ratios of sample reactivity worth for ${ }^{[15} \mathrm{Eu}$ in the Minerve experiments. The energetic contribution of the incident neutron spectrum to the ${ }^{153}$ Eu capture reaction rate is also shown (thermal region below $0.625 \mathrm{eV}$; fast region above $0.625 \mathrm{eV})$.

Table 7. Calculation-to-experiment ratio of ${ }^{153}$ Eu by measuring the ${ }^{153}{ }^{\mathrm{Eu}} /{ }^{238} \mathrm{U}$ ratio .......................23

Table 8. $\quad$ Resonance energy regions in ENDF, JENDL, and JEFF libraries for ${ }^{143}{ }^{\text {Nd }}$..........................22

Table 9. Calculation-to-experiment ratio of sample reactivity worth for ${ }^{143} \mathrm{Nd}$ in the Minerve and Dimple experiments...

Table 10. $\quad$ Resonance energy regions in ENDF, JENDL, and JEFF libraries for ${ }^{149} \mathrm{Sm}$........................35

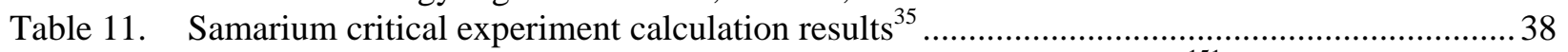

Table 12. $\quad$ Resonance energy regions in ENDF, JENDL, and JEFF libraries for ${ }_{151}^{15} \mathrm{Sm}$.......................4

Table 13. $\quad$ Resonance energy regions in ENDF, JENDL, and JEFF libraries for ${ }^{152} \mathrm{Sm}$.......................4 45

Table 14. $\quad$ Resonance energy regions in ENDF, JENDL, and JEFF libraries for ${ }^{155}$ Gd.......................4 47

Table 15. Resonance energy regions in ENDF, JENDL, and JEFF libraries for ${ }^{155} \mathrm{Eu}$.........................51

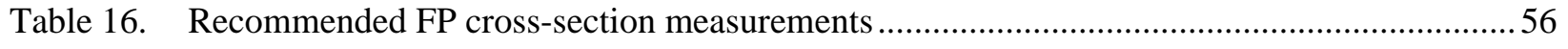

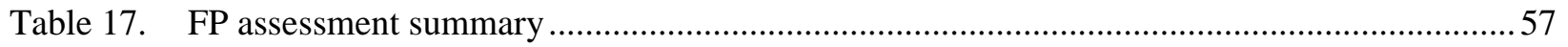




\section{ACRONYMS}

$\begin{array}{ll}\text { C/E } & \text { calculated-to-experiment } \\ \text { CEA } & \text { Comissariat a l'Energie Atomique } \\ \text { CY } & \text { calendar year } \\ \text { BNL } & \text { Brookhaven National Laboratory } \\ \text { BWR } & \text { boiling water reactor } \\ \text { DOE } & \text { Department of Energy } \\ \text { ENDF } & \text { Evaluated Nuclear Data File } \\ \text { EPRI } & \text { Electric Power Research Institute } \\ \text { EXFOR } & \text { EXchange FORmat } \\ \text { FP } & \text { fission product } \\ \text { FY } & \text { fiscal year } \\ \text { GELINA } & \text { Geel Electron Linear Accelerator } \\ \text { IHECSBE } & \text { International Handbook of Evaluated Criticality Safety Benchmark Experiments } \\ \text { IRMM } & \text { Institute for Reference Materials and Measurements } \\ \text { JEFF } & \text { Joint European Fission and Fusion } \\ \text { JENDL } & \text { Japanese Evaluated Nuclear Data Library } \\ \text { keV } & \text { kiloelectron volts } \\ \text { LWR } & \text { light-water-reactor } \\ \text { MLBW } & \text { Multilevel Breit-Wigner } \\ \text { Nd } & \text { natural neodymium } \\ \text { NNDC } & \text { National Nuclear Data Center } \\ \text { NRC } & \text { Nuclear Regulatory Commission } \\ \text { OCRWM } & \text { Office of Civilian Radioactive Waste Management } \\ \text { OFA } & \text { optimized fuel assembly } \\ \text { OLM } & \text { Office of Logistics Management } \\ \text { ORELA } & \text { Oak Ridge Electron Linear Accelerator } \\ \text { ORNL } & \text { Oak Ridge National Laboratory } \\ \text { PWR } & \text { pressurized-water reactor } \\ \text { RR } & \text { resolved resonance } \\ \text { RRR } & \text { resolved-resonance region } \\ \text { SNF } & \text { spent nuclear fuel } \\ \text { SNL } & \text { Sandia National Laboratories } \\ \text { URR } & \text { unresolved resonance region } \\ \text { YMP } & \text { Yucca Mountain Project } \\ & \end{array}$




\section{ACKNOWLEDGMENTS}

The initial phase of this work was sponsored by the Office of Logistics Management, Office of Civilian Radioactive Waste Management (OCRWM) of the U.S. Department of Energy (DOE), and the authors would like to acknowledge Nancy Slater Thompson as the responsible DOE manager. In FY 2007, this work was completed with support from the DOE OCRWM Yucca Mountain Project. The authors would like to thank Cecil V. Parks, and John C. Wagner of the Oak Ridge National Laboratory (ORNL) for valuable technical discussions on data issues related to burnup credit applications. In addition, the authors would like to acknowledge Arnaud Courcelle of Comissariat a l'Energie Atomique (CEA) in Cadarache, France, who visited ORNL for a period of 9 months in CY 2004 and 2005. Discussions between the authors and Mr. Courcelle provided further insight to current fission product cross-section data performance in burnup credit applications. The authors also express gratitude to Joyce Echols for her assistance in the preparation of this report. 


\begin{abstract}
Past efforts by the Department of Energy (DOE), the Electric Power Research Institute (EPRI), the Nuclear Regulatory Commission (NRC), and others have provided sufficient technical information to enable the NRC to issue regulatory guidance for implementation of pressurized-water reactor (PWR) burnup credit; however, consideration of only the reactivity change due to the major actinides is recommended in the guidance. Moreover, DOE, NRC, and EPRI have noted the need for additional scientific and technical data to justify expanding PWR burnup credit to include fission product (FP) nuclides and enable burnup credit implementation for boiling-water reactor (BWR) spent nuclear fuel (SNF). The criticality safety assessment needed for burnup credit applications will utilize computational analyses of packages containing SNF with FP nuclides. Over the years, significant efforts have been devoted to the nuclear data evaluation of major isotopes pertinent to reactor applications (i.e., uranium, plutonium, etc.); however, efforts to evaluate FP cross-section data in the resonance region have been less thorough relative to actinide data. In particular, resonance region cross-section measurements with corresponding R-matrix resonance analyses have not been performed for FP nuclides. Therefore, the objective of this work is to assess the status and performance of existing FP cross-section and crosssection uncertainty data in the resonance region for use in burnup credit analyses. Recommendations for new cross-section measurements and/or evaluations are made based on the data assessment. The assessment focuses on seven primary FP isotopes $\left({ }^{103} \mathrm{Rh},{ }^{133} \mathrm{Cs},{ }^{143} \mathrm{Nd},{ }^{149} \mathrm{Sm},{ }^{151} \mathrm{Sm},{ }^{152} \mathrm{Sm}\right.$, and $\left.{ }^{155} \mathrm{Gd}\right)$ that impact reactivity analyses of transportation packages and two FP isotopes $\left({ }^{153} \mathrm{Eu}\right.$ and $\left.{ }^{155} \mathrm{Eu}\right)$ that impact prediction of ${ }^{155} \mathrm{Gd}$ concentrations. Much of the assessment work was completed in 2005, and the assessment focused on the latest FP cross-section evaluations available in the international nuclear data community as of March 2005. The accuracy of the cross-section data was investigated by comparing existing cross-section evaluations against available measured cross-section data. When possible, benchmark calculations were also used to assess the performance of the latest FP cross-section data. Since March 2005, the U.S. and European data projects have released newer versions of their respective data files. Although there have been updates to the international data files and to some degree FP data, much of the updates have included nuclear cross-section modeling improvements at energies above the resonance region. The one exception is improved ENDF/B-VII cross-section uncertainty data or covariance data for gadolinium isotopes. In particular, ENDF/B-VII includes improved ${ }^{155} \mathrm{Gd}$ resonance parameter covariance data, but they are based on previously measured resonance data. Although the new covariance data are available for ${ }^{155} \mathrm{Gd}$, the conclusions of the FP cross-section data assessment of this report still hold in lieu of the newer international cross-section data files. Based on the FP data assessment, there is judged to be a need for new total and capture cross-section measurements and corresponding cross-section evaluations, in a prioritized manner, for the nine FPs to provide the improved information and technical rigor needed for criticality safety analyses.
\end{abstract}




\section{INTRODUCTION}

\subsection{BACKGROUND}

This work has been performed as part of a larger Department of Energy (DOE) Office of Civilian Radioactive Waste Management (OCRWM) project to establish the technical data and information needed to support the implementation of burnup credit for spent nuclear fuel (SNF). The objective of this work is to assess the status and performance of fission product (FP) nuclear cross-section data evaluations in the thermal, resolved-resonance region (RRR) and unresolved resonance region (URR) for supporting burnup credit analyses. The focus of the assessment is seven FPs with the highest worth to burnup credit: ${ }^{149} \mathrm{Sm},{ }^{143} \mathrm{Nd},{ }^{103} \mathrm{Rh},{ }^{151} \mathrm{Sm},{ }^{133} \mathrm{Cs},{ }^{155} \mathrm{Gd}$, and ${ }^{152} \mathrm{Sm}$. In addition, ${ }^{153} \mathrm{Eu}$, and ${ }^{155} \mathrm{Eu}$ are included in this assessment because the ${ }^{155} \mathrm{Gd}$ composition in SNF is highly dependent on ${ }^{155} \mathrm{Eu}$ and to a lesser extent ${ }^{153} \mathrm{Eu}$, and calculated isotopic predictions for ${ }^{155} \mathrm{Gd}$ often show significant differences when compared to measured results. ${ }^{1}$ These FPs, except for the europium isotopes, can account for a significant amount of negative reactivity worth in SNF. As an example, the FP reactivity worth for the first seven isotopes in the above list can account for $\sim 5 \% \Delta \mathrm{k}$ in a cask loaded with $4 \mathrm{wt} \%$ enriched Westinghouse $17 \times 17$ assemblies burned to $40 \mathrm{GWd} / \mathrm{MTU} .^{2}$

\subsection{DATA ASSESSMENT METHODOLOGY}

Evaluated data play an important role in the design of nuclear reactors, criticality safety applications, and other nuclear system designs. Over the years a great deal of effort has been devoted to the evaluation of major isotopes pertinent to reactor applications, including the uranium isotopes, plutonium isotopes, etc. However, the effort to evaluate FP data has not been as thorough when compared with actinide data. In particular, resonance region cross-section measurements with corresponding R-matrix resonance analyses have not been performed for FP nuclides. Indeed, for some FP isotopes the evaluations included in the nuclear data libraries such as the U.S. Evaluated Nuclear Data File (ENDF) library, ${ }^{\beta}$ Japanese Evaluated Nuclear Data Library (JENDL), ${ }^{4}$ and the Joint European Fission and Fusion (JEFF) data library, perceived to be deficient. In most cases, the data deficiency in a cross-section evaluation can largely be attributed to the lack of measured experimental data to allow a consistent data evaluation. A procedure frequently used when no experimental data are available is to generate the nuclear data based on theoretical physics models. Although nuclear model calculations are routinely used for cross-section energies above the resonance region, nuclear model calculations are not adequate to predict the detailed cross-section structure in the resonance region. For example, it is impossible to identify all resonance energies or level spacings from nuclear model calculations; rather, detailed energy resolution crosssection measurements and analyses must be performed to accurately determine the detailed resonance structure. Therefore, cross-section evaluations that are based solely on nuclear model calculations in the resonance region are approximations to the actual cross-section structure in the resonance region.

The procedure used in this report to assess the FP data is as follows:

(1) Identify the most up-to-date and well documented FP evaluation from the three cross-section evaluation libraries, ENDF, JENDL, and JEFF. As a first step in the assessment, the crosssection evaluations among the different libraries can be compared to identify possible variations between evaluated data libraries; however, direct comparisons between the cross-section evaluations do not determine whether a specific evaluation is appropriate for burnup credit applications. Further studies are needed to qualify the data (i.e., comparison of the evaluated data with measured data and use of the evaluated data in benchmark calculations). 
(2) Search for experimental data in the EXFOR (EXchange FORmat) measurements database..$^{\text {日 }}$ EXFOR is the exchange format system designed to allow the sharing of nuclear data among users throughout the world. The EXFOR library contains an extensive compilation of experimental nuclear reaction data. The data bank system is maintained by the National Nuclear Data Center (NNDC) of the Brookhaven National Laboratory (BNL). ${ }^{3}$. Although measurement facilities routinely maintain copies of data measurements performed at their respective facility, EXFOR is the only database used to exchange measured cross-section data in the international community. If measured cross-section data are not submitted to the EXFOR system, the measured data are not available for dissemination to the international data community. For this assessment work, newer cross-section data may have been measured relative to that in the EXFOR database; however, if the data have not been submitted to EXFOR, the authors did not have access to the data and could not include the data in the assessment. Therefore, the assessment only considers measured crosssection data in the EXFOR system.

(3) Process the evaluation with cross-section processing codes such as $\mathrm{AMPX}^{\natural}$ or $\mathrm{NJOY}^{\mathrm{B}}$ and compare the results with experimental data whenever the experimental data exist.

(4) Perform energy-dependent sensitivity calculations for the FP in a burnup credit application. The sensitivity profiles are used to determine the cross-section energy ranges of interest for burnup credit. Details concerning the burnup credit model used in the assessment are provided in Sect. 1.3.

(5) Identify integral benchmark systems that are sensitive to the FP data under consideration and perform benchmark calculations when possible. Critical benchmark experiments and integral reactor measurements are used in this report to assess the performance of nuclear data for a specific FP.

A basic understanding of the evaluated cross-section data representation is needed to understand the FP assessment and recommendations of this report. In general, the data representation in the ENDF libraries, as well as other libraries, can be constructed using pointwise data (energy and cross-sections pairs), using data parameterization along with a nuclear physics model, or a combination of pointwise cross sections and parameters. In the low-energy region up to the kilo-electron volts $(\mathrm{keV})$ resolved resonance-region (RRR), the data are represented with resonance parameters together with a resonance formalism derived from the R-matrix theory. Above the RRR up to the megaelectron volts $(\mathrm{MeV})$ region is the unresolved resonance region (URR), and the cross section data are represented by average resonance parameters. Beyond the unresolved energy region (high-energy region), the cross-section data are represented by "smooth" or slowly varying pointwise data.

Recommendations for new cross-section measurements and/or evaluations are made as appropriate for each FP based on the above procedure used to assess the differential data. In addition, a sensitivity profile for a burnup credit application is provided for each FP to show the energy-dependent sensitivity of the system $\mathrm{k}_{\text {effective. }}$ The application-dependent sensitivity profiles are used to emphasize the cross-section energy regions of importance for the respective FP. In each case, the authors have provided an assessment of the differential data at resonance energies that are important for burnup credit as well as higher resonance region energies that fall outside the area of applicability for burnup credit. The primary reason for providing a general data assessment along with an assessment that is specific to burnup credit is one cannot simply make "spot" improvements to differential cross-section data in a limited energy range of interest in the resonance region. When a cross-section measurement is performed, the measurement is performed to the upper limit of energy resolution for the accelerator facility. The upper limit of energy resolution is determined by the accelerator facility parameters (e.g., neutron flux, neutron pulse width, flight path length, etc.) and isotope-dependent parameters (e.g., resonance spacing, 
temperature of the sample, etc.). To produce a cross-section evaluation, an R-matrix resonance analysis is performed on measured data from the specific accelerator facility. The R-matrix analysis provides resonance parameters for each resonance. Moreover, interference effects between resonances can impact the structure and magnitude of the resonances, and these interference effects must be accounted for in the analysis. Also, the resonance-resonance interference effects are not limited to neighboring resonances; rather, resonances that are separated by orders of magnitude in energy can exhibit interference effects. As a result, one cannot simply perform a partial resonance energy range analysis to produce an improved cross-section evaluation. In addition, the need to perform a full energy-range analysis is extremely important for providing accurate covariance information. Because there are resonance-resonance interference effects, there can be important correlations between neighboring resonances in addition to resonances that are separated by orders of magnitude in energy. In an effort to provide appropriate recommendations for FP measurements and/or evaluations, the full resonance region is addressed; however, the authors have noted the specific energy regions that are particularly important to burnup credit. Based on the noted nuclear physics arguments, the general cross-section recommendations for the resonance region must be implemented to properly address the energy regions of applicability for burnup credit.

As an additional note, there are cases where the cross-section evaluation does not match the measured data, and one could argue that only a new cross-section evaluation is needed. Unfortunately, the only way to determine whether a new evaluation can be performed from the existing measured data is to actually perform an R-matrix analysis of the measured data, and this is beyond the scope of the assessment report. In many cases, the cross-section measurement and evaluation work can be an iterative process where the evaluator attempts to analyze the measured data only to learn that a new/revised capture or transmission measurement is needed to resolve an issue in the R-matrix analyses. Although the authors are aware that some FP cross-section measurements are being planned or have been recently completed, a review of the EXFOR database has revealed that the "latest" measured cross-section data are more than 20 to 40 years old. With regard to the specific FPs considered in this assessment, the cross-section measurements available in EXFOR were performed between 1954 and 1980. Moreover, only one measurement $\left({ }^{153} \mathrm{Eu}\right)$ was performed in 1980, while the majority of cross-section measurements were performed in the 1950s and 1960s. Although the age of the measurement should not determine the quality of the cross-section data, recent work by Guber ${ }^{9}$ has shown that previous capture cross-section measurements can exhibit excessive neutron sensitivity due to additional neutron-absorbing material in the original experimental setup. As a result, older (>15 years) cross-section measurements may overestimate neutron capture, resulting in an overestimation in neutron capture in the cross-section evaluation. In addition, detector technology and instrumentation have advanced greatly in the past 20 years. For cases where issues with the FP evaluation and/or measurement are identified, it is more prudent to plan for a new cross-section measurement because of substantial improvements to be gained with new measurement technology (e.g., decreased neutron sensitivity of measurement systems, improved detectors, data acquisition systems, etc.).

The FP assessment has been performed using the latest evaluations and measured cross-section data available in the open literature as of March 2005. The latest evaluations used in the report correspond to ENDF/B-VI.8, JEFF3.0, and JENDL3.3. Since March 2005, the U.S. and European data projects have released newer versions of their respective data files (i.e., ENDF/B-VII and JEFF3.1). Although there have been updates to the international data files and to some degree FP data, much of the updates have included nuclear cross-section modeling improvements at energies above the resonance region. The one exception is improved ENDF/B-VII cross-section uncertainty data or covariance data for gadolinium isotopes. Relative to burnup credit, ENDF/B-VII includes improved ${ }^{155} \mathrm{Gd}$ resonance parameter covariance data that can benefit burnup credit analyses. ${ }^{10}$ However, new gadolinium covariance data were not produced as part of a new resonance analysis; rather, the existing cross-section resonance parameters were preserved, and approximate methods were used to estimate the covariance information. 
Although the ENDF/B-VII ${ }^{155} \mathrm{Gd}$ covariance data may benefit sensitivity/uncertainty analyses with the existing cross-section files, improved ${ }^{155} \mathrm{Gd}$ cross-section data are needed to improve performance for criticality safety analyses. Although new FP data are available, the conclusions in the FP data assessment of this report still hold in lieu of the newer international cross-section data files.

\subsection{TYPICAL BURNUP-CREDIT MODEL USED IN DATA ASSESSMENT}

In an effort to identify the cross-section energy regions that are important for burnup credit analysis, energy-dependent $k_{\text {effective }}$ sensitivity profiles have been calculated for each FP using a representative burnup credit application. The $\mathrm{k}_{\text {effective }}$ sensitivity profiles are based on a generic cask model with a 32-PWR assembly capacity, which was previously developed and is described in NUREG/CR-6747 (Ref. 2). This model, referred to as the GBC-32, was created to serve as a computational benchmark. The features of the GBC-32 include 32 cells with 365.76-cm-tall and 19.05-cm-wide Boral $(0.0225 \mathrm{~g}$ ${ }^{10} \mathrm{~B} / \mathrm{cm}^{2}$ ) panels between and on the external faces of each cell. The cell walls are constructed of stainless steel having inner dimensions of 22 by $22 \mathrm{~cm}$ and are spaced on 23.76-cm centers. The cells are located $15 \mathrm{~cm}$ above the bottom of a stainless steel cask having an inner radius of $87.5 \mathrm{~cm}$ and internal height of $410.76 \mathrm{~cm}$. The radial thickness of the side walls is $20 \mathrm{~cm}$, and the cask bottom and lid are $30 \mathrm{~cm}$ thick. The cask was modeled as loaded with Westinghouse 17 by 17 optimized fuel assemblies $($ W17 $\times 17$ OFA). The dimensions for the W17×17 OFA were taken from Table 3 of Ref. 2 . The interior of the cask was modeled as filled with water.

The fuel had an initial enrichment of $3.8 \mathrm{wt} \%{ }^{235} \mathrm{U}$ and was burned to $40 \mathrm{GWd} / \mathrm{MTU}$. The STARBUCS sequence in SCALE $5^{11}$ was used to generate 18 axial region-dependent fuel compositions. The STARBUCS sequence and available input parameters are discussed in Ref. 11. The normalized axial burnup profile from Table 5 of Ref. 2 was used. The fuel burnup was modeled at a power density of $40 \mathrm{MW} / \mathrm{MTU}$ for $1000 \mathrm{~d}$, with a postshutdown cooling period of 5 years. The fuel burnup calculations model the depletion of the ${ }^{235} \mathrm{U}$ and the in-growth of actinide and FP nuclides. From the depletion calculations, fuel compositions for the following nuclides were retained for the criticality calculations: ${ }^{234} \mathrm{U},{ }^{235} \mathrm{U},{ }^{236} \mathrm{U},{ }^{238} \mathrm{U},{ }^{237} \mathrm{~Np},{ }^{238} \mathrm{Pu},{ }^{239} \mathrm{Pu},{ }^{240} \mathrm{Pu},{ }^{241} \mathrm{Pu},{ }^{242} \mathrm{Pu},{ }^{241} \mathrm{Am},{ }^{243} \mathrm{Am},{ }^{95} \mathrm{Mo},{ }^{99} \mathrm{Tc},{ }^{101} \mathrm{Ru},{ }^{103} \mathrm{Rh},{ }^{109} \mathrm{Ag}$, ${ }^{133} \mathrm{Cs},{ }^{147} \mathrm{Sm},{ }^{149} \mathrm{Sm},{ }^{150} \mathrm{Sm},{ }^{151} \mathrm{Sm},{ }^{152} \mathrm{Sm},{ }^{143} \mathrm{Nd},{ }^{145} \mathrm{Nd},{ }^{151} \mathrm{Eu},{ }^{153} \mathrm{Eu}$, and ${ }^{155} \mathrm{Gd}$.

Sensitivity analysis for the GBC-32 cask was performed with the SCALE 5.1 version of TSUNAMI-3D 12 and was checked using direct perturbation calculations. The GBC-32 cask model included different mixtures of uranium, plutonium, other actinides, and 15 FPs in each of 18 axial zones in the fuel.

\subsection{COMPARISON WITH PREVIOUS DATA ASSESSMENT STUDIES}

It is important to place the current FP data assessment in context with previous attempts to assess crosssection data for SNF applications. A previous study ${ }^{13}$ by Los Alamos National Laboratory in 2004 provided an "assessment” of FP and actinide data relevant to the Yucca Mountain Project (YMP). However, the assessment methodology of the previous work and this work are completely different. As noted in the report for the previous work,

The report provides a chronological evolution of the ENDF/B-V, ENDF/B-VI and proposed ENDF/B-VII libraries for each of the primary YMP isotopes. The primary isotopes consist of various fission product and actinide nuclides that are important for the burnup credit aspects of the nuclear criticality safety methodology for the YMP.

A careful examination of the evaluators' comments for each isotope by library release provided a historical evolution of the various parameters and cross sections that were derived from these evaluations. Based on this historical information, a judgment as to the level of confidence in the 
cross sections of interest can be made, which subsequently can be translated into a confidence level in criticality safety calculations that use this nuclear data. This historical information for each isotope is documented in the same fashion as Reference 1. The report appendices include the actual ENDF/B evaluations (for ENDF/B-V, VI and the proposed VII) and NJOY processed cross section plots when the data were available.

The previous study ${ }^{13}$ examined the chronological changes of the cross-section data between ENDF/B releases. While this historical information is somewhat informative and enlightening, this information has little or no practical value for providing a quantitative assessment of the cross-section data performance for burnup credit analyses. Moreover, one cannot predict future performance or confidence levels associated with cross-section data based on observed historical changes in the cross-section evaluation. Therefore, a more methodical and quantitative procedure is needed to assess the performance of cross-section data for criticality safety analyses.

In contrast, this work investigates the underlying measured cross-section data relative to the latest crosssection evaluation. Benchmark calculations are performed where possible to assess the performance of the cross-section data against integral experiments. Further, sensitivity calculations for a burnup credit application are used to quantify the cross-section energy regions of interest for each FP. Together, the differential and integral data studies are used to assess the performance of FP cross-section data for burnup credit analyses. 


\section{INVESTIGATION OF THE ${ }^{103}$ Rh EVALUATION}

\subsection{COMPARISON OF ${ }^{103}$ Rh ENDF, JENDL, AND JEFF EVALUATIONS}

Cross-section data for ${ }^{103} \mathrm{Rh}$ are of interest because of the relatively high capture cross section throughout the resonance region. The element rhodium is $100 \%$ naturally abundant in the stable isotope ${ }^{103} \mathrm{Rh}$. Among the ${ }^{103} \mathrm{Rh}$ evaluations available in the three cross section libraries-ENDF, JENDL, and JEFFthe evaluation in the ENDF library (adopted in the JEFF evaluation) is more up-to-date and better documented. A comparison of the energy limits for the resolved and unresolved energy regions of the basic nuclear data libraries ENDF and JENDL are shown in Table 1.

Table 1. Resonance energy regions in ENDF and JENDL libraries for ${ }^{103} \mathrm{Rh}$

\begin{tabular}{|c|c|c|}
\hline \multirow[b]{2}{*}{ Energy range } & \multicolumn{2}{|c|}{ Data library } \\
\hline & ENDF & JENDL \\
\hline Resolved resonance region energy range & $10^{-5} \mathrm{eV}$ to $4.115 \mathrm{keV}$ & $10^{-5} \mathrm{eV}$ to $3.580 \mathrm{keV}$ \\
\hline Unresolved resonance region energy range & $4.115 \mathrm{keV}$ to $40.146 \mathrm{keV}$ & $3.580 \mathrm{keV}$ to $100 \mathrm{keV}$ \\
\hline
\end{tabular}

The cross section representation in both evaluations in the RRR is based on the Multilevel Breit-Wigner (MLBW) formalism. The resonance parameters included in these evaluations were originally obtained from the Mughabghab compilation. ${ }^{14}$ The resonance parameters in these evaluations were revised with the purpose of reproducing the experimental thermal cross-section value at $0.0253 \mathrm{eV}$. A comparison between the ENDF and JENDL capture cross section from $10^{-5}$ to $10 \mathrm{eV}$ is shown in Fig. 1.

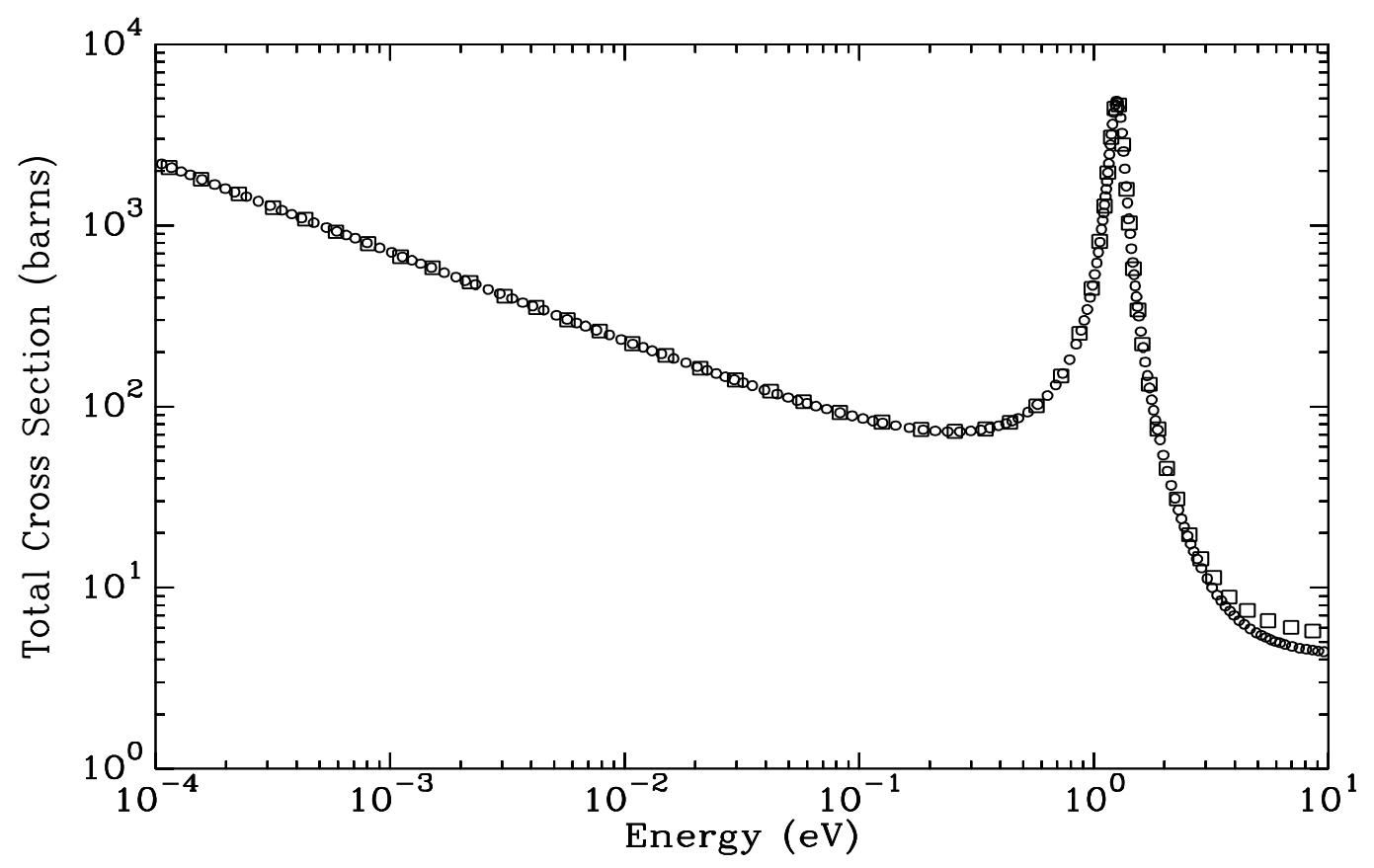

Fig. 1. Comparison of the ENDF ( $\odot$ ) and JENDL ( $\square$ ) total cross sections for ${ }^{103} \mathrm{Rh}$. 
The total cross sections in the two libraries agree up to $3 \mathrm{eV}$; that is, the resonance at $1.26 \mathrm{eV}$ in the two evaluations are in good agreement as shown in Fig. 1. Above $3 \mathrm{eV}$, as shown in Fig. 2, the ENDF total cross section is lower than the JENDL evaluation. Figure 2 displays the ENDF and JENDL total cross sections from 3 to $200 \mathrm{eV}$.

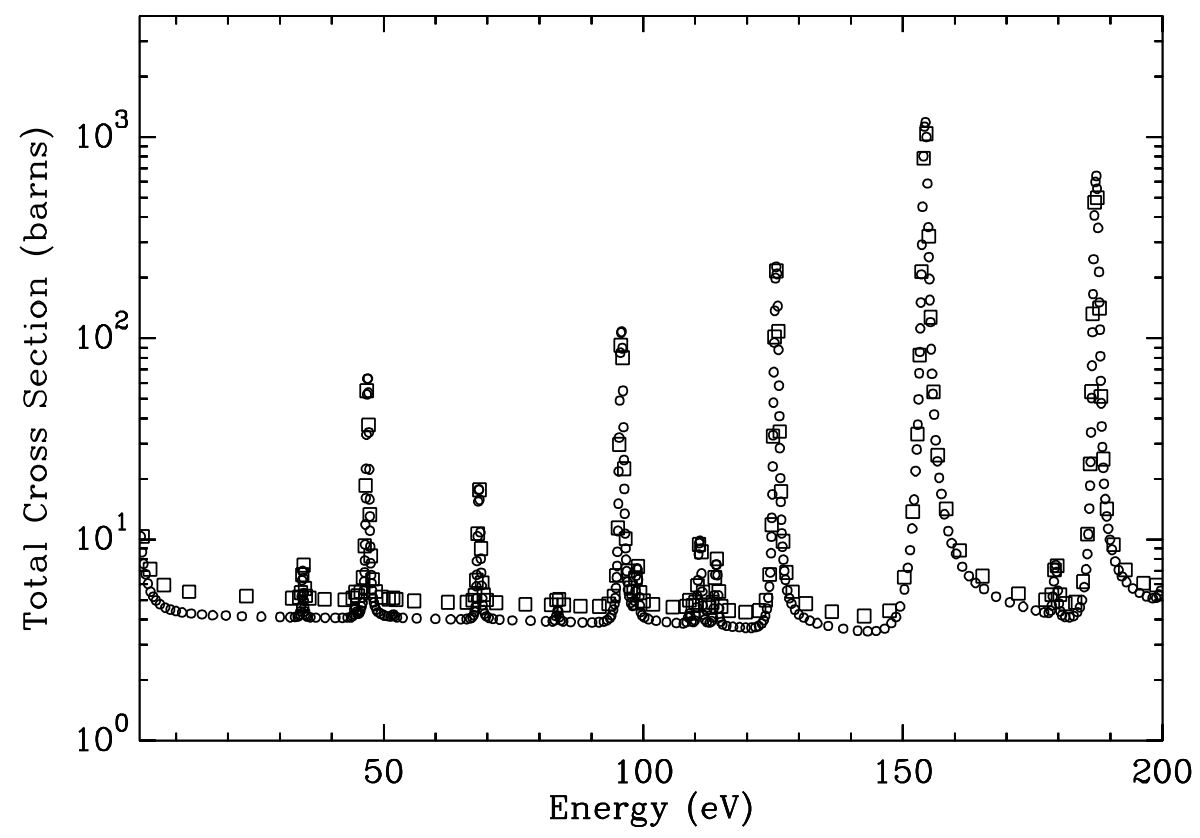

Fig. 2. Comparison of the ENDF ( $)$ and JENDL $(\square)$ total cross sections from 3 to $200 \mathrm{eV}$ for ${ }^{103} \mathrm{Rh}$.

The capture cross sections calculated with the two evaluations are more consistent, although the ENDF evaluation calculates a capture cross section slightly lower than the JENDL evaluation between resonances. Figure 3 shows a comparison of the ENDF and JENDL capture cross section in the energy range from 3 to $50 \mathrm{eV}$.

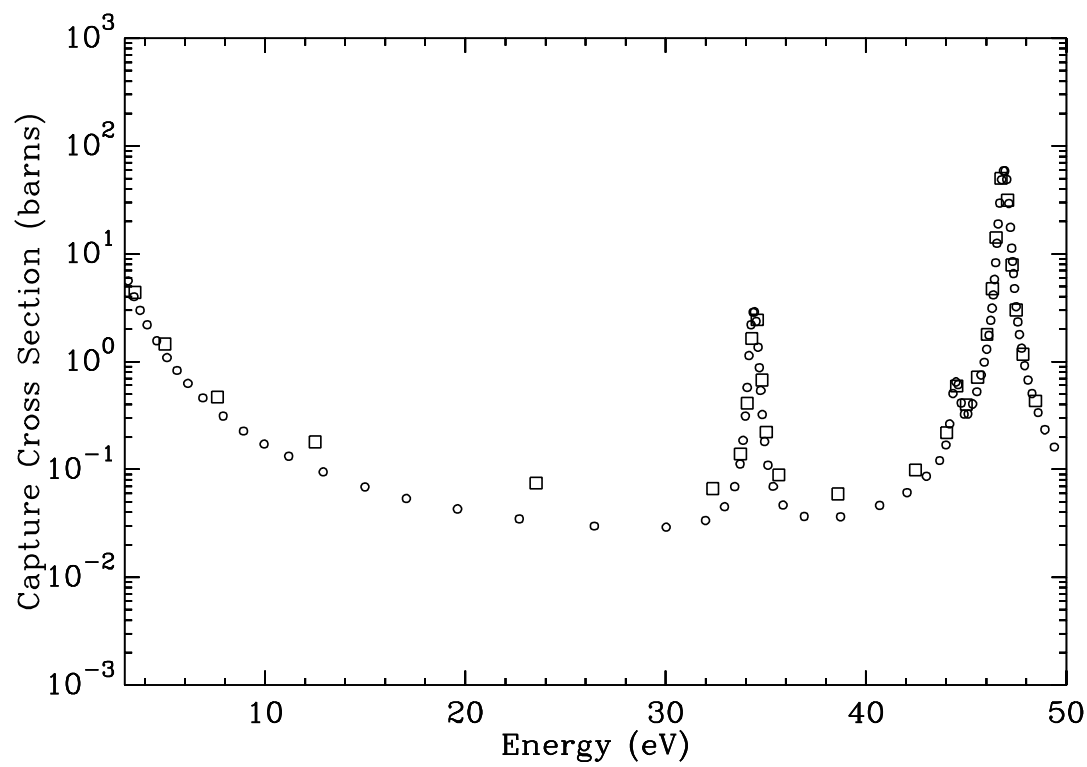

Fig. 3. Comparison of the ENDF ( $\left(\right.$ ) and JENDL $(\square)$ capture cross sections from 3 to $50 \mathrm{eV}$ for ${ }^{103} \mathrm{Rh}$. 


\subsection{COMPARISON OF THE ${ }^{103}$ Rh ENDF EVALUATION WITH EXPERIMENTAL DATA}

A search of the available experimental cross-section data for ${ }^{103} \mathrm{Rh}$ in the EXFOR system was performed. High-resolution total cross-section measurements by Ribon et al. ${ }^{15}$ at room temperature $(293 \mathrm{~K})$ are available from $18 \mathrm{eV}$ to $4.2 \mathrm{keV}$. A comparison of the ENDF total cross section processed with the NJOY code compared with the experimental data of Ribon is shown in Fig. 4 in the energy region from 20 to $500 \mathrm{eV}$.

Although not shown here, the calculated total cross sections with the ENDF evaluation agree with the experimental data of Ribon et al. to $4000 \mathrm{eV}$. In contrast, the capture cross-section data are deficient relative to the total cross section: An investigation of the capture cross-section data revealed the following deficiencies: (1) there is a lack of measured ${ }^{103} \mathrm{Rh}$ capture cross-section data available in the EXFOR system and (2) for the available experimental data, the agreement between the calculated ENDF capture cross section and the experimental data is very poor. At the time of the assessment, the only available ${ }^{103} \mathrm{Rh}$ experimental capture cross-section data are a set of measurements performed by Moxon et al. ${ }^{16}$ from $100 \mathrm{eV}$ to $20 \mathrm{MeV}$. The data are very sparse and with poor resolution. Comparisons of the ENDF capture cross section and the measured capture cross-section data of Moxon et al. in the energy from 100 to $500 \mathrm{eV}$ are shown in Fig. 5. As can be seen from Fig. 5, the experimental data of Moxon et al. (crosses) are missing between resonances. The calculated ENDF capture cross sections (solid line) do not agree with the experimental data. The quality of the cross-section data decreases with increasing energy as shown in Fig. 6 . At higher energies, the resolution of the capture data deteriorates, and there is complete disagreement between measured and calculated cross-section values. Note that only the resolution due to the temperature effect (Doppler effects) is included in the calculated cross sections shown in Figs. 5 and 6 .

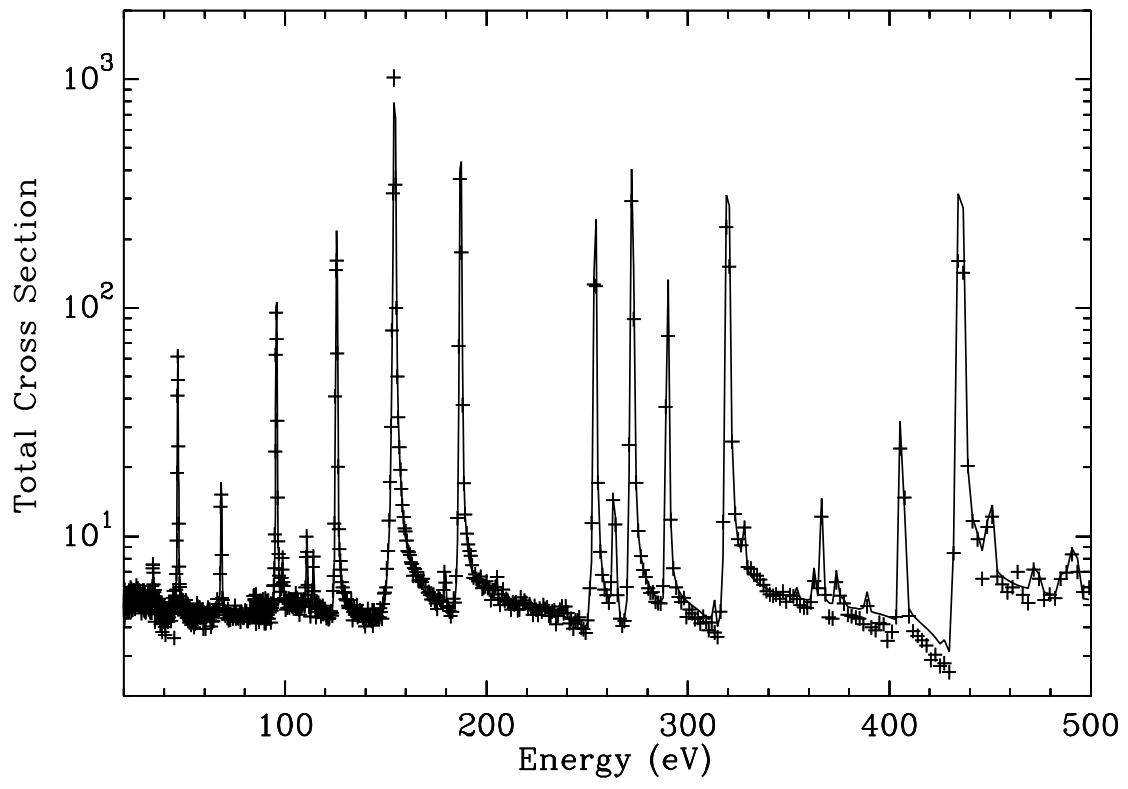

Fig. 4. Comparison of the ENDF ( - ) total cross section with the experimental data of Ribon et al. $\left({ }^{+}\right)$ in the energy region 20 to $500 \mathrm{eV}$ for ${ }^{103} \mathrm{Rh}$. 


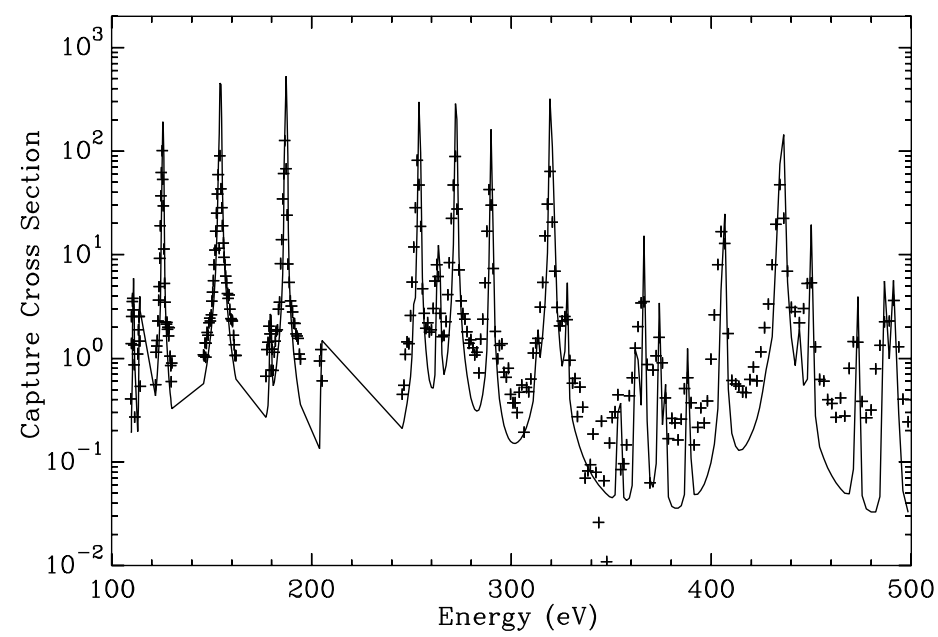

Fig. 5. Comparison of the ENDF ( - ) capture cross section with the experimental data of Moxon et al. $(+)$ in the energy region 100 to $500 \mathrm{eV}$ for ${ }^{103} \mathrm{Rh}$.

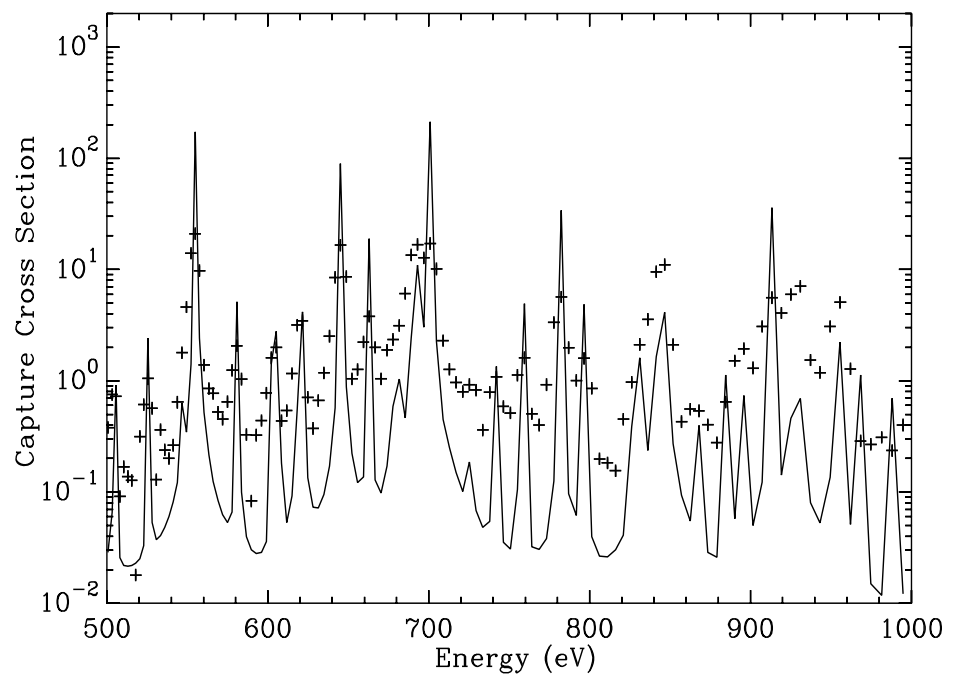

Fig. 6. Comparison of the ENDF ( - ) capture cross section with the experimental data of Moxon et al. $(+)$ in the energy region 200 to $1000 \mathrm{eV}$ for ${ }^{103} \mathrm{Rh}$.

Unfortunately, there is no measured total and capture data in the low-energy region from thermal $(0.0253 \mathrm{eV})$ to $1 \mathrm{eV}$. The paucity of experimental data at thermal energies is a concern for burnup credit applications involving transportation packages. Also, it appears that there is only one capture data measurement covering the energy region from 0.39 to $34 \mathrm{keV}$ with very poor energy resolution (Popov et al.). $\frac{17}{17}$ 


\subsection{BENCHMARK CALCULATIONS}

Sandia National Laboratories (SNL) have performed critical experiments ${ }^{18}$ for the investigation of burnup credit for transportation, storage, and disposal of SNF. These experiments are described in the International Handbook of Evaluated Critical Safety Benchmark Equipments (IHECSBE) as evaluation LEU-COMP-THERM-079. ${ }^{19}$ As part of the studies, critical benchmark experiments were performed with and without the presence of rhodium. The SNL experiments consist of ten thermal benchmark critical configurations with one set of five experiments with fuel rod pitch of $2.0 \mathrm{~cm}$ and another set of five experiments with 2.8-cm fuel-rod pitch. The critical assemblies consist of water-moderated Zircaloy clad $\mathrm{UO}_{2}$ with $4.31 \%$ enrichment. Rhodium foils were inserted between fuel pellets in some of the fuel rods. Rhodium foil thicknesses of 25.2, 49.7, and $105.0 \mu \mathrm{m}$ were used. The experiment was performed at a temperature of $300 \mathrm{~K}$. As reported by the evaluators, benchmark model calculations were performed with the MCNP ${ }^{20}$ code using the ${ }^{103} \mathrm{Rh}$ cross-section evaluation from ENDF/B-VI.8 and with SCALE 4.4a (Ref. 21) using the ENDF/B-V 238 group library distributed with SCALE 4.4a. The experimental $\mathrm{k}_{\text {effective }}$ values recommended by the experimentalist and the calculated $k_{\text {effective }}$ values are provided in Table 2 .

Table 2. Results of $\mathbf{k}_{\text {effective }}$ calculated with the MCNP and SCALE codes

\begin{tabular}{ccccc}
\hline \multirow{2}{*}{$\begin{array}{c}\text { Pitch } \\
(\mathbf{c m})\end{array}$} & $\begin{array}{c}{ }^{103} \mathbf{R h} \text { foil thickness } \\
\mathbf{( m m )}\end{array}$ & Experimental results & SCALE 4.4a & MCNP v5 \\
\cline { 3 - 5 } & 0 & $1.0002 \pm 0.0016$ & $0.9916 \pm 0.0004$ & $0.9914 \pm 0.0004$ \\
& 0.0252 & $1.0005 \pm 0.0016$ & $0.9919 \pm 0.0004$ & $0.9923 \pm 0.0004$ \\
2.0 & 0.0497 & $1.0004 \pm 0.0016$ & $0.9923 \pm 0.0004$ & $0.9920 \pm 0.0004$ \\
& 0.1050 & $1.0004 \pm 0.0016$ & $0.9915 \pm 0.0003$ & $0.9915 \pm 0.0004$ \\
& 0 & $1.0003 \pm 0.0008$ & $0.9960 \pm 0.0004$ & $0.9944 \pm 0.0003$ \\
& 0.0252 & $1.0008 \pm 0.0008$ & $0.9970 \pm 0.0004$ & $0.9948 \pm 0.0003$ \\
2.8 & 0.0497 & $1.0003 \pm 0.0008$ & $0.9966 \pm 0.0004$ & $0.9939 \pm 0.0003$ \\
& 0.1050 & $1.0009 \pm 0.0008$ & $0.9973 \pm 0.0004$ & $0.9951 \pm 0.0003$ \\
\hline
\end{tabular}

Comparison of the cases with the same pitch does not conclusively indicate any bias associated with the presence of the ${ }^{103} \mathrm{Rh}$. There is a weak (i.e., not statistically significant) indication that there is a small underprediction of ${ }^{103} \mathrm{Rh}$ worth as indicated by the slightly higher $\mathrm{k}_{\mathrm{effective}}$ values calculated for the cases with ${ }^{103} \mathrm{Rh}$.

The Comissariat al'Energie Atomique (CEA) performed reactivity worth measurements by the oscillation method in the Minerve experimental reactor located at Cadarache. The experiments were performed in support of the French burnup credit program. Four configurations were investigated: R1-UO2 (PWR lattice made of low-enriched $\mathrm{UO}_{2}$ rods), R2-UO2 (lattice with a softer neutron spectrum), R1MOX (lattice made of mixed-oxide rods), and a boiling-water reactor (BWR) configuration. The ${ }^{103} \mathrm{Rh}$ samples were oscillated at the center of the Minerve reactor, and the reactivity worth was directly measured after careful calibration using borated $\mathrm{UO}_{2}$ samples and variable-enriched $\mathrm{UO}_{2}$ samples. The experimental uncertainty on reactivity worths (mainly coming from the calibration procedure and from ${ }^{103} \mathrm{Rh}$ concentrations in the sample) is about 3 to $4 \%$. The interpretation of these experiments was performed at the CEA-Cadarache ${ }^{22}$ with the deterministic APOLLO2 code ${ }^{23}$ and the JEFF2.2 multigroup library. Special care was paid to the treatment of resonance self-shielding in APOLLO2, which was validated using the continuous-energy Monte Carlo code TRIPOLI4 (Ref. 24) with pointwise data from the JEFF2.2 library. The ratio of calculated-to-experiment (C/E) values is displayed in Table 3. 
Table 3. Calculation-to-experiment ratios of sample reactivity worth for ${ }^{103} \mathrm{Rh}$ in the Minerve experiments. The energetic contribution of the incident neutron spectrum to the ${ }^{103} \mathrm{Rh}$ capture reaction rate is also shown.

\begin{tabular}{cccccc}
\hline & & BWR & R1MOX & R1UO2 & R2UO2 \\
\hline \multicolumn{2}{c}{ C/E-1(\%) } & $+12.9 \pm 3.2$ & $+7.7 \pm 3.2$ & $+11.0 \pm 4.0$ & $+8.0 \pm 4.2$ \\
\cline { 1 - 3 } $\begin{array}{c}\text { Energetic } \\
\text { contribution }\end{array}$ & Above $0.625 \mathrm{eV}$ & - & $69.1 \%$ & $53.8 \%$ & $40.4 \%$ \\
\cline { 5 - 6 } & Below $0.625 \mathrm{eV}$ & - & $30.9 \%$ & $46.2 \%$ & $59.6 \%$ \\
\hline
\end{tabular}

The results displayed in Table 3 show that the ${ }^{103} \mathrm{Rh}$ capture resonance integral in JEFF2.2 seems to be overestimated. The same trend was observed by using other nuclear cross section libraries, such as ENDF/B-VI.8 or JENDL3.3. Improving the ${ }^{103} \mathrm{Rh}$ cross-section evaluation should improve the results for the capture resonance integral calculations noted in Table 3.

\subsection{SENSITIVITY ANALYSIS FOR ${ }^{103} \mathrm{Rh}$ IN A BURNUP CREDIT APPLICATION}

Sensitivity analyses of the ${ }^{103} \mathrm{Rh}$ in a typical burnup credit application were performed with the TSUNAMI sequence in SCALE 5.1 (Ref. 12). The sensitivity of $\mathrm{k}_{\text {effective }}$ to the ${ }^{103} \mathrm{Rh}$ total cross section for the GBC-32 model is shown in Fig. 7. The burnup credit model is sensitive to the ${ }^{103} \mathrm{Rh}$ capture cross section in the thermal energy region $(0.0253 \mathrm{eV})$ up to about $3 \mathrm{eV}$ and is insensitive to cross-section data above $3 \mathrm{eV}$. 


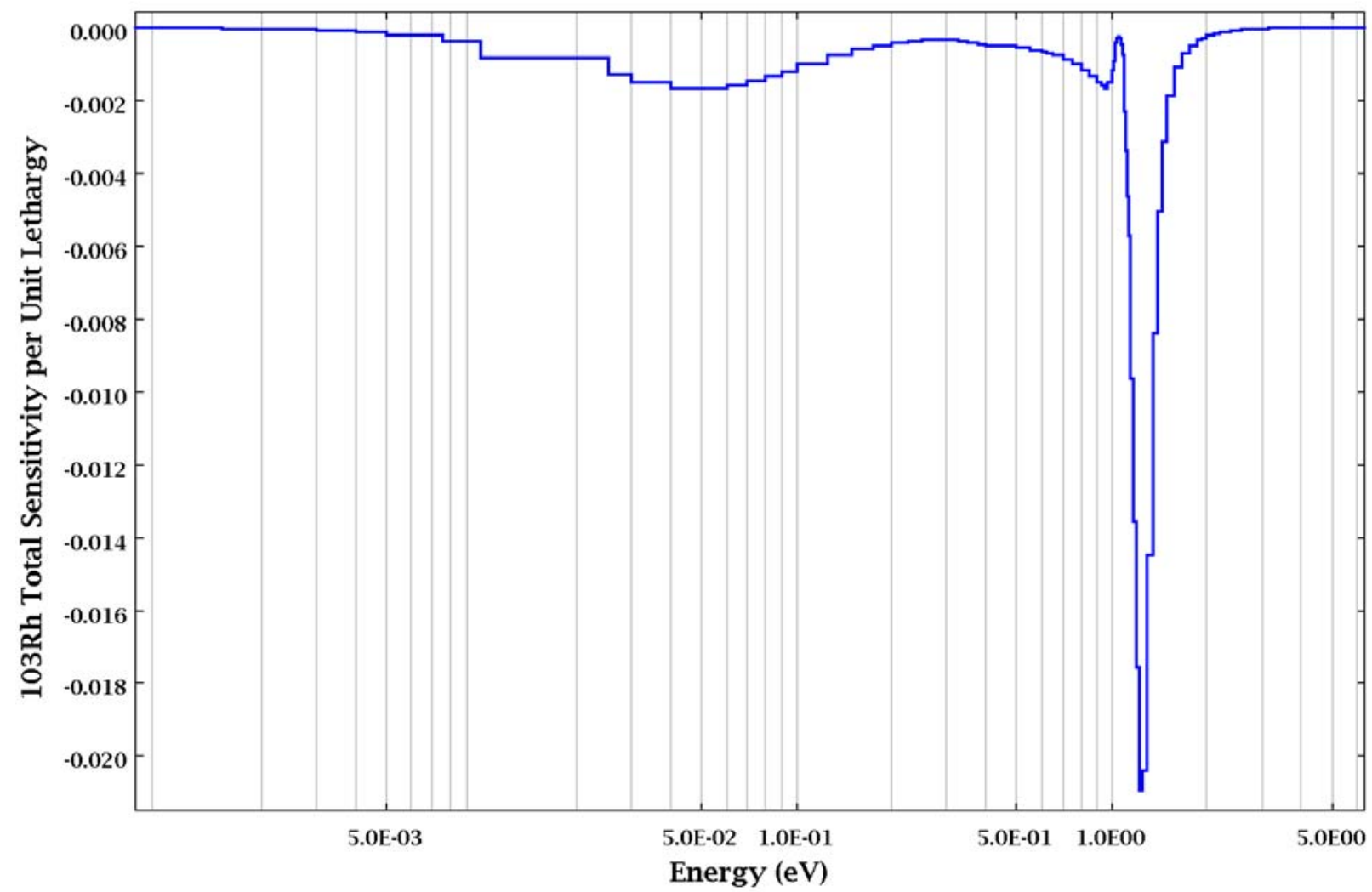

Fig. 7. Sensitivity of the $k_{\text {effective }}$ to the ${ }^{103} \mathrm{Rh}$ total cross section for the GBC-32 model.

\subsection{ASSESSMENT SUMMARY AND RECOMMENDATIONS FOR ${ }^{103} \mathbf{R h}$}

For ${ }^{103} \mathrm{Rh}$, both the ENDF and JENDL data appear to be the most recent cross-section evaluations, and both evaluation sources agree in the representation of the cross-section data. When compared with available experimental data, the evaluated total cross section agrees with the experimental data up to $4 \mathrm{keV}$; however, there is no measured total cross-section data below $18 \mathrm{eV}$ in the experimental database (EXFOR). Moreover, there is only one capture measurement in the experimental database, and the measured capture data are only available between $0.39 \mathrm{keV}$ and $34 \mathrm{keV}$. As a result, there is no total or capture data from $0.0253 \mathrm{eV}$ to $1 \mathrm{eV}$. Critical benchmark calculations using MCNP and KENO V.a were evaluated. The calculated system multiplication factors do not indicate a statistically significant bias due to the presence of ${ }^{103} \mathrm{Rh}$. CEA reactivity worth calculations demonstrate that the ${ }^{103} \mathrm{Rh}$ capture rate is overestimated relative to measured values from the Minerve experiment by $8 \%$ to $12.9 \%$ with 3 to $4 \%$ uncertainty.

In general, total cross-section measurements are needed below $1 \mathrm{eV}$. In addition, capture cross-section measurements are needed from $10^{-5} \mathrm{eV}$ and extending through the resonance region. The justification for the needed cross-section measurements is largely based on the absence of measured cross-section data in the noted energy regions coupled with the poor fit of the cross-section evaluation to the measured data that are available. While there is a general need for cross-section measurements, sensitivity analysis of a typical burnup credit application indicates that cross-section measurements for energies up to about $3 \mathrm{eV}$ are most important for burnup credit applications. In addition, the latest evaluated data files do not 
provide cross-section covariance information for ${ }^{103} \mathrm{Rh}$, and new measurement and evaluation efforts will provide cross-section covariance data in addition to improved cross-section data. At a minimum, providing covariance data will benefit burnup credit analyses by enabling the propagation of ${ }^{103} \mathrm{Rh}$ crosssection uncertainty to calculated $\mathrm{k}_{\text {effective }}$ values. 


\section{INVESTIGATION OF THE ${ }^{133}$ Cs EVALUATION}

\subsection{COMPARISON OF ${ }^{133}$ Cs ENDF, JENDL, AND JEFF EVALUATIONS}

Cross-section data for ${ }^{133} \mathrm{Cs}$ are available in the ENDF, JEFF, and JENDL libraries. The most recent revision of the ${ }^{133} \mathrm{Cs}$ cross sections have been adopted in the JEFF library. Comparison of the energy limits for the resolved and unresolved energy regions and the basic nuclear data libraries ENDF, JEFF, and JENDL are shown in Table 4.

Table 4. Resonance energy regions in ENDF, JENDL, and JEFF libraries for ${ }^{133} \mathrm{Cs}$

\begin{tabular}{llcc}
\hline & \multicolumn{3}{c}{ Data library } \\
\cline { 2 - 4 } Energy range & \multicolumn{1}{c}{ ENDF } & JEFF & JENDL \\
\hline $\begin{array}{l}\text { Resolved resonance } \\
\text { region energy range }\end{array}$ & $10^{-5} \mathrm{eV}$ to $2.50 \mathrm{keV}$ & $10^{-5} \mathrm{eV}$ to $3.9833 \mathrm{keV}$ & $10^{-5} \mathrm{eV}$ to $5.980 \mathrm{keV}$ \\
$\begin{array}{l}\text { Unresolved } \\
\text { resonance region } \\
\text { energy range }\end{array}$ & $\begin{array}{l}\text { No unresolved resonance } \\
\text { parameters given }\end{array}$ & $3.9893 \mathrm{keV}$ to $81.607 \mathrm{keV}$ & $5.980 \mathrm{keV}$ to $100 \mathrm{keV}$ \\
\hline
\end{tabular}

Comparisons of the ${ }^{133} \mathrm{Cs}$ total and capture cross section from $10^{-5}$ to $4 \mathrm{eV}$ are shown in Figs. 8 and 9 , respectively. The ENDF cross section is represented by the square symbol, whereas the JEFF and JENDL cross sections are given by the star symbol and small circles, respectively. The results shown in these figures indicate that the total and capture cross sections in ENDF, JEFF, and JENDL below 4 eV are very similar.

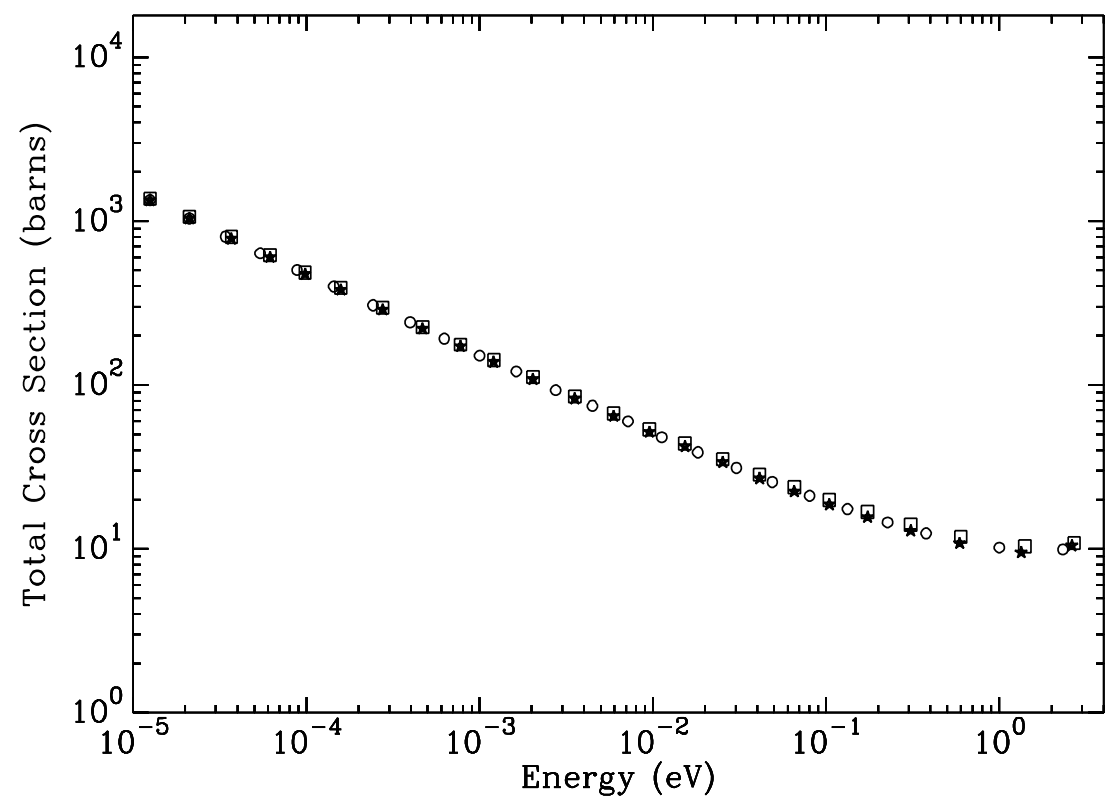

Fig. 8. Comparison of the total cross sections for ${ }^{133}$ Cs in the ENDF ( $\square$ ), JEFF ( $\star$ ), and JENDL ( $)$ ) evaluations. 


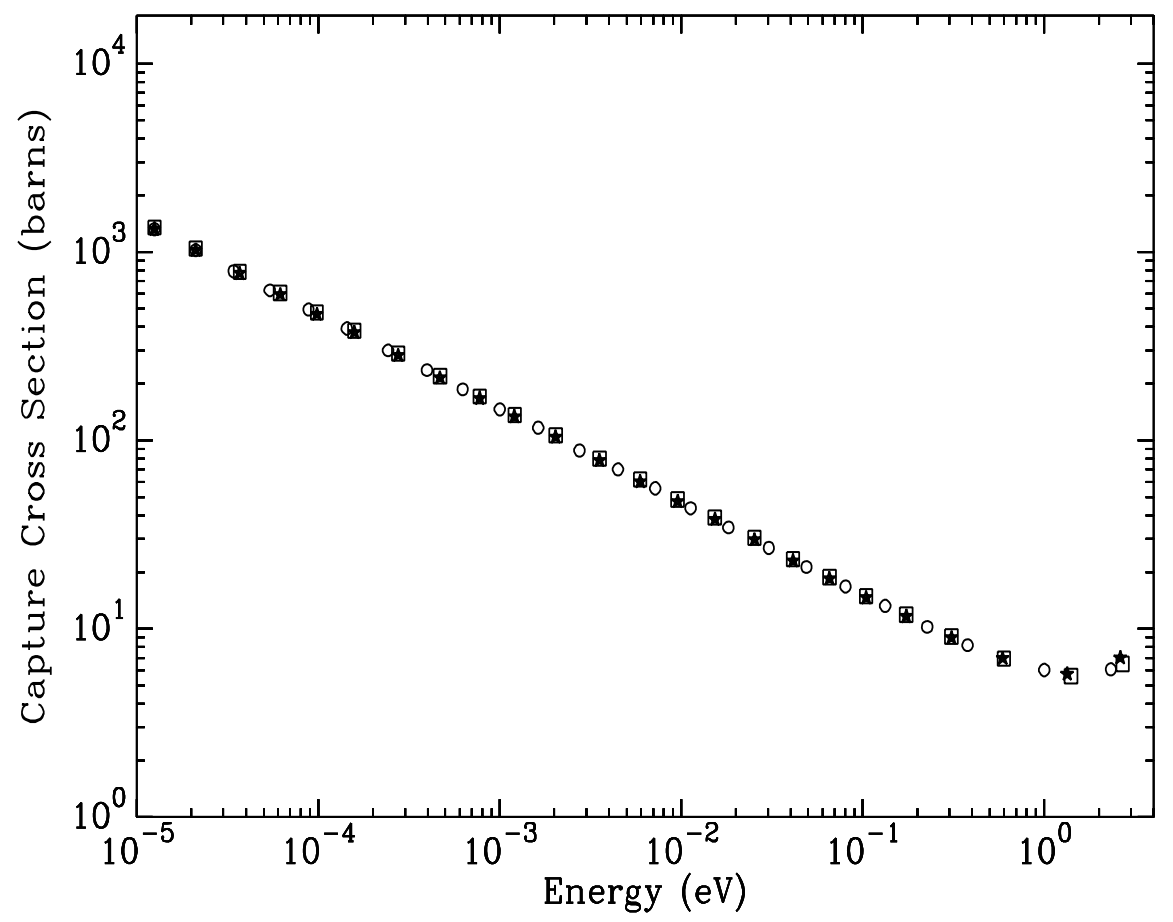

Fig. 9. Comparison of the capture cross sections for ${ }^{133}$ Cs in the ENDF ( $\square$ ), JEFF ( $\star$ ), and JENDL (o) evaluations.

Above $4 \mathrm{eV}$ the JEFF and JENDL evaluations appear to be very similar, while the ENDF evaluation gives cross-section values higher than JEFF and JENDL in the valleys between resonances. This feature is shown in Figs. 10 and 11 for the total and capture cross sections, respectively.

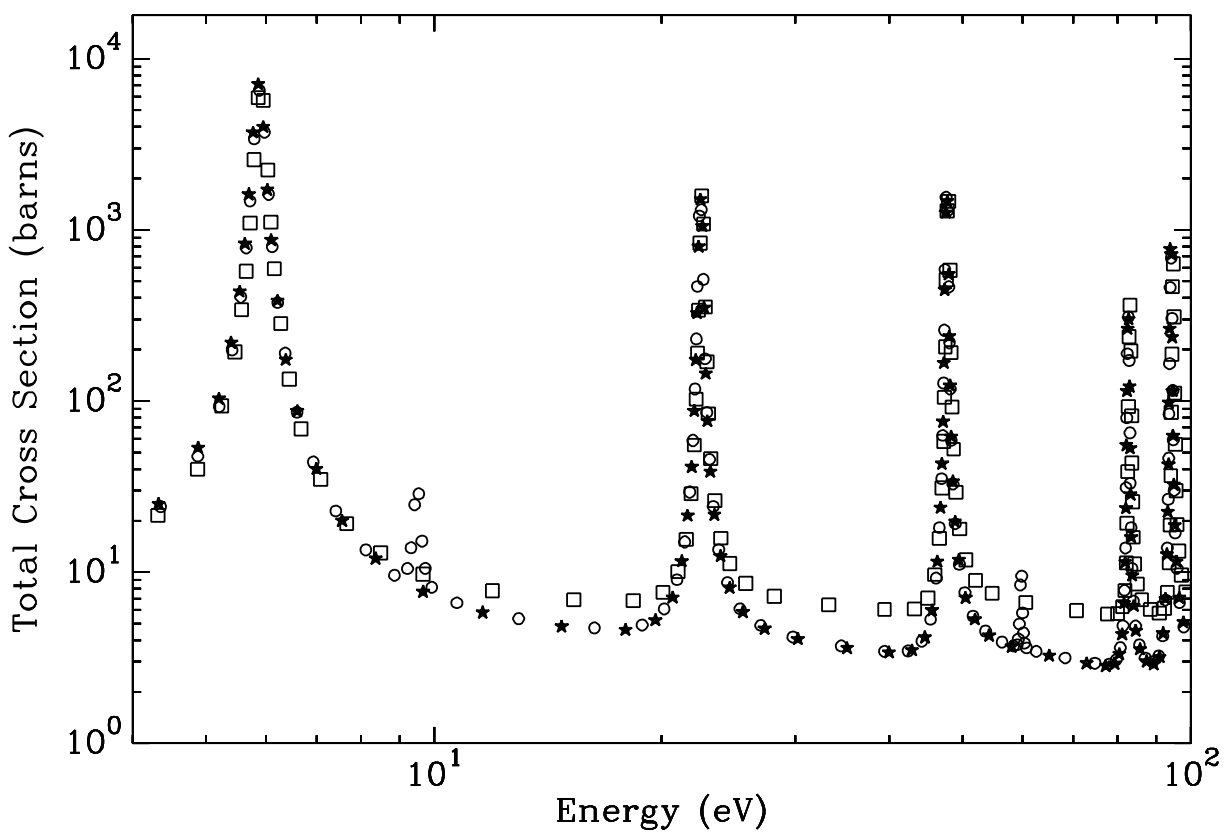

Fig. 10. Comparison of the total cross sections for ${ }^{133}$ Cs in the ENDF ( $\square$ ), JEFF ( $\star$ ), and JENDL (o) evaluations. 


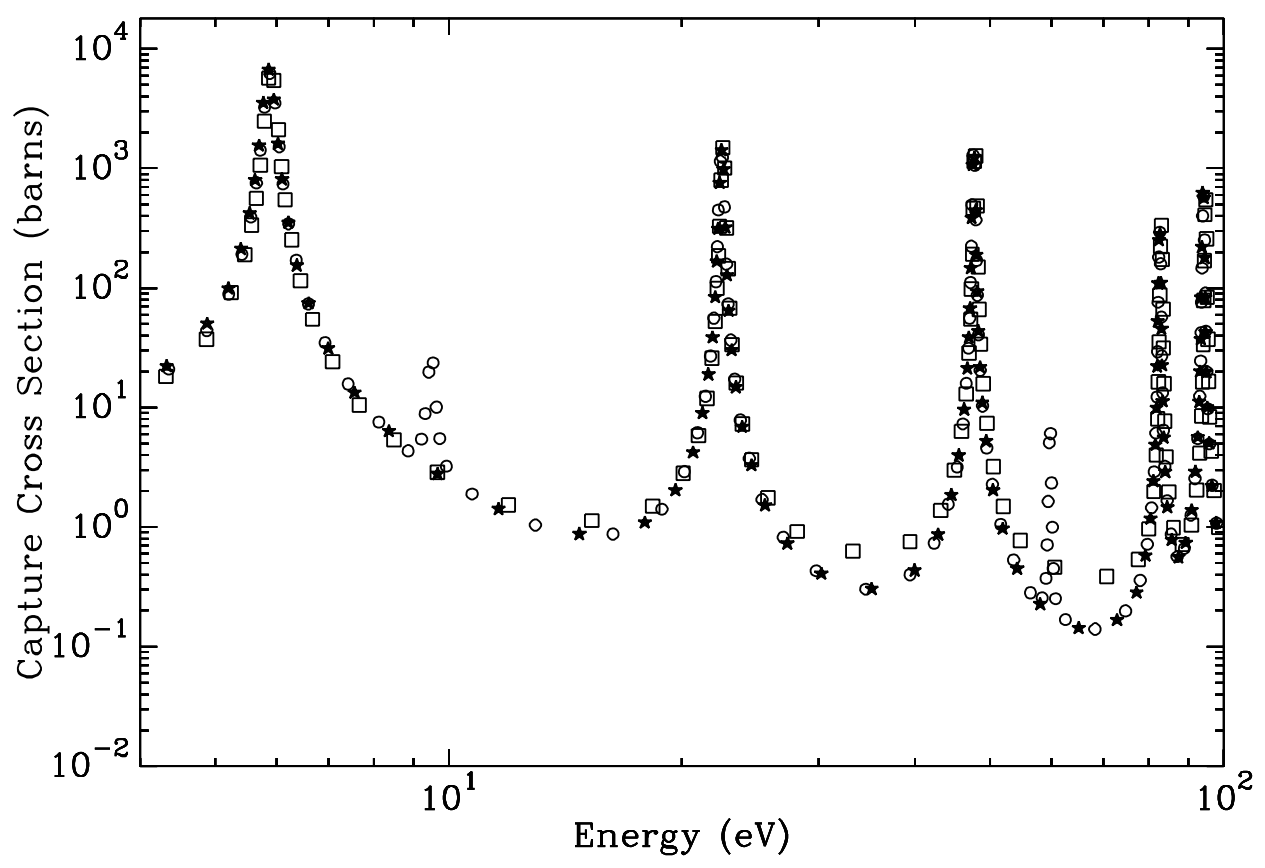

Fig. 11. Comparison of the capture cross sections for ${ }^{133}$ Cs in the ENDF ( $\square$ ), JEFF ( $\star$ ), and JENDL (o) evaluations.

\subsection{COMPARISONS OF THE ${ }^{133}$ Cs JEFF EVALUATION WITH EXPERIMENTAL DATA}

Below $10 \mathrm{eV}$, two sets of experimental data were listed in the EXFOR system, for example, the total cross section of Landon et al. ${ }^{25}$ in the energy region from 0.6 to $20 \mathrm{eV}$ and the total cross-section data of Hickman ${ }^{26}$ in the energy range $0.016 \mathrm{eV}$ to $4.4 \mathrm{eV}$. A comparison of the ${ }^{133} \mathrm{Cs}$ evaluation in the JEFF library with the experimental data is shown in Fig. 12.

The results shown in Fig. 12 indicate that the JEFF evaluation represents the total experimental cross section below $10 \mathrm{eV}$. In the energy range 10 to $100 \mathrm{eV}$ the only data found in the EXFOR system is the total cross section of Harvey et al., ${ }^{27}$ which is listed in the energy range from $11 \mathrm{eV}$ to $570 \mathrm{eV}$. Graphical comparisons of the Harvey data and the JEFF evaluation are given in Fig. 13. Note that the only resolution effect included in the calculation of the cross section is the temperature effect due to the Doppler broadening at $300 \mathrm{~K}$. The Doppler broadening effect is dominant below $100 \mathrm{eV}$. The results shown in Fig. 13 indicate that the JEFF evaluation does not agree with the experimental total cross section. The same trend is observed above $100 \mathrm{eV}$. Figure 14 shows comparisons of the total cross sections of Harvey et al. and Garg et al. ${ }^{28}$ in the energy range from 100 to $500 \mathrm{eV}$. In Figs. 13 and 14, the cross-section evaluation does not represent the measured data, and the poor fit may be attributed to the use of the Breit-Wigner formalism in the resonance representation. The discrepancy between the evaluation and measured data indicates that a new R-matrix analysis of the ${ }^{133} \mathrm{Cs}$ data is needed; however, as noted in the Introduction, the only way to determine whether the existing measured data can be used for a new evaluation is to actually perform an R-matrix analysis of the measured data, and this is beyond the scope of this report. Moreover, the ${ }^{133}$ Cs cross-section measurements were performed in the 1950s and 1960s, and there have been significant advances in measurement technology over the past 40 to 50 years. Therefore, a new cross-section measurement and analysis is recommended for ${ }^{133} \mathrm{Cs}$. 


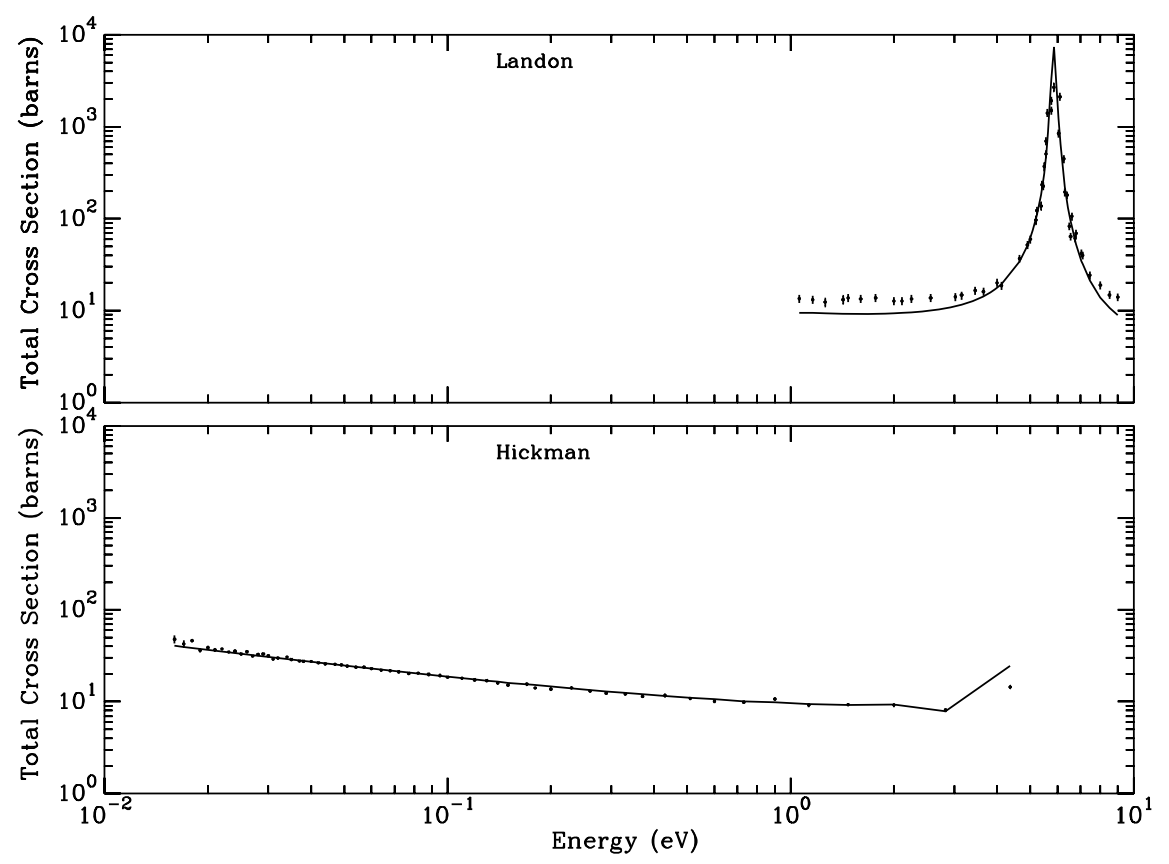

Fig. 12. Comparison of the experimental total cross section of Landon et al. and Hickman with the ${ }^{133} \mathrm{Cs}$ JEFF evaluation.

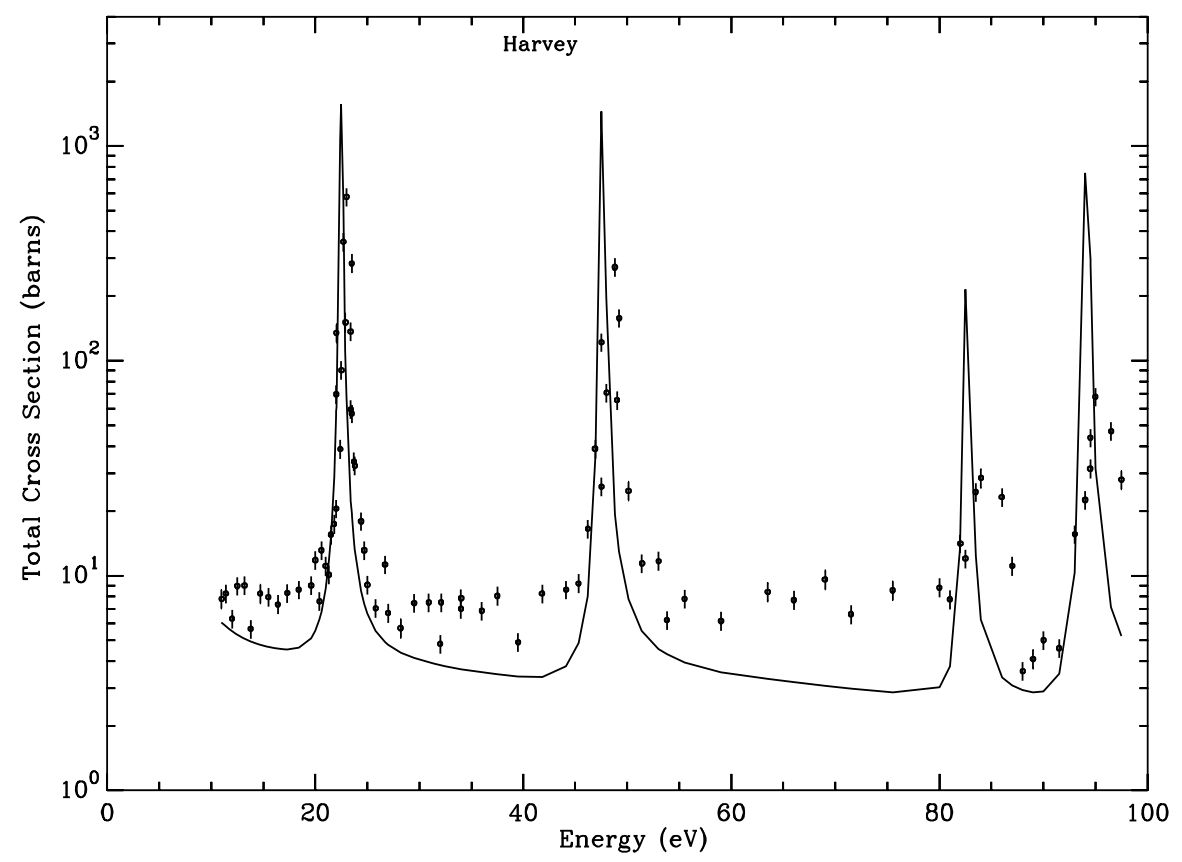

Fig. 13. Comparison of the experimental total cross section of Harvey et al. and the total cross section calculated with JEFF evaluation for ${ }^{133} \mathrm{Cs}$. 

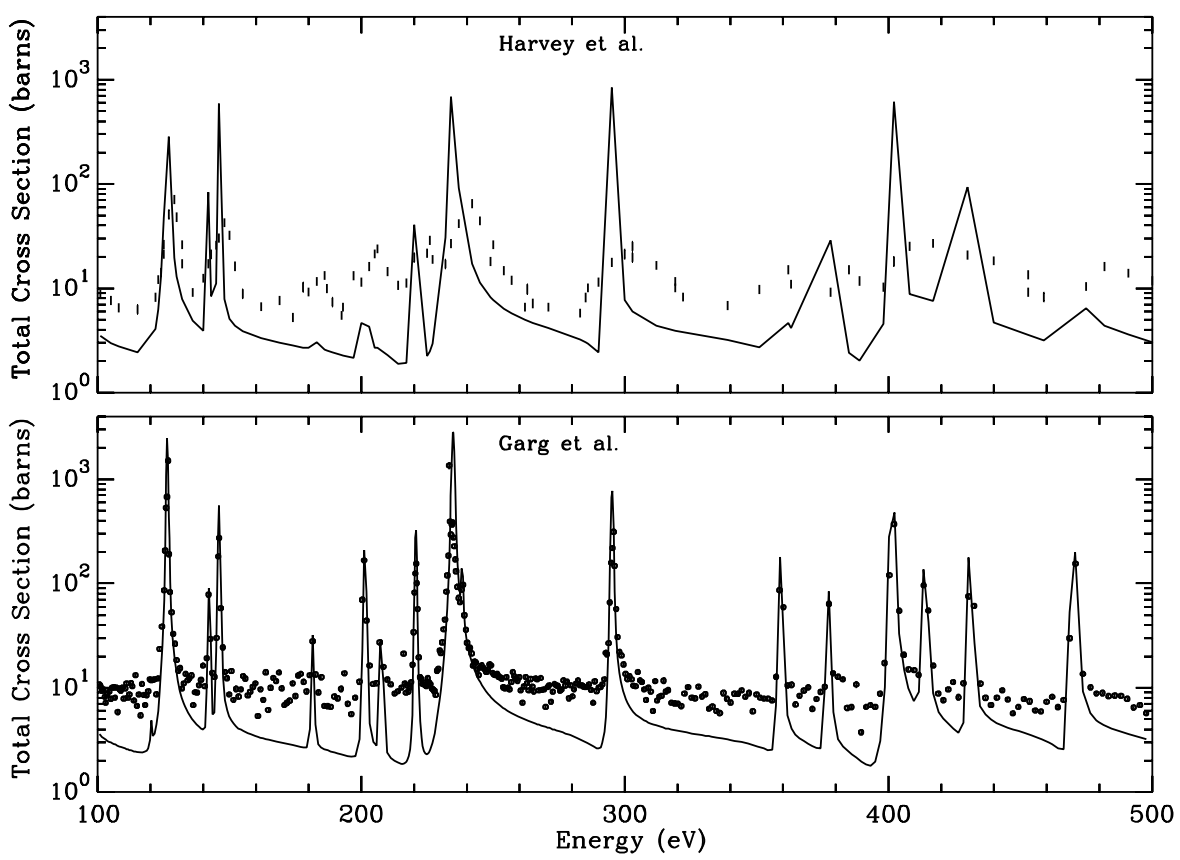

Fig. 14. Comparison of the experimental total cross sections of Harvey et al. data (top plot) and Garg et al. data (bottom plot) with cross section calculated with the JEFF evaluation for ${ }^{133}$ Cs.

A survey of the EXFOR data base indicates that there is no experimental capture cross-section data available in the resonance region. Because ${ }^{133} \mathrm{Cs}$ is a fission product with a high capture cross section, a measurement of the ${ }^{133}$ Cs capture cross section is needed.

\subsection{BENCHMARK CALCULATIONS}

While there is no integral benchmark experiment available in the United States for specifically testing the ${ }^{133}$ Cs cross section, experimental data are available from measurements performed in the framework of the French burnup credit program. ${ }^{22}$ To qualify the ${ }^{133} \mathrm{Cs}$ cross section for application in burnup credit calculations, CEA-Cadarache performed reactivity worth measurements in the Minerve experimental reactor. The calculated-to-experiment ratio result, C/E-1 (\%), for the R1-UO2 (PWR lattice made of low-enriched $\mathrm{UO}_{2}$ rods) is $+5.5 \pm 1.5$. The calculations were performed using the JEFF evaluation. The result indicates that the capture cross section in the JEFF evaluation needs to be decreased to improve the results of reactivity worth calculations. A new ${ }^{133} \mathrm{Cs}$ capture cross-section measurement and evaluation could improve calculated results for the Minerve benchmark.

\subsection{SENSITIVITY ANALYSIS FOR ${ }^{133}$ Cs IN A BURNUP CREDIT APPLICATION}

Sensitivity analyses of the ${ }^{133} \mathrm{Cs}$ in a typical burnup credit application were performed with the TSUNAMI sequence in SCALE 5.1 (Ref. 12). The sensitivity of $\mathrm{k}_{\text {effective }}$ to the ${ }^{133} \mathrm{Cs}$ total cross section for the GBC-32 model is shown in Fig. 15. The burnup credit model is sensitive to the ${ }^{133} \mathrm{Cs}$ capture cross-section in the thermal energy region $(0.0253 \mathrm{eV})$ up to about $1 \mathrm{keV}$ and is insensitive to crosssection data above $1 \mathrm{keV}$. Therefore, cross-section data improvements up to $1 \mathrm{keV}$ would be beneficial to burnup credit analyses. 


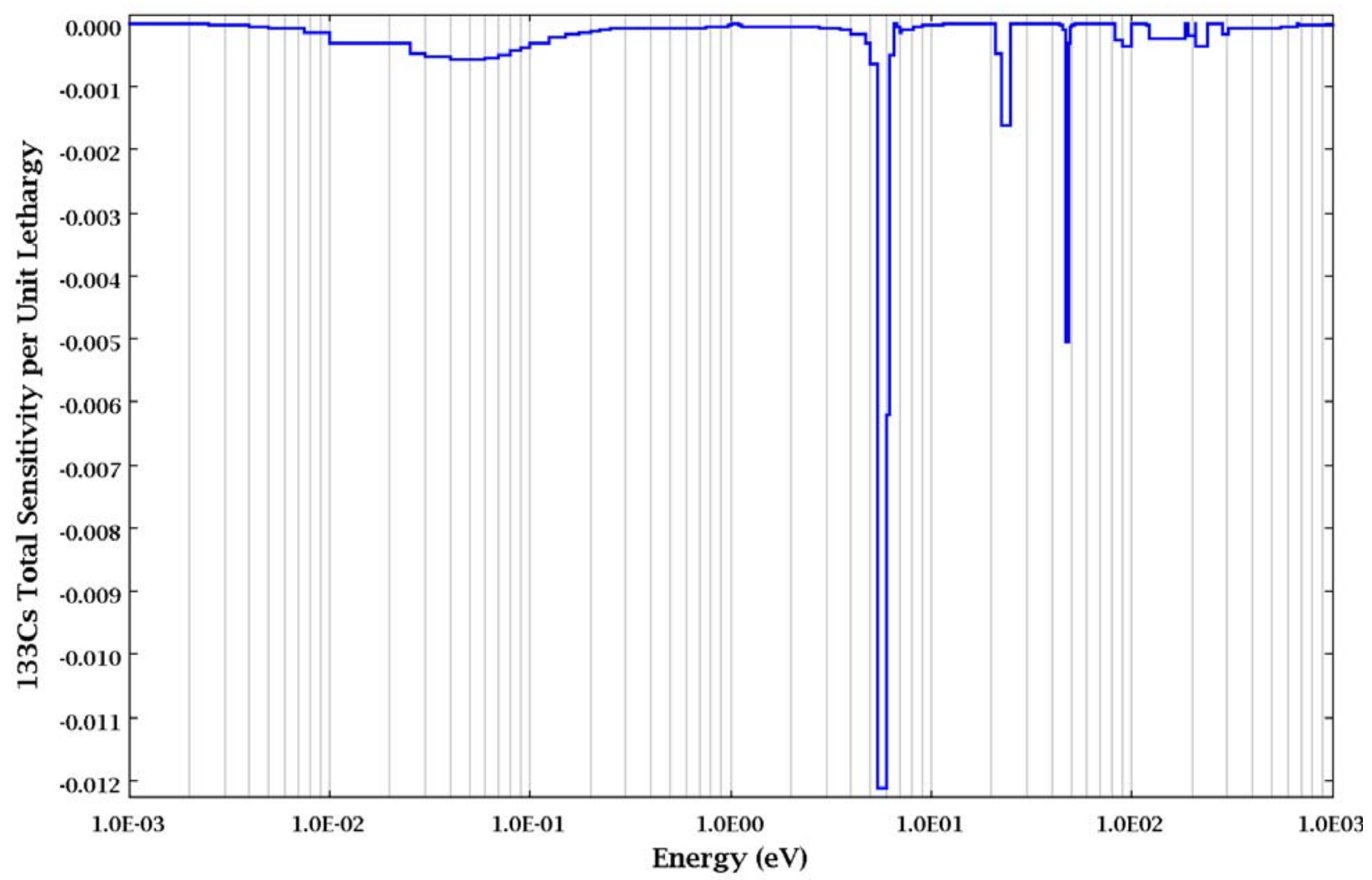

Fig. 15. Sensitivity of the $\mathbf{k}_{\text {effective }}$ to the ${ }^{133}$ Cs total cross section for the GBC-32 model.

\subsection{ASSESSMENT SUMMARY AND RECOMMENDATIONS FOR ${ }^{133} \mathrm{Cs}$}

Based on comparison of the latest ENDF, JEFF, and JENDL evaluations for ${ }^{133} \mathrm{Cs}$, the JEFF evaluation appears to be the most recent and better documented evaluation. When compared with available experimental data, the evaluated total cross section agrees with the experimental data below $10 \mathrm{eV}$; however, there is poor agreement between the total cross-section and measured data between $10 \mathrm{eV}$ and $500 \mathrm{eV}$. With regard to capture, no measured capture cross-section data could be located in the available experimental database (EXFOR). When compared with benchmark data, CEA reactivity worth calculations demonstrate that the ${ }^{133} \mathrm{Cs}$ capture rate overestimates measured capture rates in a PWR experiment by $5.5 \%$ with $1.5 \%$ uncertainty. Based on the assessment, total cross-section measurements are needed from $10 \mathrm{eV}$ and extending through the resonance region. Likewise, capture cross-section measurements are needed from $10^{-5} \mathrm{eV}$ and extending through the resonance region. While there is a general need for cross-section measurements throughout this energy range, sensitivity analysis of a typical burnup credit application indicates that cross-section measurements for energies up to about $1 \mathrm{keV}$ are most important for burnup credit applications. In addition, the latest evaluated data files do not provide cross-section covariance information for ${ }^{133} \mathrm{Cs}$, and new measurement and evaluation efforts will provide cross-section covariance data in addition to improved cross-section data. At a minimum, providing covariance data will benefit burnup credit analyses by enabling the propagation of ${ }^{133} \mathrm{Cs}$ cross-section uncertainty to calculated $k_{\text {effective }}$ values. Because of the limited amount of benchmark experiments involving ${ }^{133} \mathrm{Cs}$, there is also a need for ${ }^{133} \mathrm{Cs}$ benchmark critical experiments. 


\section{INVESTIGATION OF THE ${ }^{153}$ Eu EVALUATION}

\subsection{COMPARISON OF ${ }^{153}$ Eu ENDF, JENDL, AND JEFF EVALUATIONS}

The latest resonance evaluation of ${ }^{153} \mathrm{Eu}$ in the ENDF, JENDL, and JEFF libraries is very similar. Indeed, the JEFF and JENDL evaluations are identical. The energy limits for the resolved and unresolved energy regions for the ENDF, JENDL, and JEFF libraries are shown in Table 5.

Table 5. Resonance energy regions in ENDF, JENDL, and JEFF libraries for ${ }^{153}$ Eu

\begin{tabular}{|c|c|c|c|}
\hline \multirow[b]{2}{*}{ Energy range } & \multicolumn{3}{|c|}{ Data library } \\
\hline & ENDF & JEFF & JENDL \\
\hline $\begin{array}{l}\text { Resolved resonance region } \\
\text { energy range }\end{array}$ & $10^{-5} \mathrm{eV}$ to $97.8 \mathrm{eV}$ & $10^{-5} \mathrm{eV}$ to $97.2 \mathrm{eV}$ & $10^{-5} \mathrm{eV}$ to $97.2 \mathrm{eV}$ \\
\hline $\begin{array}{l}\text { Unresolved resonance } \\
\text { region energy range }\end{array}$ & $97.8 \mathrm{eV}$ to $83.91 \mathrm{keV}$ & $97.2 \mathrm{eV}$ to $100 \mathrm{keV}$ & $97.2 \mathrm{eV}$ to $100 \mathrm{keV}$ \\
\hline
\end{tabular}

The resolved-region representation is based on the resonance parameters listed in the Mughabghab compilation of resonance parameters. ${ }^{14}$ The resonance parameters were modified in the evaluation to reproduce the thermal capture cross section by adjusting the negative resonances (bound energy levels). It is not clear whether experimental data were used in the resonance evaluation.

\subsection{COMPARISON OF THE ${ }^{153}$ Eu ENDF EVALUATION WITH EXPERIMENTAL DATA}

A comparison of the ENDF total and capture cross sections from $10^{-3}$ to $1 \mathrm{eV}$ with experimental data of Adib et al. ${ }^{29}$ and Widder ${ }^{30}$ are shown in Fig. 16. It is clear that the evaluation does not reproduce the experimental results.

A comparison of the calculated ENDF capture cross section with the experimental data of Widder in the energy range from 1 to $10 \mathrm{eV}$ is shown in Fig. 17. The ENDF evaluation does not accurately represent the experimental data throughout the energy range. As noted in the Introduction section, differences between the measured data and cross-section evaluation may indicate a need to perform a new crosssection evaluation with the previously measured data. However, the only way to determine whether a new evaluation can be performed from the existing measured data is to actually perform an R-matrix analysis of the measured data, and this is beyond the scope of this report. In many cases, the cross-section measurement and evaluation work can be an iterative process where the evaluator attempts to analyze the measured data only to learn that a new/revised capture or transmission measurement is needed to resolve an issue in the R-matrix analyses. In the case of ${ }^{153} \mathrm{Eu}$, the cross-section data were measured in the 1975 to 1980 time frame. Therefore, it is prudent to plan for a new cross-section measurement based on substantial improvements in measurement technology (e.g., improved detectors, data acquisition systems, etc.) over the past 27 years. 


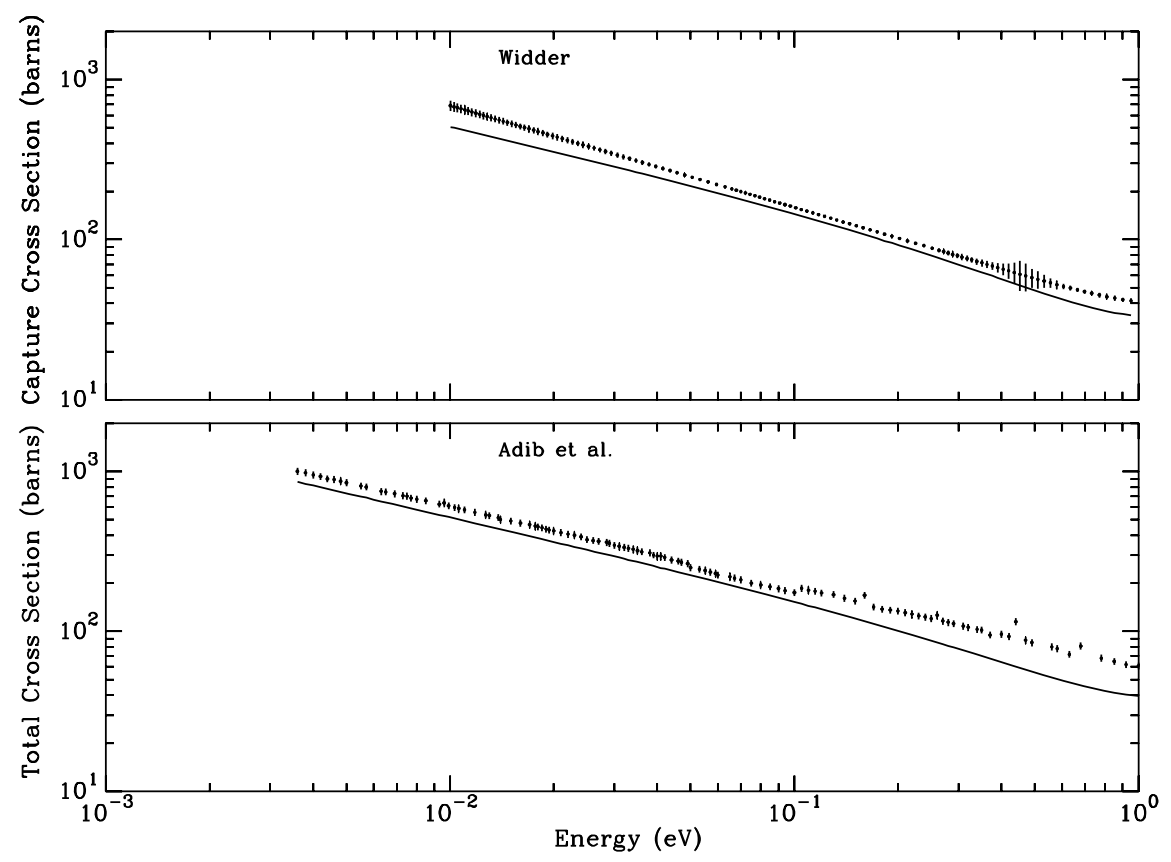

Fig. 16. Comparison of the ENDF total (bottom plot) and capture (upper plot) cross section with experimental data for ${ }^{153} \mathrm{Eu}$.

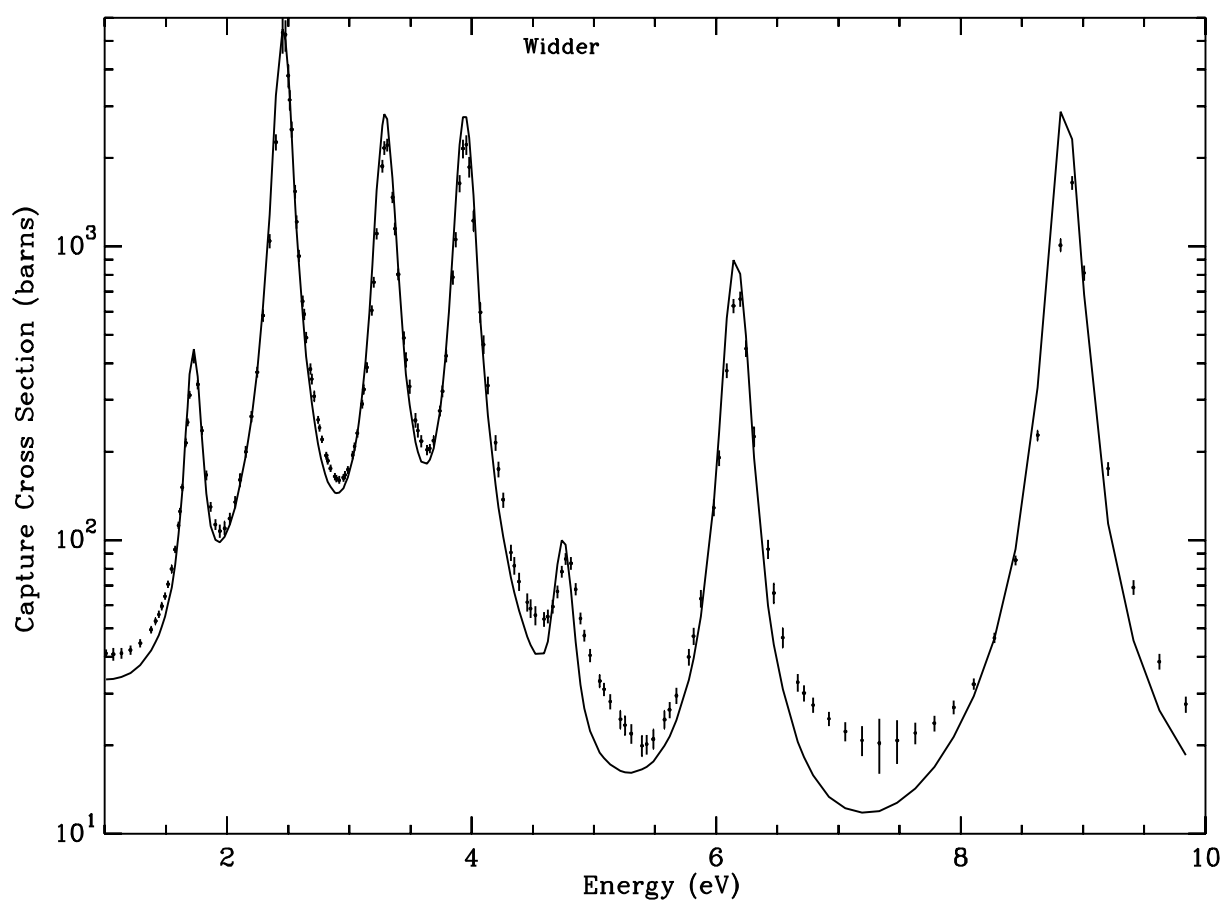

Fig. 17. Comparison of the ENDF capture cross section with experimental data for ${ }^{153} \mathrm{Eu}$. 


\subsection{BENCHMARK CALCULATIONS}

Integral measurements performed at the Minerve reactor, ${ }^{22} \mathrm{CEA} /$ Cadarache, identified a deficiency in the capture cross section of ${ }^{153} \mathrm{Eu}$ for the prediction of reactivity worth. Three configurations were investigated: R1-UO2 (PWR lattice made of low-enriched $\mathrm{UO}_{2}$ rods), R2-UO2 (lattice with a softer neutron spectrum), R1MOX (lattice made of mixed-oxide rods). The ratio of calculated-to-experiment $(\mathrm{C} / \mathrm{E})$ values is presented in Table 6 .

Table 6. Calculation-to-experiment ratios of sample reactivity worth for ${ }^{153} \mathrm{Eu}$

in the Minerve experiments. The energetic contribution of the incident neutron spectrum to the ${ }^{153} \mathrm{Eu}$ capture reaction rate is also shown (thermal region below $0.625 \mathrm{eV}$; fast region above $0.625 \mathrm{eV}$ )

\begin{tabular}{llccc}
\hline & & R1MOX & R1UO2 & R2UO2 \\
\hline \multicolumn{2}{c}{ C/E-1(\%) } & $-1.6 \pm 4.1$ & $-4.2 \pm 4.0$ & $-1.3 \pm 4.6$ \\
\cline { 1 - 2 } Energetic & Fast & $76.6 \%$ & $58.3 \%$ & $42.7 \%$ \\
contribution & Thermal & $23.4 \%$ & $41.7 \%$ & $57.3 \%$ \\
\hline
\end{tabular}

Because the uncertainties in the reactivity worth calculations in Table 6 are on the order of the integral results, the results shown in Table 6 are inconclusive with regard to the ${ }^{153} \mathrm{Eu}$ capture cross-section data. In addition to the reactivity worth measurements, CEA has also performed integral measurements based on postirradiated experiments. The experiments consisted of irradiation of uranium oxide fuel and mixedoxide fuel and the postirradiated chemical analyses of the buildup of ${ }^{153} \mathrm{Eu}$ for burnup by measuring the ${ }^{153} \mathrm{Eu} /{ }^{238} \mathrm{U}$ ratio. The resulting calculated-to-experiment values are shown in Table 7.

Table 7. Calculation-to-experiment ratio of ${ }^{153} \mathrm{Eu}$ by measuring the ${ }^{153} \mathrm{Eu} /{ }^{238} \mathrm{U}$ ratio

\begin{tabular}{lrrrc}
\hline Burnup (MWd/t) & $\mathbf{2 0 4 0 0}$ & $\mathbf{3 8 3 6 0}$ & $\mathbf{5 0 8 0 0}$ & $\mathbf{5 9 8 5 0}$ \\
\hline $\mathrm{C} / \mathrm{E}-1$ in \% of the & $5.84 \pm 2.33$ & $7.79 \pm 2.01$ & $11.04 \pm 1.86$ & $12.74 \pm 1.63$ \\
${ }^{153} \mathrm{Eu} /{ }^{238} \mathrm{U}$ ratio & & & & \\
\hline
\end{tabular}

The results displayed in Table 7 suggest that the overestimation on the ${ }^{153}$ Eu buildup could be due to an underestimation of the ${ }^{153} \mathrm{Eu}$ capture cross section. However, as noted in Figure 1 of Ref. 1, the concentration of ${ }^{153} \mathrm{Eu}$ in SNF is influenced by the cross sections of ${ }^{153} \mathrm{Eu},{ }^{152} \mathrm{Sm}$, and to a lesser extent ${ }^{151} \mathrm{Sm}$. Therefore, the overestimation of ${ }^{153} \mathrm{Eu}$ concentrations is not solely dependent on the ${ }^{153} \mathrm{Eu}$ capture cross section. Nonetheless, the ${ }^{153} \mathrm{Eu}$ capture cross-section is an important component in predicting ${ }^{153} \mathrm{Eu}$ concentrations in SNF. Because ${ }^{153} \mathrm{Eu}$ is a byproduct of fission yields ${ }^{153} \mathrm{Pm}$ and/or ${ }^{153} \mathrm{Sm}$, an overestimation in the buildup of ${ }^{153} \mathrm{Eu}$ may also be due to an overestimation of these fission yields. As shown in Fig. 18, ${ }^{153}$ Eu neutron capture cross section is also important because ${ }^{155} \mathrm{Gd}$, which has high capture cross sections, is produced in the decay chain of ${ }^{155} \mathrm{Eu}$, which is produced by neutron capture in ${ }^{154} \mathrm{Eu}$ following neutron capture in ${ }^{153} \mathrm{Eu}$. As noted previously, the uncertainty in the reactivity worth calculations are on the order of the integral results. Therefore the benchmark calculations are inconclusive relative to the performance of the ${ }^{153} \mathrm{Eu}$ cross-section data. Based on the comparisons of the evaluated differential data with existing measured data, ${ }^{153} \mathrm{Eu}$ capture cross-section measurements are needed to improve the cross-section data for ${ }^{153} \mathrm{Eu}$. 


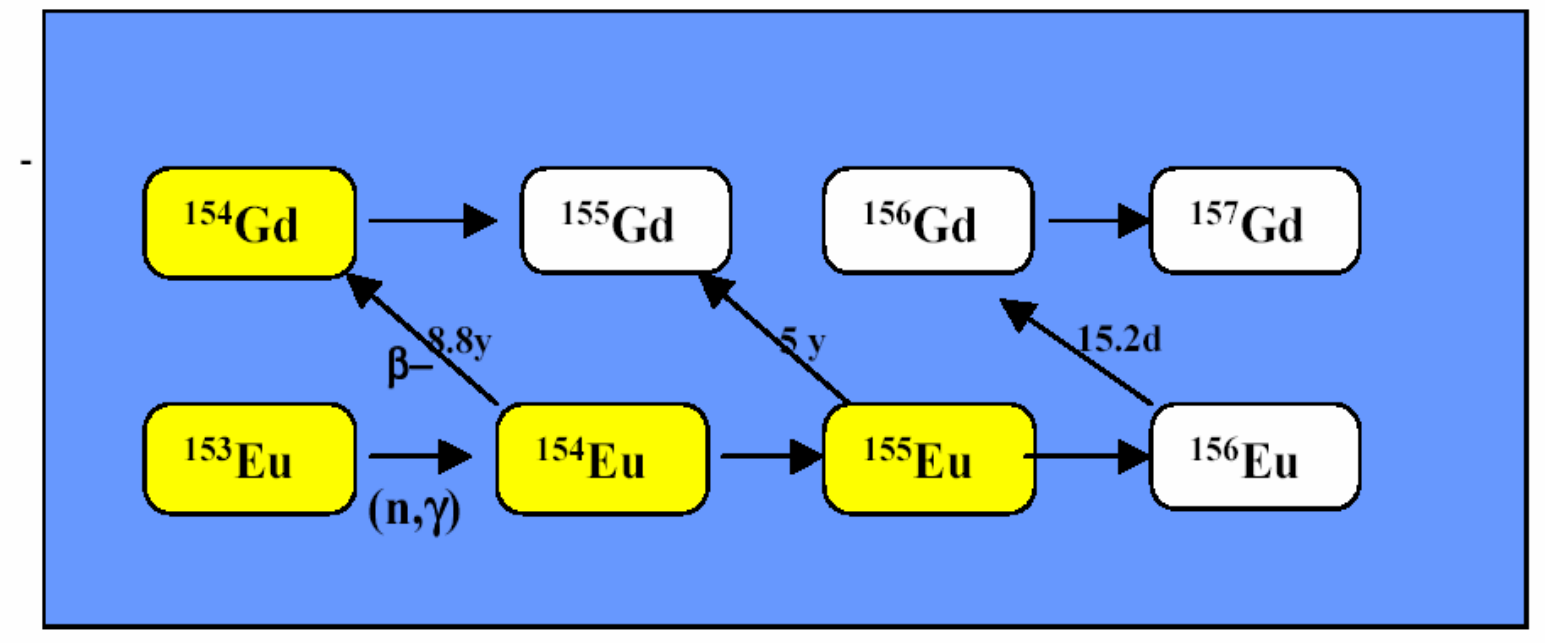

Fig. 18. ${ }^{153} \mathrm{Eu}$ chain for production of ${ }^{155} \mathrm{Gd}$.

\subsection{SENSITIVITY ANALYSIS FOR ${ }^{153}$ Eu IN A BURNUP CREDIT APPLICATION}

Sensitivity analyses of the ${ }^{153} \mathrm{Eu}$ in a typical burnup credit application were performed with the TSUNAMI sequence in SCALE 5.1 (Ref. 12). The sensitivity of $\mathrm{k}_{\text {effective }}$ to the ${ }^{153} \mathrm{Eu}$ total cross section for the GBC-32 model is shown in Fig. 19. The burnup credit model is sensitive to the ${ }^{153}$ Eu capture cross section in the thermal energy region $(0.0253 \mathrm{eV})$ up to about $1 \mathrm{keV}$ and is insensitive to crosssection data above $1 \mathrm{keV}$. This figure reflects sensitivity of $\mathrm{k}_{\text {effective }}$ to perturbations in the cross sections for burned fuel in a flooded burnup credit cask. The sensitivity profile for ${ }^{153} \mathrm{Eu}$ neutron capture in the PWR environment is similar to the profile from the GBC-32 because both systems involve flooded arrays of intact fuel assemblies. 


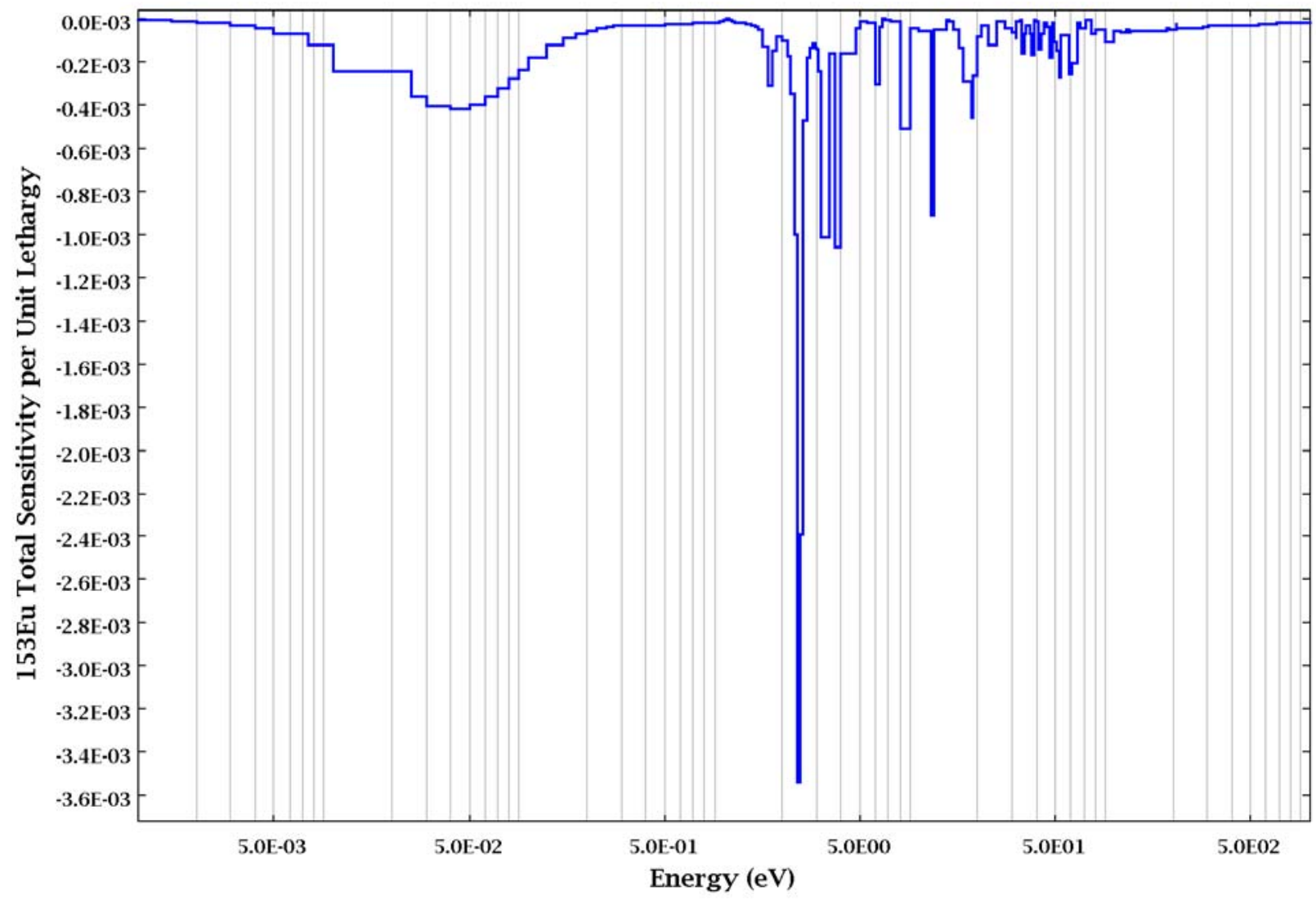

Fig. 19. Sensitivity of the $k_{\text {effective }}$ to the ${ }^{153}$ Eu total cross section for the GBC-32 model.

\subsection{ASSESSMENT SUMMARY AND RECOMMENDATIONS FOR ${ }^{153} \mathrm{Eu}$}

For ${ }^{153} \mathrm{Eu}$, the latest ENDF, JEFF, and JENDL evaluations are similar, and the JEFF and JENDL evaluations are identical. The ENDF evaluation for ${ }^{153} \mathrm{Eu}$ is judged to be the most up-to-date evaluation. An investigation of the ${ }^{153} \mathrm{Eu}$ resonance evaluation revealed that the resonance parameters are based on the work of Mughabghab; ${ }^{14}$ however, it is not clear whether the resonance parameters are based on crosssection measurements. When compared with available experimental data, the evaluated total and capture cross-section data do not show desired agreement with measured data between $10^{-5} \mathrm{eV}$ and $10 \mathrm{eV}$. With regard to benchmark performance, CEA reactivity worth measurements indicate that the calculated ${ }^{153} \mathrm{Eu}$ capture rate underestimates measured capture rates by $1.3 \%$ to $4.2 \%$; however, the uncertainty of the reactivity worth predictions is on the order of the integral results. Therefore, the reactivity worth benchmark results are not conclusive to assess the performance of ${ }^{153} \mathrm{Eu}$ capture. Based on postirradiation chemical analyses of uranium oxide fuel and mixed-oxide fuel, the calculated buildup of ${ }^{153} \mathrm{Eu}$ may be overestimated because of the underestimation of ${ }^{153} \mathrm{Eu}$ capture rates. Based on the assessment, total and capture ${ }^{153} \mathrm{Eu}$ cross-section measurements are needed from $10^{-5} \mathrm{eV}$ and extending through the resonance region. While there is a general need for cross-section measurements throughout this energy range, sensitivity analysis of a typical burnup credit application indicates that cross-section measurements for energies up to about $1 \mathrm{keV}$ are most important for burnup credit applications. In addition, the latest evaluated data files do not provide cross-section covariance information for ${ }^{153} \mathrm{Eu}$, and new measurement 
and evaluation efforts will provide cross-section covariance data in addition to improved cross-section data. At a minimum, providing covariance data will benefit burnup credit analyses by enabling the propagation of ${ }^{153} \mathrm{Eu}$ cross-section uncertainty to calculated $\mathrm{k}_{\text {effective }}$ values. 


\section{INVESTIGATION OF THE ${ }^{143}$ Nd EVALUATION}

\subsection{COMPARISON OF ${ }^{143} \mathrm{Nd}$ ENDF, JENDL, AND JEFF EVALUATIONS}

Natural neodymium $(\mathrm{Nd})$ consists of seven stable isotopes, and ${ }^{143} \mathrm{Nd}$ (abundance of $12.18 \%$ ) has the largest thermal capture cross section. Cross-section data for ${ }^{143} \mathrm{Nd}$ are of interest because of the relatively high capture cross section throughout the resonance region. The existing ${ }^{143} \mathrm{Nd}$ evaluations in the three cross-section libraries, ENDF, JENDL, and JEFF, in the resonance regions, resolved and unresolved energy regions, are very similar. The evaluation in the ENDF library has been recently revised and is better documented. A comparison of the energy limits for the resolved and unresolved energy regions in the basic nuclear data libraries ENDF and JENDL, and JEFF is shown in Table 8.

Table 8. Resonance energy regions in ENDF, JENDL, and JEFF libraries for ${ }^{143} \mathrm{Nd}$

\begin{tabular}{lccc}
\hline & \multicolumn{3}{c}{ Data library } \\
\cline { 2 - 4 } Energy range & ENDF & JENDL & JEFF \\
\hline $\begin{array}{l}\text { Resolved resonance } \\
\text { region energy range }\end{array}$ & $10^{-5} \mathrm{eV}$ to $5.503 \mathrm{keV}$ & $10^{-5} \mathrm{eV}$ to $5 \mathrm{keV}$ & $10^{-5} \mathrm{eV}$ to $5.521 \mathrm{keV}$ \\
& & \\
$\begin{array}{l}\text { Unresolved resonance } \\
\text { region energy range }\end{array}$ & $5.503 \mathrm{keV}$ to $225 \mathrm{keV}$ & $5 \mathrm{keV}$ to $100 \mathrm{keV}$ & $5.521 \mathrm{keV}$ to $10 \mathrm{keV}$ \\
\hline
\end{tabular}

The cross-section representation in these evaluations in the RRR is based on the MLBW formalism. The resonance parameters included in these evaluations are the parameters published in the Mughabghab compilation. ${ }^{14}$ The resonance parameters in these evaluations were revised with the purpose of reproducing the experimental thermal cross-section value. A comparison between the ENDF, JENDL, and JEFF capture cross section from $10^{-3}$ to $10 \mathrm{eV}$ is shown in Fig. 20.

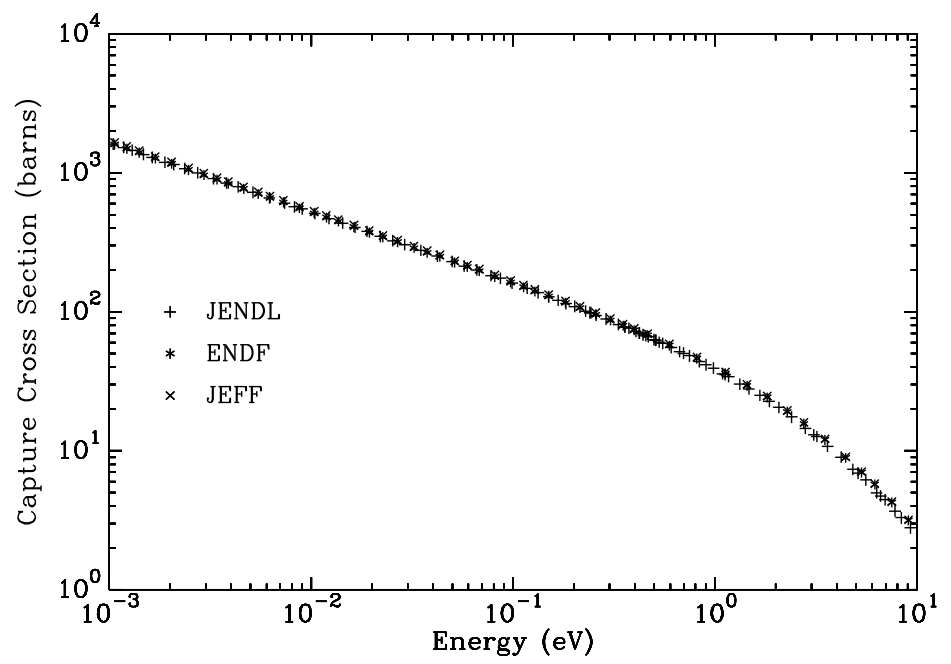

Fig. 20. Comparison of the ENDF (*), JENDL (+), and JEFF $(\times)$ capture cross sections from $10^{-3}$ to $10 \mathrm{eV}$ for ${ }^{143} \mathrm{Nd}$. 
The capture cross sections in the three libraries agree up to $10 \mathrm{eV}$. Figure 21 displays the ENDF, JENDL, and JEFF capture cross sections from 10 to $200 \mathrm{eV}$. The capture cross sections calculated with the three evaluations are consistent.

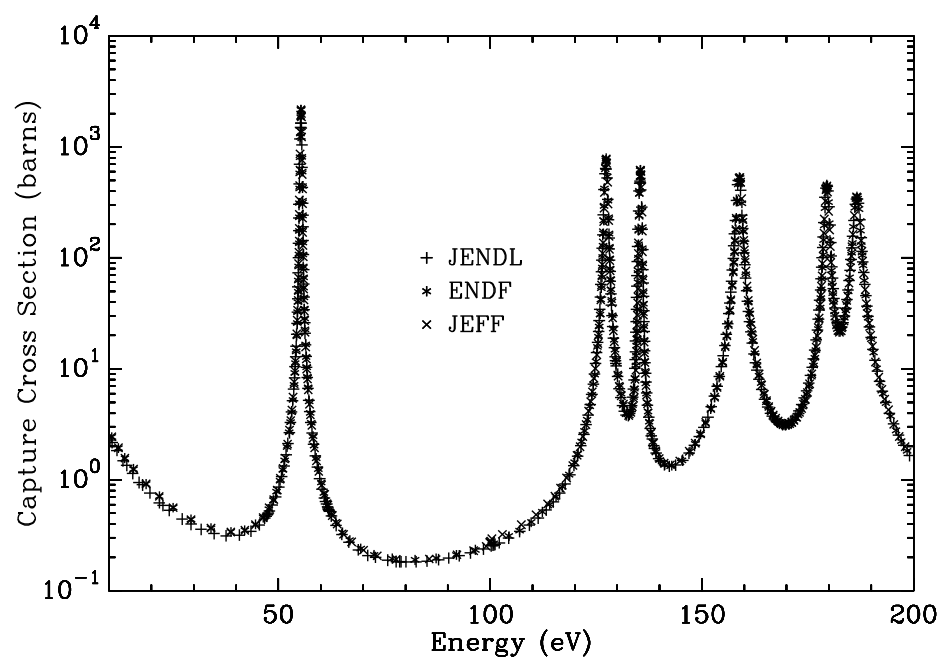

Fig. 21. Comparison of the ENDF (*), JENDL $(+)$, and JEFF $(\times)$ capture cross sections from 10 to $200 \mathrm{eV}$ for ${ }^{143} \mathrm{Nd}$.

Figure 22 shows a comparison of the ENDF, JENDL, and JEFF capture cross sections in the energy range from 500 to $1000 \mathrm{eV}$. The three evaluations are consistent in this energy region although the JEFF evaluation calculates a higher capture cross section between resonances.

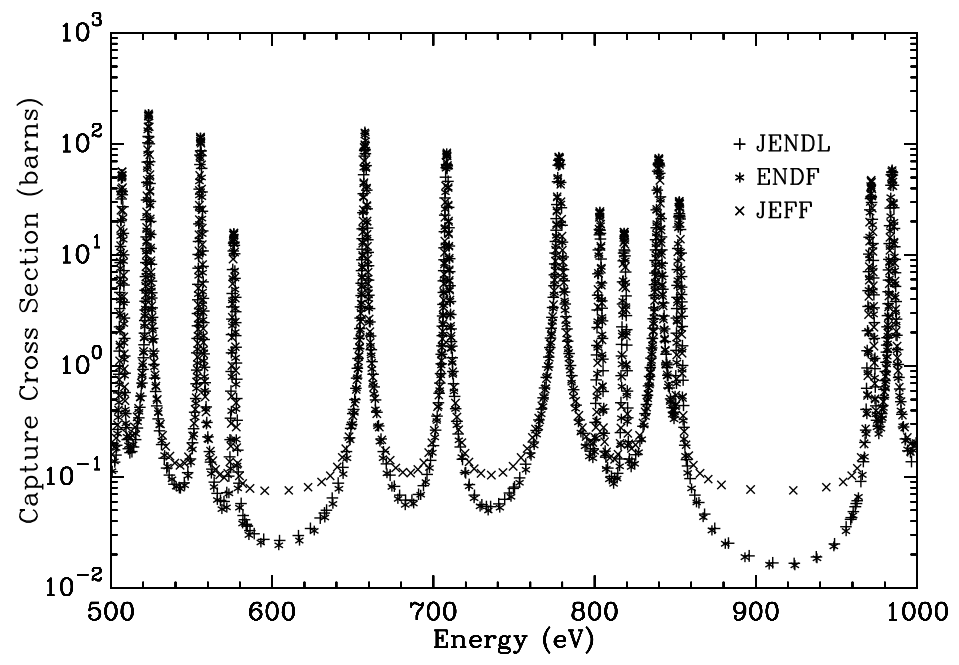

Fig. 22. Comparison of the ENDF $(*)$, JENDL $(+)$, and JEFF $(\times)$ capture cross sections from 500 to $1000 \mathrm{eV}$ for ${ }^{143} \mathrm{Nd}$. 


\subsection{COMPARISONS OF THE ${ }^{143} \mathrm{Nd}$ ENDF EVALUATION WITH EXPERIMENTAL DATA}

A search of the available experimental cross-section data for ${ }^{143} \mathrm{Nd}$ in the EXFOR system was performed. Total, capture, and scattering cross-section measurements by Vertebny et al. ${ }^{11}$ at room temperature $(293 \mathrm{~K})$ are available from $0.02 \mathrm{eV}$ to $10 \mathrm{eV}$. A comparison of the ENDF evaluation processed with NJOY with the experimental data of Vertebny is shown in Fig. 23.

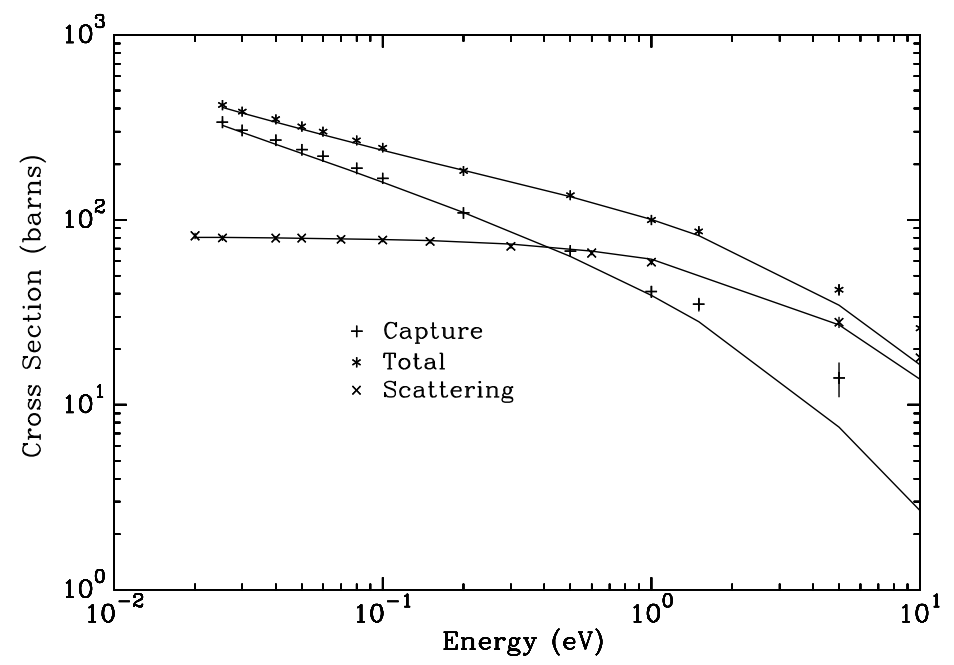

Fig. 23. Comparison of the experimental total $(*)$, capture $(+)$, and scattering $(\times)$ cross sections with the ENDF data from 0.02 to $10 \mathrm{eV}$ for ${ }^{143} \mathrm{Nd}$.

The results shown in Fig. 23 indicate that the ENDF evaluation of ${ }^{143} \mathrm{Nd}$ cross sections below $10 \mathrm{eV}$ agree with the experimental data; however, no experimental data are available between 10 and $60 \mathrm{eV}$ in the EXFOR system. Above $60 \mathrm{eV}$ the only data found in the EXFOR system are based on the total crosssection measurements by Tellier ${ }^{32}$ spanning the energy region from 60 to $30,000 \mathrm{eV}$. Comparisons of the total cross section measured by Tellier and calculation based on the ENDF evaluation in the energy region from 60 to $200 \mathrm{eV}$ are shown in Fig. 24. 


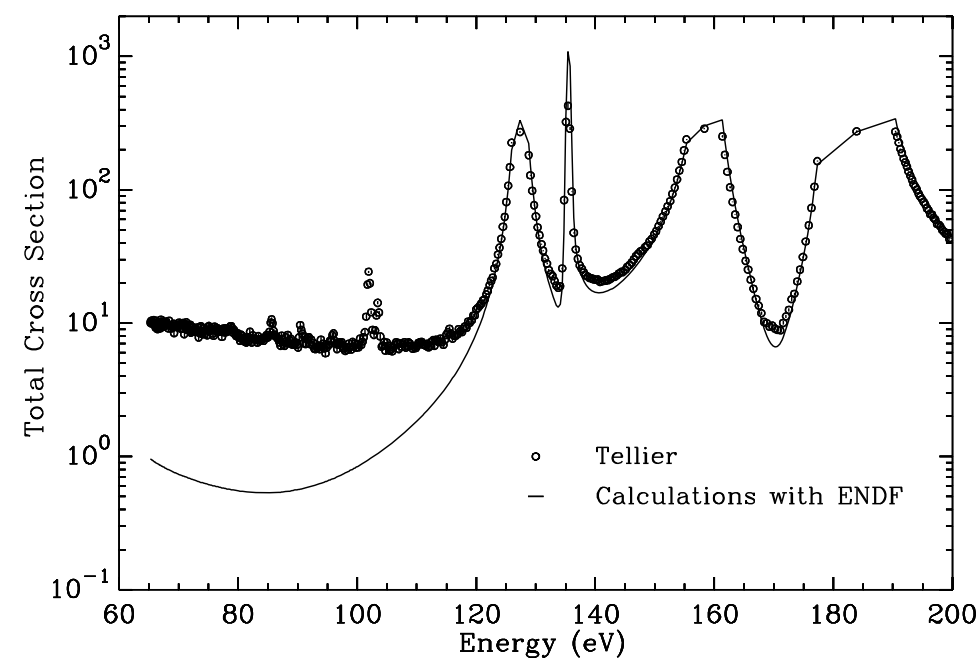

Fig. 24. Comparison of the experimental total cross sections (o) and calculations carried out with ENDF evaluation (一) for ${ }^{143} \mathrm{Nd}(60$ to $200 \mathrm{eV})$.

Between 60 and $120 \mathrm{eV}$, the total cross sections obtained from the ENDF evaluation are lower than the experimental data of Tellier. From 120 to $200 \mathrm{eV}$, experimental and calculated total cross sections are in fairly good agreement. The calculated ENDF total cross section in the energy region from 200 to $500 \mathrm{eV}$ does not agree with the experimental data as shown in Fig. 25. The calculated cross section shows a potential scattering interference around $280 \mathrm{eV}$. This feature is not shown in the experimental data. Calculated and experimental cross sections agree at the resonance peaks.

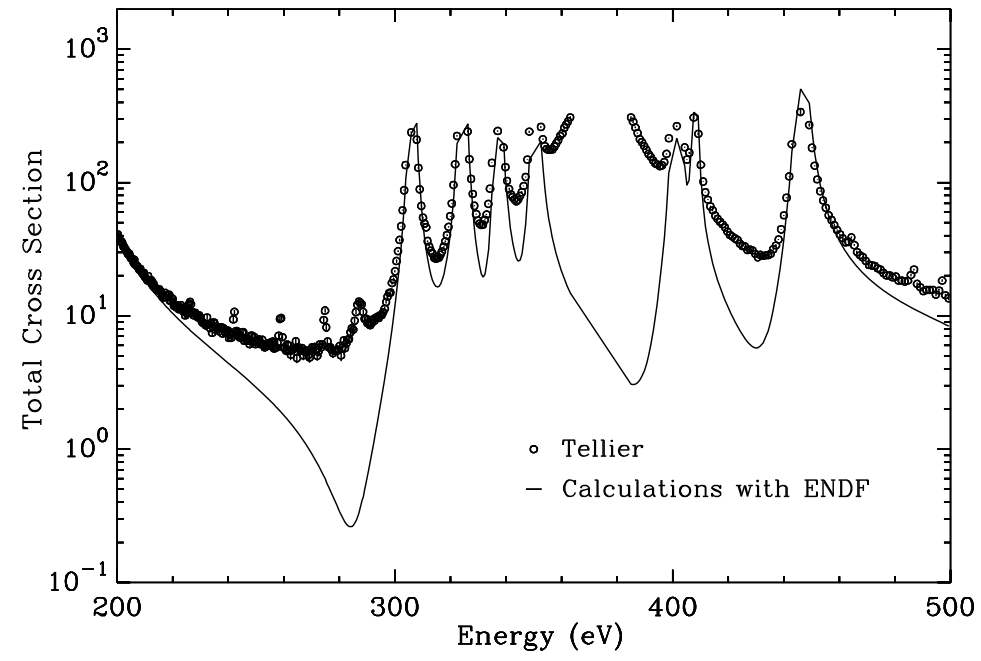

Fig. 25. Comparison of the experimental total cross sections (0) and calculations carried out with ENDF evaluation (一) for ${ }^{143} \mathrm{Nd}(200$ to $500 \mathrm{eV})$. 
Comparison of the experimental total cross section and corresponding ENDF evaluation in the energy region 500 to $1000 \mathrm{eV}$ is show in Fig. 26. In general, the evaluation produces a lower value of the total cross section between resonances. In some energy intervals, the evaluation misses resonance structure that is present in the measured data.

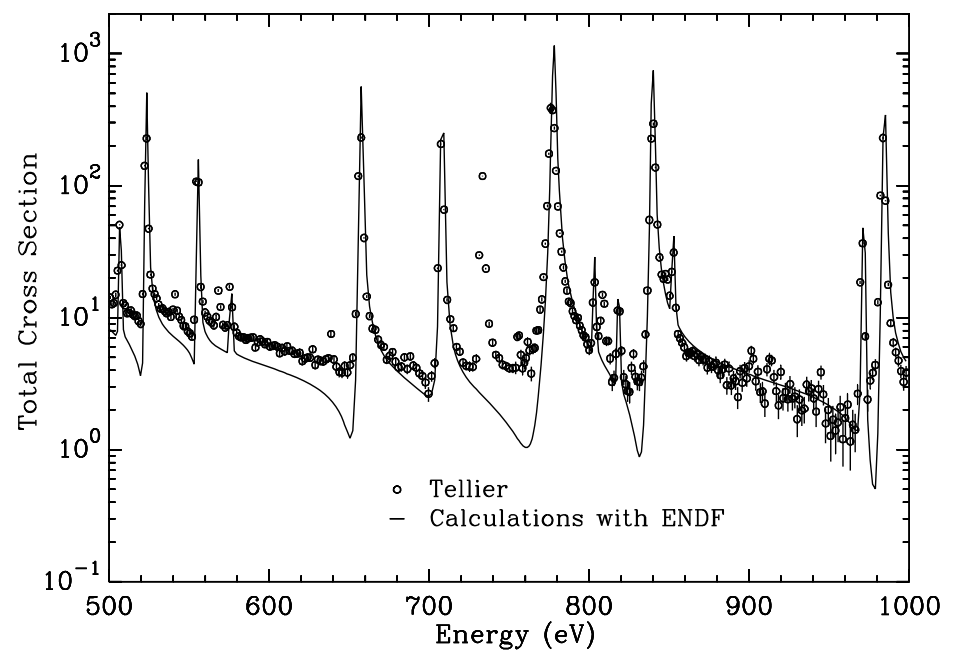

Fig. 26. Comparison of the experimental total cross sections (o) and calculations carried out with ENDF evaluation (-) for ${ }^{143} \mathrm{Nd}(500$ to $1000 \mathrm{eV})$.

At the time of the assessment, measured capture cross-section data were not available in the EXFOR system in the energy region from 10 to $4000 \mathrm{eV}$. The evaluations in the ENDF, JENDL, and JEFF libraries are based on experimental capture cross-section data performed by Rohr et al. ${ }^{33}$ in the early 1970s. The capture data are not available in the EXFOR system, and no new capture data have been measured.

Both total and capture evaluated cross-section data for ${ }^{143} \mathrm{Nd}$ exhibit inconsistencies with the measured cross-section data. The discrepancies indicate that a new R-matrix analysis of the ${ }^{143} \mathrm{Nd}$ data is needed at a minimum; however, as noted previously, the only way to determine whether the existing measured data can be used for a new evaluation is to perform an R-matrix analysis of the measured data, and this is beyond the scope of this report. The ${ }^{143} \mathrm{Nd}$ cross-section measurements were performed in the 1970s, and there have been significant advances in measurement technology over the past 30 to 40 years. Therefore, it is prudent to consider new cross-section measurement and corresponding resonance analysis as part of a plan to improve the ${ }^{143} \mathrm{Nd}$ cross-section data. The important ${ }^{143} \mathrm{Nd}$ cross-section energies for burnup credit are addressed in Sect. 5.4.

\subsection{BENCHMARK CALCULATIONS}

Integral measurements were performed in France and the United Kingdom for testing the ${ }^{143} \mathrm{Nd}$ cross section for burnup credit applications. The experiments consisted of reactivity worth measurements by the oscillation method carried out in the Minerve and Dimple experimental reactors located at Cadarache, France, and Winfrith, United Kingdom, respectively. The experiments were performed in support of the burnup credit program. Four configurations were investigated in the Minerve reactor: R1-UO2 (PWR lattice made of low-enriched $\mathrm{UO}_{2}$ rods), R2-UO2 (lattice with a softer neutron spectrum), R1MOX (lattice made of mixed-oxide rods), and a BWR configuration. Two experimental configurations were investigated in the Dimple reactor (DIMPLE II and DIMPLE III experiments). DIMPLE II is 
similar to the MINERVE R1-UO2 experiments, and they are representative of PWR configurations. The DIMPLE III measurements consisted of PWR and BWR irradiated fuel samples. The ${ }^{143} \mathrm{Nd}$ samples were oscillated at the center of the reactors, and the reactivity worth was directly measured after careful calibration using borated $\mathrm{UO}_{2}$ samples and variably enriched $\mathrm{UO}_{2}$ samples. The experimental uncertainty on reactivity worths (mainly coming from the calibration procedure and from ${ }^{143} \mathrm{Nd}$ concentrations in the sample) is about 3 to $4 \%$. The interpretation of these experiments was performed at CEA-Cadarache ${ }^{12}$ with the deterministic APOLLO2 code ${ }^{23}$ and the JEFF2.2 multigroup library. Special care was paid to the treatment of resonance self-shielding in APOLLO2, which was validated using the continuous-energy Monte Carlo code TRIPOLI4 (Ref. 24) with pointwise data from the JEF2.2 library. The ratio of calculated-to-experiment (C/E) values is displayed in Table 9.

Table 9. Calculation-to-experiment ratio of sample reactivity worth for ${ }^{143} \mathrm{Nd}$ in the Minerve and Dimple experiments

\begin{tabular}{|c|c|c|c|c|c|c|}
\hline & BWR & R1MOX & R1UO2 & R1UO2 & DIMPLE II & DIMPLE III \\
\hline C/E-1(\%) & $-4.7 \pm 2.9$ & $-0.7 \pm 4.6$ & $-7.1 \pm 3.1$ & $-8.5 \pm 3.8$ & $-6 \pm 2$ & $-4 \pm 2$ \\
\hline
\end{tabular}

The results displayed in Table 9 show that the ${ }^{143} \mathrm{Nd}$ capture resonance integral in JEFF2.2 seems to be underestimated. The results shown in Table 9 suggest that an increase in the capture cross section is needed to improve the integral results. The same trend was observed with other nuclear cross-section libraries. Based on the performance of ${ }^{143} \mathrm{Nd}$ in the French benchmark calculations and comparisons of the evaluated differential data with existing measured data, ${ }^{143} \mathrm{Nd}$ capture cross-section measurements are needed to improve the accuracy of ${ }^{143} \mathrm{Nd}$.

\subsection{SENSITIVITY ANALYSIS FOR ${ }^{143} \mathrm{Nd}$ IN A BURNUP CREDIT APPLICATION}

Sensitivity analyses of the ${ }^{143} \mathrm{Nd}$ in a typical burnup credit application were performed with the TSUNAMI sequence in SCALE 5.1 (Ref. 12). The sensitivity of $\mathrm{k}_{\text {effective }}$ to the ${ }^{143} \mathrm{Nd}$ total cross section for the GBC-32 model is shown in Fig. 27. The burnup credit model is sensitive to the ${ }^{143} \mathrm{Nd}$ cross sections in the thermal energy region $(0.0253 \mathrm{eV})$ up to about $600 \mathrm{eV}$ and is relatively insensitive to cross-section data above $600 \mathrm{eV}$. 


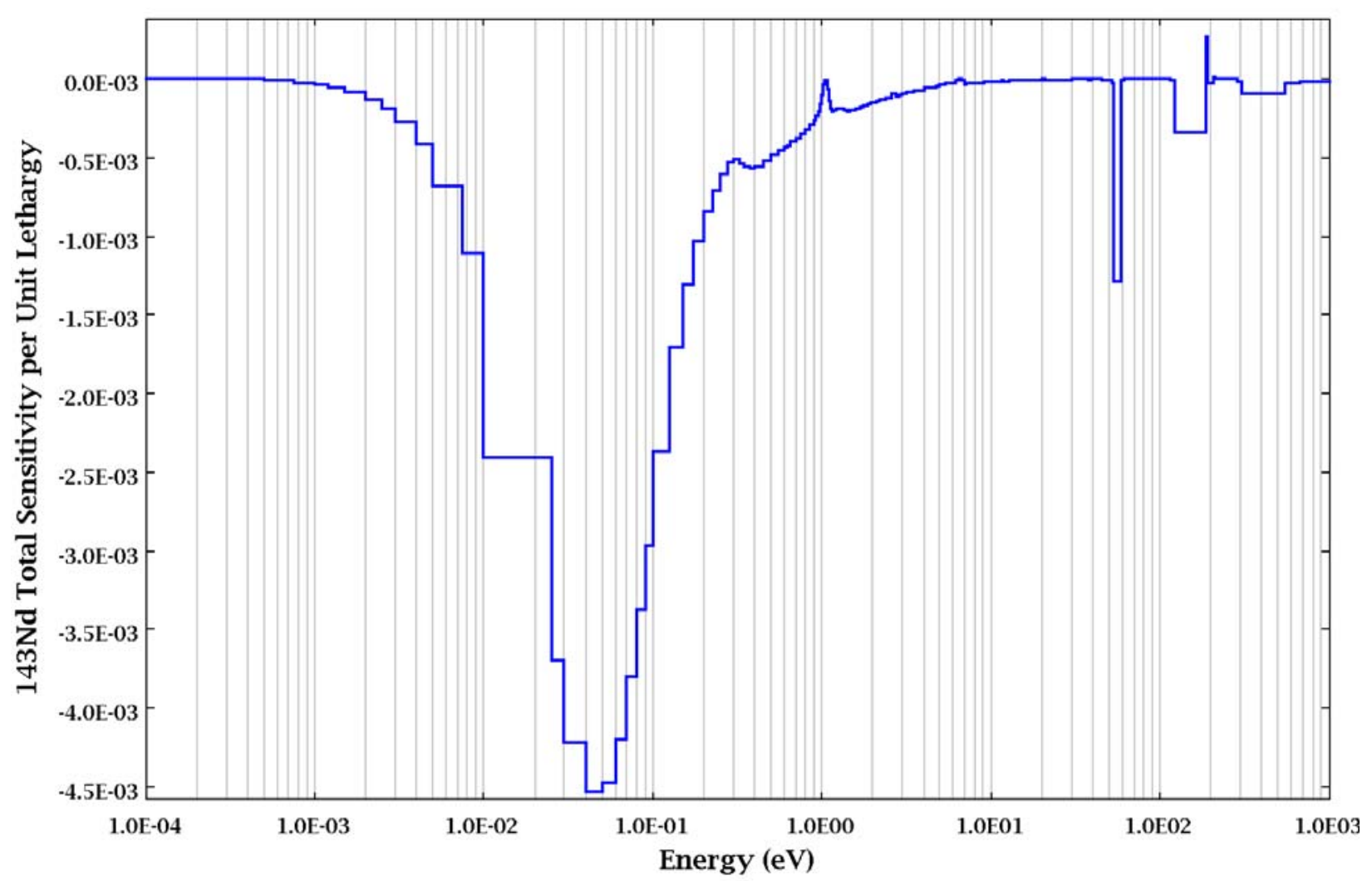

Fig. 27. Sensitivity of the $k_{\text {effective }}$ to the ${ }^{143} \mathrm{Nd}$ total cross section for the GBC-32 model.

\subsection{ASSESSMENT SUMMARY AND RECOMMENDATIONS FOR ${ }^{143} \mathrm{Nd}$}

For ${ }^{143} \mathrm{Nd}$, the latest ENDF, JEFF, and JENDL evaluations are similar, and the ENDF evaluation for ${ }^{143} \mathrm{Nd}$ is judged to be the most recent evaluation. When compared with available experimental data, the ${ }^{143} \mathrm{Nd}$ evaluated total and capture cross-sections agree with measured data below $10 \mathrm{eV}$. Measured total crosssection data could not be located for energies between $10 \mathrm{eV}$ and $60 \mathrm{eV}$. For energies between $60 \mathrm{eV}$ and $30 \mathrm{keV}$, there is poor agreement between the evaluation and measured data except for energies between $120 \mathrm{eV}$ and $200 \mathrm{eV}$. With regard to capture, measured capture cross-section data could not be located for energies between $10 \mathrm{eV}$ and $4 \mathrm{keV}$. With regard to benchmark performance, CEA reactivity worth measurements indicate that the calculated ${ }^{143} \mathrm{Nd}$ capture rate underestimates measured capture rates by $0.7 \%$ to $8.5 \%$ with 2 to $5 \%$ uncertainty. In general, total and capture ${ }^{143} \mathrm{Nd}$ cross-section measurements are needed from $10 \mathrm{eV}$ and extending through the resonance region. While there is a general need for cross-section measurements throughout this energy range, sensitivity analysis of a typical burnup credit application indicates that cross-section measurements for energies up to about $600 \mathrm{eV}$ are most important for burnup credit applications. In addition, the latest evaluated data files do not provide cross-section covariance information for ${ }^{143} \mathrm{Nd}$, and new measurement and evaluation efforts will provide cross-section covariance data in addition to improved cross-section data. At a minimum, providing covariance data will benefit burnup credit analyses by enabling the propagation of ${ }^{143} \mathrm{Nd}$ cross-section uncertainty to calculated $\mathrm{k}_{\text {effective }}$ values. Because of the limited amount of benchmark experiments involving ${ }^{143} \mathrm{Nd}$, there is also a need for ${ }^{143} \mathrm{Nd}$ benchmark critical experiments. 


\section{INVESTIGATION OF THE ${ }^{149}$ Sm EVALUATION}

\subsection{COMPARISON OF ${ }^{149}$ Sm ENDF, JENDL, AND JEFF EVALUATIONS}

Cross-section data for ${ }^{149} \mathrm{Sm}$ are available in the ENDF, JENDL, and JEFF libraries. The ${ }^{149} \mathrm{Sm}$ JEFF evaluation was adopted from the ENDF evaluation. The only difference is in the resonance region where the neutron width of the first resonance at $0.0973 \mathrm{eV}$ was increased by $3 \%$ in the JEFF evaluation. The cross-section representation in these libraries in the RRR is based on the MLBW formalism. The resonance parameters are the parameters published in the Mughabghab compilation. A comparison of the energy limits for the resolved and unresolved energy regions in ENDF, JENDL, and JEFF are presented in Table 10.

Table 10. Resonance energy regions in ENDF, JENDL, and JEFF libraries for ${ }^{149} \mathrm{Sm}$

\begin{tabular}{lccc}
\hline & \multicolumn{3}{c}{ Data library } \\
\cline { 2 - 4 } Energy range & ENDF & JENDL & JEFF \\
\hline $\begin{array}{l}\text { Resolved resonance } \\
\text { region energy range }\end{array}$ & $10^{-5} \mathrm{eV}$ to $519.7 \mathrm{eV}$ & $10^{-5} \mathrm{eV}$ to $520 \mathrm{eV}$ & $10^{-5} \mathrm{eV}$ to $519.7 \mathrm{eV}$ \\
& & \\
$\begin{array}{l}\text { Unresolved resonance } \\
\text { region energy range }\end{array}$ & $519.7 \mathrm{eV}$ to $100 \mathrm{keV}$ & $520 \mathrm{eV}$ to $100 \mathrm{keV}$ & $519.7 \mathrm{eV}$ to $100 \mathrm{keV}$ \\
\hline
\end{tabular}

Comparisons of the ${ }^{149} \mathrm{Sm}$ total and capture cross section from $10^{-5}$ to $0.4 \mathrm{eV}$ calculated at $300 \mathrm{~K}$ are shown in Figs. 28 and 29, respectively. The results shown in these figures indicate that the total and capture cross sections in ENDF, JEFF, and JENDL below $0.4 \mathrm{eV}$ are very similar.

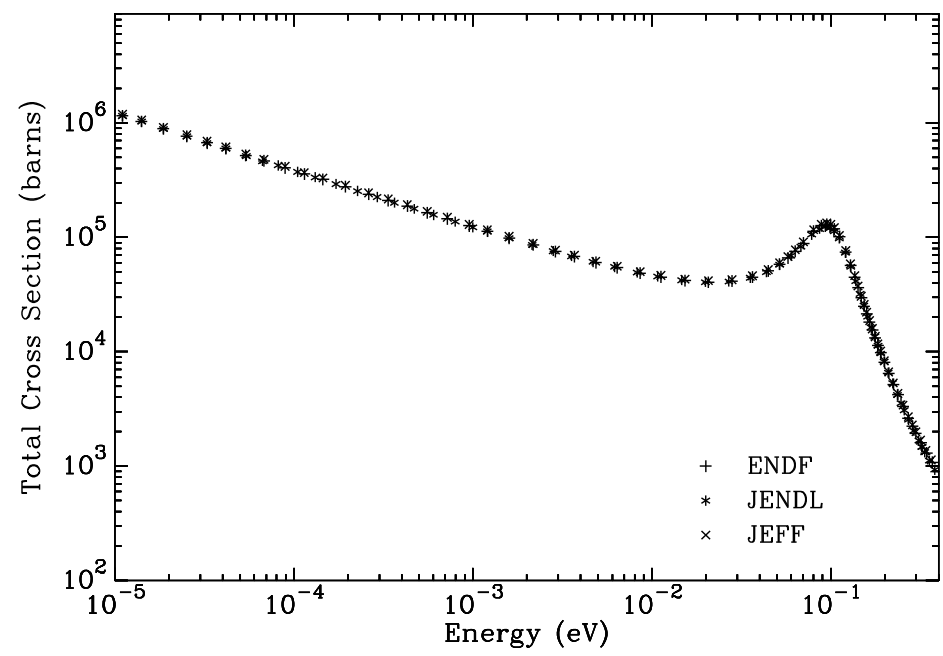

Fig. 28. Comparison of the total cross sections for ${ }^{149} \mathrm{Sm}$ from $10^{-5}$ to $0.4 \mathrm{eV}$ for the ENDF (+), JEFF ( $\times$ ), and JENDL (*) evaluations. 


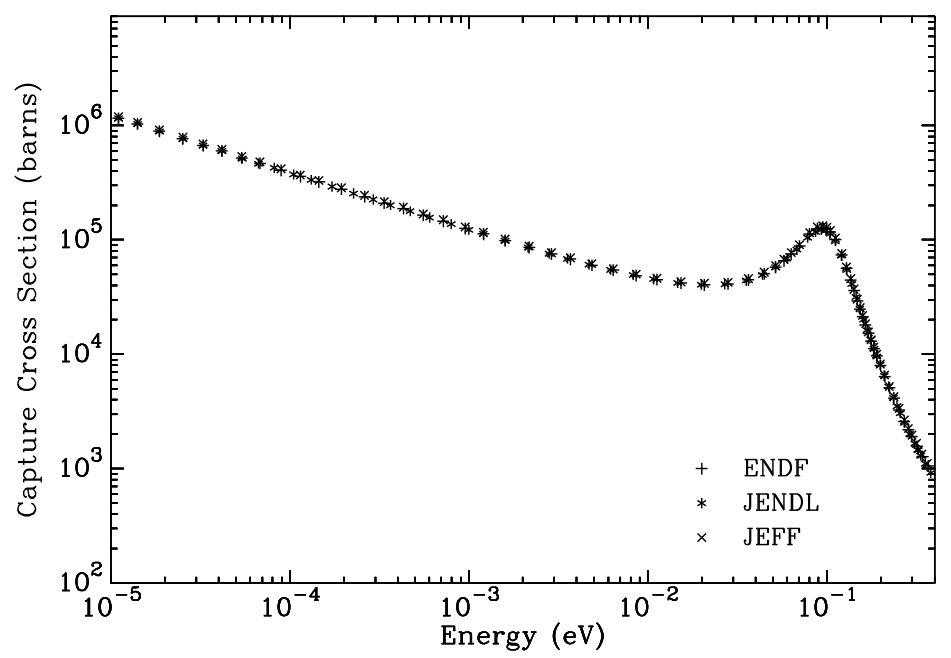

Fig. 29. Comparison of the capture cross sections for ${ }^{149} \mathrm{Sm}$ from $10^{-5}$ to $0.4 \mathrm{eV}$ for the ENDF (+), JEFF ( $\times$ ), and JENDL (*) evaluations.

Above $0.4 \mathrm{eV}$, ENDF and JEFF are essentially the same, and the JENDL evaluation gives cross-section values lower than ENDF and JEFF in the valley between resonances. This feature is shown in Figs. 30 and 31 for the total and capture cross sections, respectively, in the energy region from 0.4 to $10 \mathrm{eV}$.

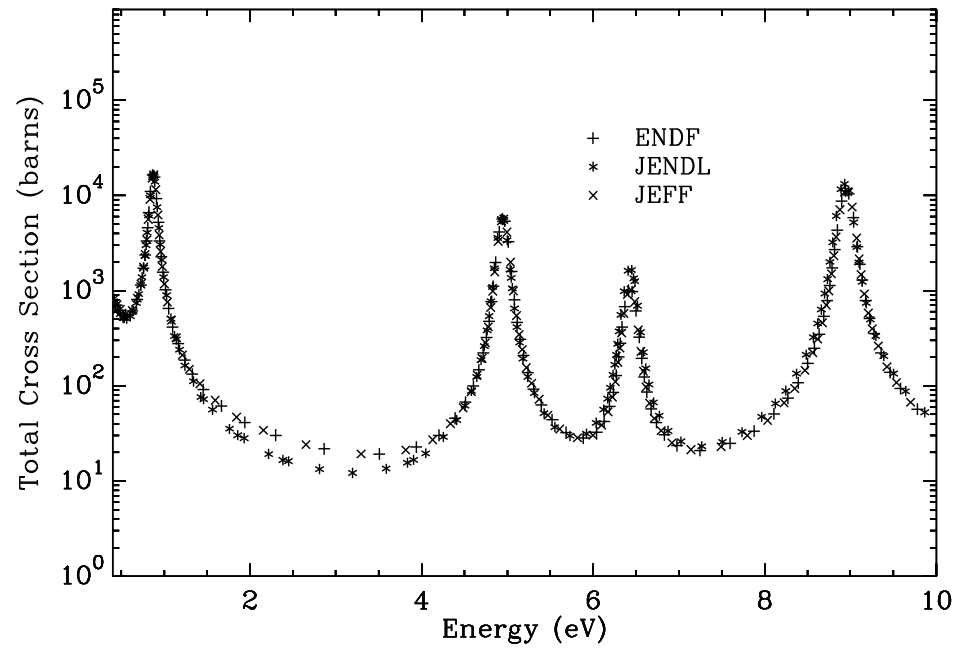

Fig. 30. Comparison of the total cross sections for ${ }^{149} \mathrm{Sm}$ from $0.4 \mathrm{eV}$ to $10 \mathrm{eV}$ for the ENDF (+), JEFF ( $\times)$, and JENDL (*) evaluations. 


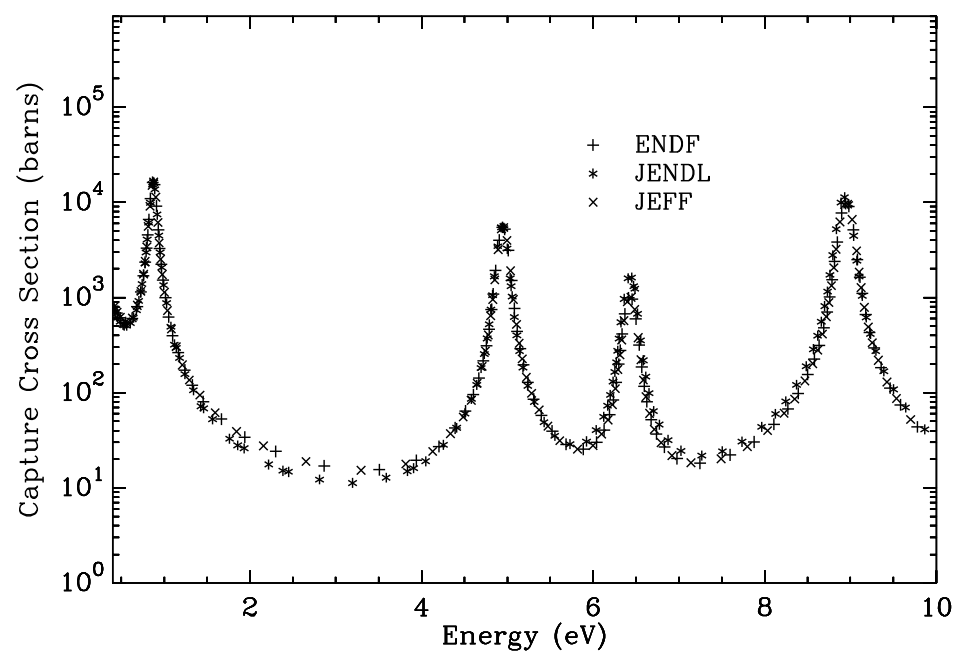

Fig. 31. Comparison of the capture cross sections for ${ }^{149} \mathrm{Sm}$ from $0.4 \mathrm{eV}$ to $10 \mathrm{eV}$ for the ENDF (+), JEFF ( $\times$ ), and JENDL (*) evaluations.

\subsection{COMPARISONS OF THE ${ }^{149}$ Sm ENDF EVALUATION WITH EXPERIMENTAL DATA}

In the resonance region, the only experimental data found in the EXFOR system is the total cross section of Ohno et al. ${ }^{34}$ in the energy region from $6.473 \times 10^{-4}$ to $0.28 \mathrm{eV}$. A comparison of the evaluation in the ENDF library with the experimental data is shown in Fig. 32.

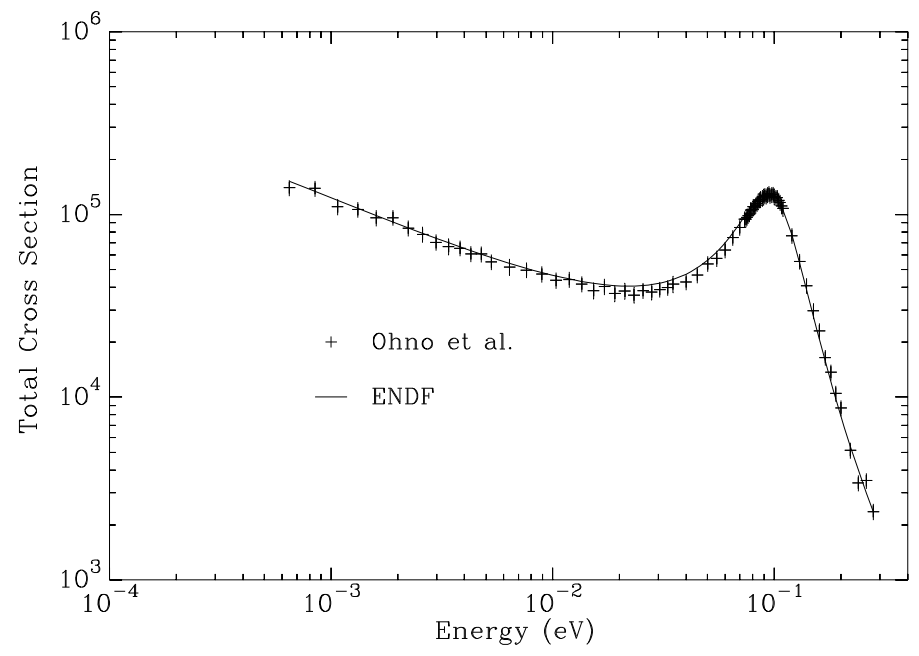

Fig. 32. Comparison of the experimental total cross section of Ohno et al. with the ENDF ${ }^{149} \mathrm{Sm}$ evaluation.

The results shown in Fig. 32 indicate that the ENDF evaluation represents the ${ }^{149} \mathrm{Sm}$ total experimental cross section below $0.3 \mathrm{eV}$; however, no other experimental data for ${ }^{149} \mathrm{Sm}$ were identified in the resonance energy region. 


\subsection{BENCHMARK CALCULATIONS}

A series of critical experiments involving ${ }^{149} \mathrm{Sm}$ were performed by the French at Valduc in 1994 . The French have published the information on these experiments in the IHECSBE as evaluation LEU-COMPTHERM-050 (Ref. 35). These experiments were water-moderated and reflected arrays of aluminum clad $\mathrm{U}(4.738) \mathrm{O}_{2}$ rods with the central $5 \times 5$ rods of the arrays replaced with a solution tank. The tank is filled either with water, boron solution, or samarium $\left(96.9 \mathrm{wt} \%{ }^{149} \mathrm{Sm}\right)$ solution. Table 11 presents the calculation results for various codes and cross-section libraries. The evaluation authors concluded that the experimental $k_{\text {effective }}$ for the recommended benchmark models was $1.0004 \pm 0.0010$.

Comparison of the results for each code and cross section combination appears to indicate that there is a small underprediction of ${ }^{149} \mathrm{Sm}$ worth as indicated by the slightly higher $\mathrm{k}_{\text {effective }}$ values calculated for the cases with ${ }^{149} \mathrm{Sm}$. This implies that the ${ }^{149} \mathrm{Sm}$ capture cross section in each of these evaluations may be low.

Table 11. Samarium critical experiment calculation results ${ }^{35}$ []

\begin{tabular}{|c|c|c|c|c|c|}
\hline \multirow[b]{2}{*}{ Case } & \multirow[b]{2}{*}{$\begin{array}{c}\text { Tank } \\
\text { contents }\end{array}$} & \multirow{2}{*}{$\begin{array}{c}\text { Solution } \\
\text { concentration } \\
\text { (g absorber/l) }\end{array}$} & \multicolumn{3}{|c|}{$\mathbf{k}_{\text {effective }} \pm 1$ standard deviation } \\
\hline & & & $\begin{array}{l}\text { CRISTAL and } \\
\text { JEFF } 2.2^{a}\end{array}$ & $\begin{array}{l}\text { MCNP and } \\
\text { JENDL3.2 }^{b}\end{array}$ & $\begin{array}{l}\text { KENO and } \\
\text { ENDF/B-V }\end{array}$ \\
\hline 1 & Water & & $1.0020 \pm 0.0003$ & $1.0005 \pm 0.0008$ & $0.9927 \pm 0.0004$ \\
\hline 2 & Water & & $1.0014 \pm 0.0003$ & $1.0002 \pm 0.0008$ & $0.9921 \pm 0.0004$ \\
\hline 3 & Boron & 0.822 & $1.0021 \pm 0.0003$ & $1.0002 \pm 0.0008$ & $0.9940 \pm 0.0004$ \\
\hline 4 & Boron & 0.822 & $1.0012 \pm 0.0003$ & $1.0003 \pm 0.0008$ & $0.9934 \pm 0.0004$ \\
\hline 5 & Boron & 5.03 & $1.0041 \pm 0.0003$ & $1.0025 \pm 0.0009$ & $0.9941 \pm 0.0004$ \\
\hline 6 & Boron & 5.03 & $1.0028 \pm 0.0003$ & $1.0024 \pm 0.0008$ & $0.9933 \pm 0.0004$ \\
\hline 7 & Boron & 5.03 & $1.0038 \pm 0.0003$ & $1.0019 \pm 0.0008$ & $0.9939 \pm 0.0004$ \\
\hline 8 & Sm & 0.1048 & $1.0000 \pm 0.0003$ & $0.9990 \pm 0.0008$ & $0.9905 \pm 0.0004$ \\
\hline 9 & $\mathrm{Sm}$ & 0.1048 & $0.9999 \pm 0.0003$ & $0.9997 \pm 0.0008$ & $0.9919 \pm 0.0004$ \\
\hline 10 & Sm & 0.1048 & $0.9994 \pm 0.0003$ & $0.9979 \pm 0.0008$ & $0.9903 \pm 0.0004$ \\
\hline 11 & Sm & 0.2148 & $1.0011 \pm 0.0003$ & $1.0005 \pm 0.0003$ & $0.9919 \pm 0.0004$ \\
\hline 12 & Sm & 0.2148 & $1.0016 \pm 0.0003$ & $1.0023 \pm 0.0008$ & $0.9926 \pm 0.0004$ \\
\hline 13 & $\mathrm{Sm}$ & 0.2148 & $1.0018 \pm 0.0003$ & $1.0020 \pm 0.0008$ & $0.9925 \pm 0.0004$ \\
\hline 14 & $\mathrm{Sm}$ & 0.6262 & $1.0018 \pm 0.0003$ & $1.0016 \pm 0.0008$ & $0.9922 \pm 0.0004$ \\
\hline 15 & $\mathrm{Sm}$ & 0.6262 & $1.0015 \pm 0.0003$ & $1.0020 \pm 0.0005$ & $0.9931 \pm 0.0004$ \\
\hline 16 & $\mathrm{Sm}$ & 0.6262 & $1.0033 \pm 0.0003$ & $1.0030 \pm 0.0008$ & $0.9942 \pm 0.0004$ \\
\hline 17 & $\mathrm{Sm}$ & 0.6262 & $1.0026 \pm 0.0003$ & $1.0018 \pm 0.0008$ & $0.9939 \pm 0.0004$ \\
\hline 18 & $\mathrm{Sm}$ & 0.6262 & $1.0030 \pm 0.0003$ & $1.0023 \pm 0.0008$ & $0.9935 \pm 0.0004$ \\
\hline
\end{tabular}

${ }^{a}$ CRISTAL (APOLLO-2, CEA93 172-group library based on JEF 2.2 evaluation)-MORET 4.

${ }^{b}$ MCNP 4b with JENDL-3.2 library.

${ }^{c}$ KENO V.a with 238-group ENDF/B-V library $\left({ }^{16} \mathrm{O}\right.$ from ENDF/B-VI evaluation).

To qualify the ${ }^{149} \mathrm{Sm}$ cross section for application in burnup credit calculations, CEA-Cadarache performed reactivity worth measurements in the Minerve experimental reactor. The calculation-toexperiment ratio result, $\mathrm{C} / \mathrm{E}-1$ (\%), for the R1-UO2 (PWR lattice made of low-enriched $\mathrm{UO}_{2}$ rods) is 
$-4.8 \pm 1.6$. The calculations were performed using the JEFF evaluation. The result indicates that the capture cross section in the JEFF evaluation is underestimated and needs to be increased to improve the results of reactivity worth calculations. As noted previously, among the three evaluations, ENDF, JEFF, and JENDL, the JEFF evaluation is more up-to-date and better documented; however, there is a need to revise the capture cross section for ${ }^{149} \mathrm{Sm}$ and perform measurements from thermal energies up to the $\mathrm{keV}$ region.

\subsection{SENSITIVITY ANALYSIS FOR ${ }^{149}$ Sm IN A BURNUP CREDIT APPLICATION}

Sensitivity analyses of the ${ }^{149} \mathrm{Sm}$ in a typical burnup credit application were performed with the TSUNAMI sequence in SCALE 5.1 (Ref. 12). The sensitivity of $\mathrm{k}_{\text {effective }}$ to the ${ }^{149} \mathrm{Sm}$ total cross section for the GBC-32 model is shown in Fig. 33. The burnup credit model is sensitive to the ${ }^{149} \mathrm{Sm}$ cross sections in the thermal energy region $(0.0253 \mathrm{eV})$ up to about $1 \mathrm{eV}$ and is relatively insensitive to cross-section data above $1 \mathrm{eV}$.

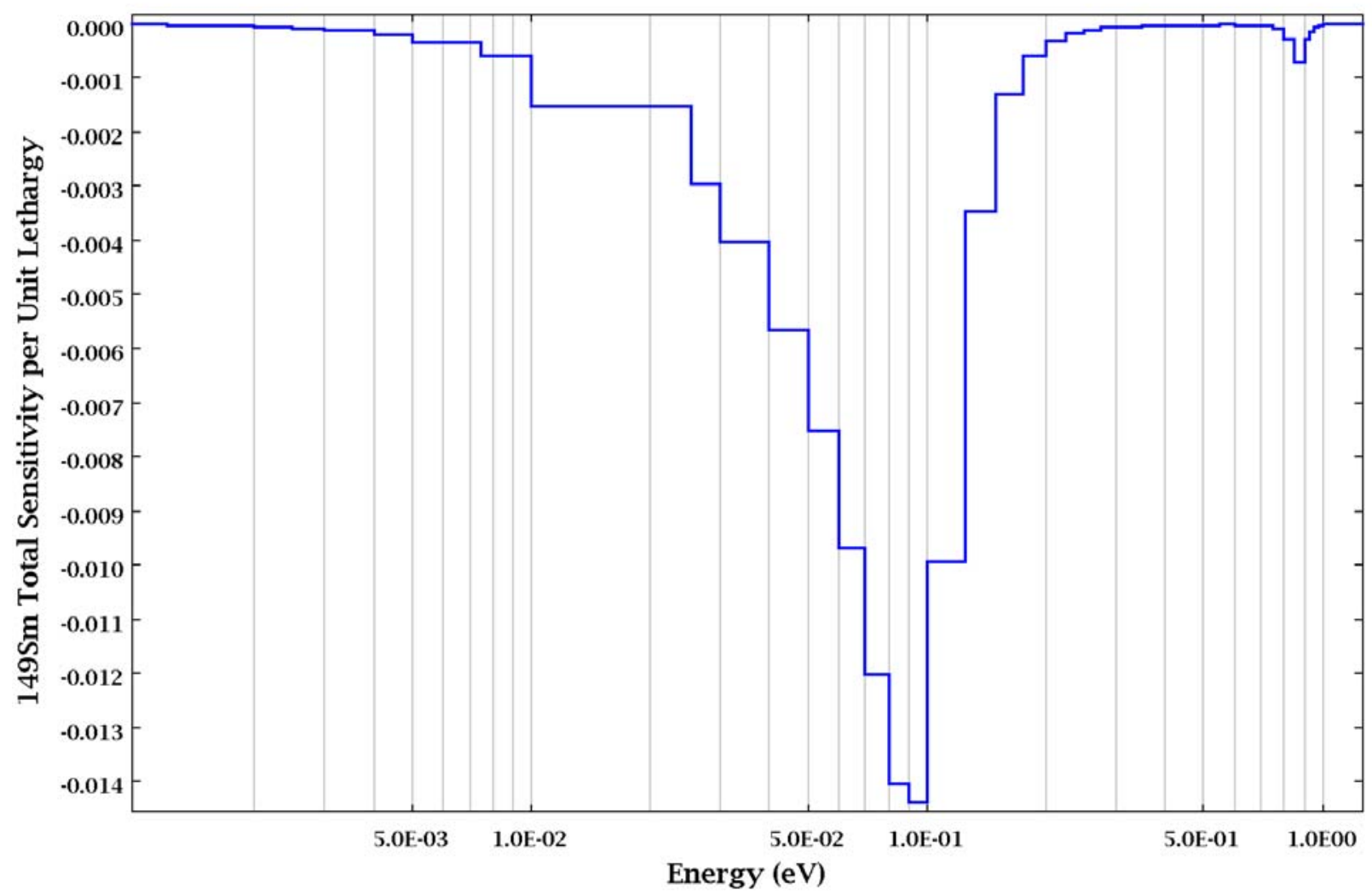

Fig. 33. Sensitivity of the $k_{\text {effective }}$ to the ${ }^{149} \mathrm{Sm}$ total cross section for the GBC-32 model.

\subsection{ASSESSMENT SUMMARY AND RECOMMENDATIONS FOR ${ }^{149} \mathrm{Sm}$}

For ${ }^{149} \mathrm{Sm}$, the latest ENDF and JEFF evaluations are judged to be the most recent evaluations. The ENDF and JEFF evaluations are essentially the same except the neutron width of the first resonance at $0.0973 \mathrm{eV}$ (i.e., the JEFF neutron width is 3\% larger relative to ENDF). Although the JEFF evaluation is 
more up-to-date with respect to one resonance, the JEFF evaluation was adopted from ENDF. As a result, the ENDF evaluation was used in the fission product assessment. When compared with the available experimental database, measured ${ }^{149} \mathrm{Sm}$ total cross-section data are only available from $6.47 \times 10^{-4} \mathrm{eV}$ to $0.028 \mathrm{eV}$, and the evaluated total cross-section agrees with measured data in this energy region.

Measured capture cross-section data could not be located in the experimental database (EXFOR). With regard to benchmark performance, the critical experiment model calculations indicate a small underprediction of ${ }^{149} \mathrm{Sm}$ worth, and the CEA reactivity worth measurements indicate that the calculated ${ }^{149} \mathrm{Sm}$ capture rate underestimates measured capture rates for PWR experiments by $4.8 \%$. Based on the assessment, total and capture ${ }^{149} \mathrm{Sm}$ cross-section measurements are needed from $10^{-5} \mathrm{eV}$ and extending through the resonance region. While there is a general need for cross-section measurements throughout this energy range, sensitivity analysis of a typical burnup credit application indicates that ${ }^{149} \mathrm{Sm}$ crosssection measurements for energies up to about $1 \mathrm{eV}$ are most important for burnup credit applications. In addition, the latest evaluated data files do not provide cross-section covariance information for ${ }^{149} \mathrm{Sm}$, and new measurement and evaluation efforts will provide cross-section covariance data in addition to improved cross-section data. At a minimum, providing covariance data will benefit burnup credit analyses by enabling the propagation of ${ }^{149} \mathrm{Sm}$ cross-section uncertainty to calculated $\mathrm{k}_{\text {effective }}$ values. 


\section{INVESTIGATION OF THE ${ }^{151}$ Sm EVALUATION}

\subsection{COMPARISON OF ${ }^{151}$ Sm ENDF, JENDL, AND JEFF EVALUATIONS}

An outline of the energy limits for the resolved and unresolved resonance regions for the ${ }^{151}$ Sm evaluation in ENDF, JEFF, and JENDL is presented in Table 12. In these cross-section libraries, the energy range of the resolved energy region is nearly the same, while the upper limit of the unresolved-resonance region is different between libraries. The resolved-resonance parameters included in these cross-section libraries are basically the MLBW parameters listed in the Mughabghab compilation. ${ }^{14}$ In the unresolvedresonance region, average resonance parameters are given to reproduce the cross sections. The average parameters were obtained from a physics model calculation.

Table 12. Resonance energy regions in ENDF, JENDL, and JEFF libraries for ${ }^{151} \mathrm{Sm}$

\begin{tabular}{lccc}
\hline & \multicolumn{3}{c}{ Data library } \\
\cline { 2 - 4 } \multicolumn{1}{c}{ Energy range } & ENDF & JENDL & JEFF \\
\hline $\begin{array}{l}\text { Resolved resonance } \\
\text { region energy range }\end{array}$ & $10^{-5} \mathrm{eV}$ to $296.3 \mathrm{eV}$ & $10^{-5} \mathrm{eV}$ to $246.1 \mathrm{eV}$ & $10^{-5} \mathrm{eV}$ to $296.56 \mathrm{eV}$ \\
$\begin{array}{l}\text { Unresolved resonance } \\
\text { region energy range }\end{array}$ & $296.3 \mathrm{eV}$ to $66.24 \mathrm{keV}$ & $246.1 \mathrm{eV}$ to $100 \mathrm{keV}$ & $296.56 \mathrm{eV}$ to $4 \mathrm{keV}$ \\
\hline
\end{tabular}

A comparison between the ENDF, JENDL, and JEFF capture cross sections from $10^{-5}$ to $10 \mathrm{eV}$ is shown in Fig. 34. The cross-section data from the different evaluation sources do not show significant differences.

\subsection{COMPARISONS OF THE ${ }^{151} \mathrm{Sm}$ ENDF EVALUATION WITH EXPERIMENTAL DATA}

Very few experimental datasets are available for ${ }^{151} \mathrm{Sm}$ in the EXFOR system. It appears that no new cross-section measurements for ${ }^{151} \mathrm{Sm}$ have been made since the early 1980s. The only experimental data found in the EXFOR data system for the resonance region are total cross-section data by Kirouac et al. ${ }^{36}$ A comparison of the ENDF total cross-section evaluation for energies between $10^{-5} \mathrm{eV}$ and $4 \mathrm{eV}$ relative to the experimental data of Kirouac et al. is shown in Fig. 35. The ENDF evaluation reproduces the total measured cross-section data below $4 \mathrm{eV}$. Because of the lack of measured data above $4 \mathrm{eV}$, there is a need for measured ${ }^{151} \mathrm{Sm}$ cross- section data in the resonance region. New capture cross-section measurements would facilitate a complete resonance-parameter evaluation in the resolved and unresolved energy regions. 


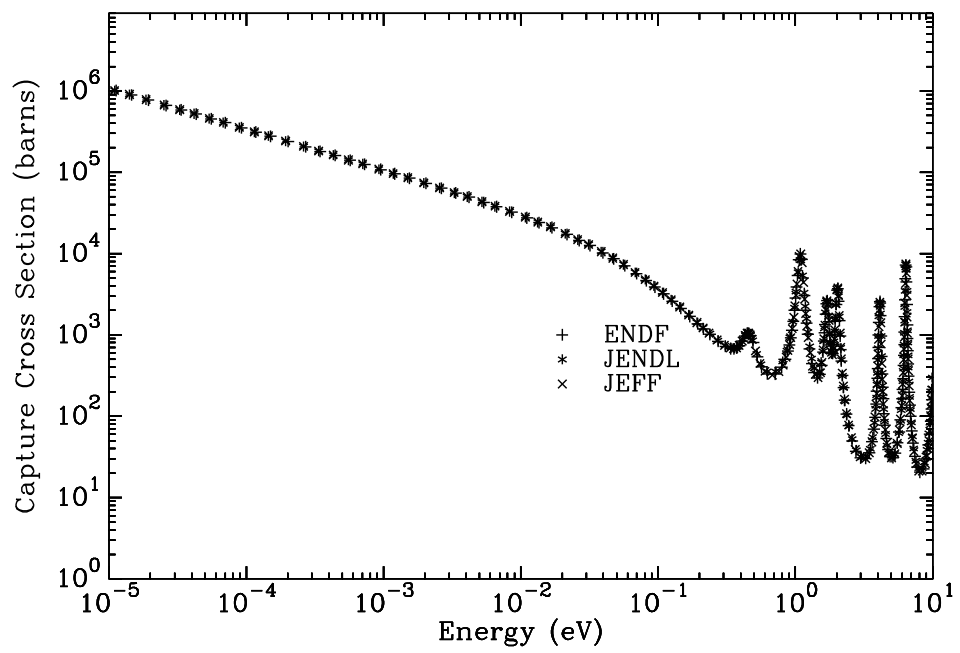

Fig. 34. Comparison of the capture cross sections for ${ }^{151} \mathrm{Sm}$ from $10^{-5}$ to $10 \mathrm{eV}$ for the ENDF (+), JENDL (*), and JEFF $(\times)$ evaluations.

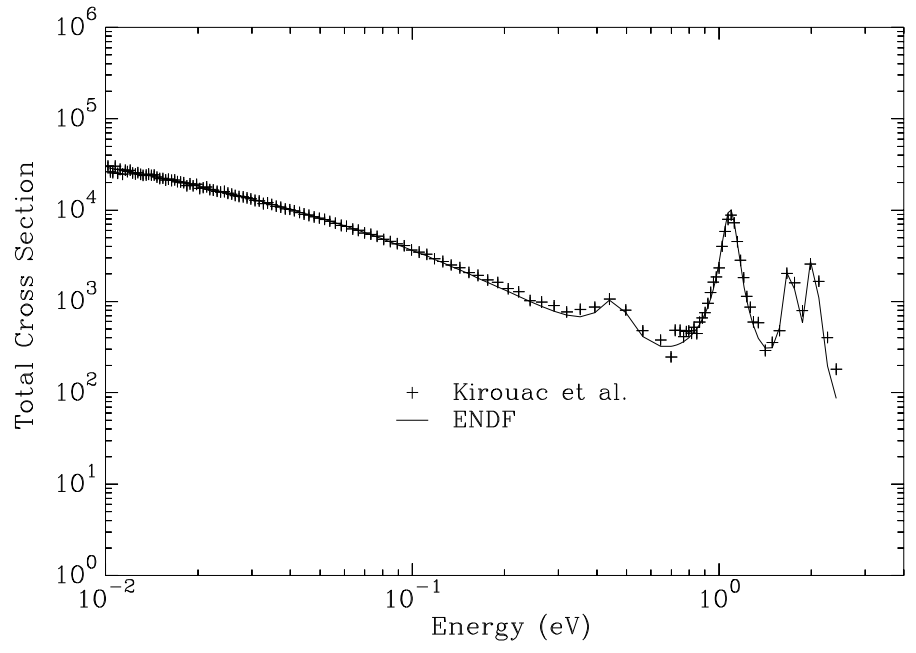

Fig. 35. Comparison of the experimental total cross section of Kirouac et al. with the ${ }^{151} \mathrm{Sm}$ ENDF evaluations.

\subsection{BENCHMARK CALCULATIONS}

Benchmark experiments that are sensitive to ${ }^{151} \mathrm{Sm}$ are not available in the open literature. The CERES international experimental program was designed for the validation of cross-section data and inventory predictions for actinides and fission products important for burnup credit applications. A summary of calculation-to-experiment ratios for the reactivity worth of various $\mathrm{Sm}$ isotopes (i.e., ${ }^{147,149,152} \mathrm{Sm}$ ) is provided in the open literature. ${ }^{37}$ However, ${ }^{151} \mathrm{Sm}$ results are not documented in the summary. As a result, benchmark data for ${ }^{151} \mathrm{Sm}$ were not available for this study. Therefore, no additional benchmark testing was performed for ${ }^{151} \mathrm{Sm}$. 


\subsection{SENSITIVITY ANALYSIS FOR ${ }^{151}$ Sm IN A BURNUP CREDIT APPLICATION}

Sensitivity analyses of ${ }^{151} \mathrm{Sm}$ in a typical burnup credit application were performed with the TSUNAMI sequence in SCALE 5.1 (Ref. 12). The sensitivity of $\mathrm{k}_{\text {effective }}$ to the ${ }^{151} \mathrm{Sm}$ total cross section for the GBC32 model is shown in Fig. 36. The burnup credit model is sensitive to the ${ }^{151} \mathrm{Sm}$ cross sections in the thermal energy region $(0.0253 \mathrm{eV})$ up to about $10 \mathrm{eV}$ and is relatively insensitive to cross-section data above $10 \mathrm{eV}$.

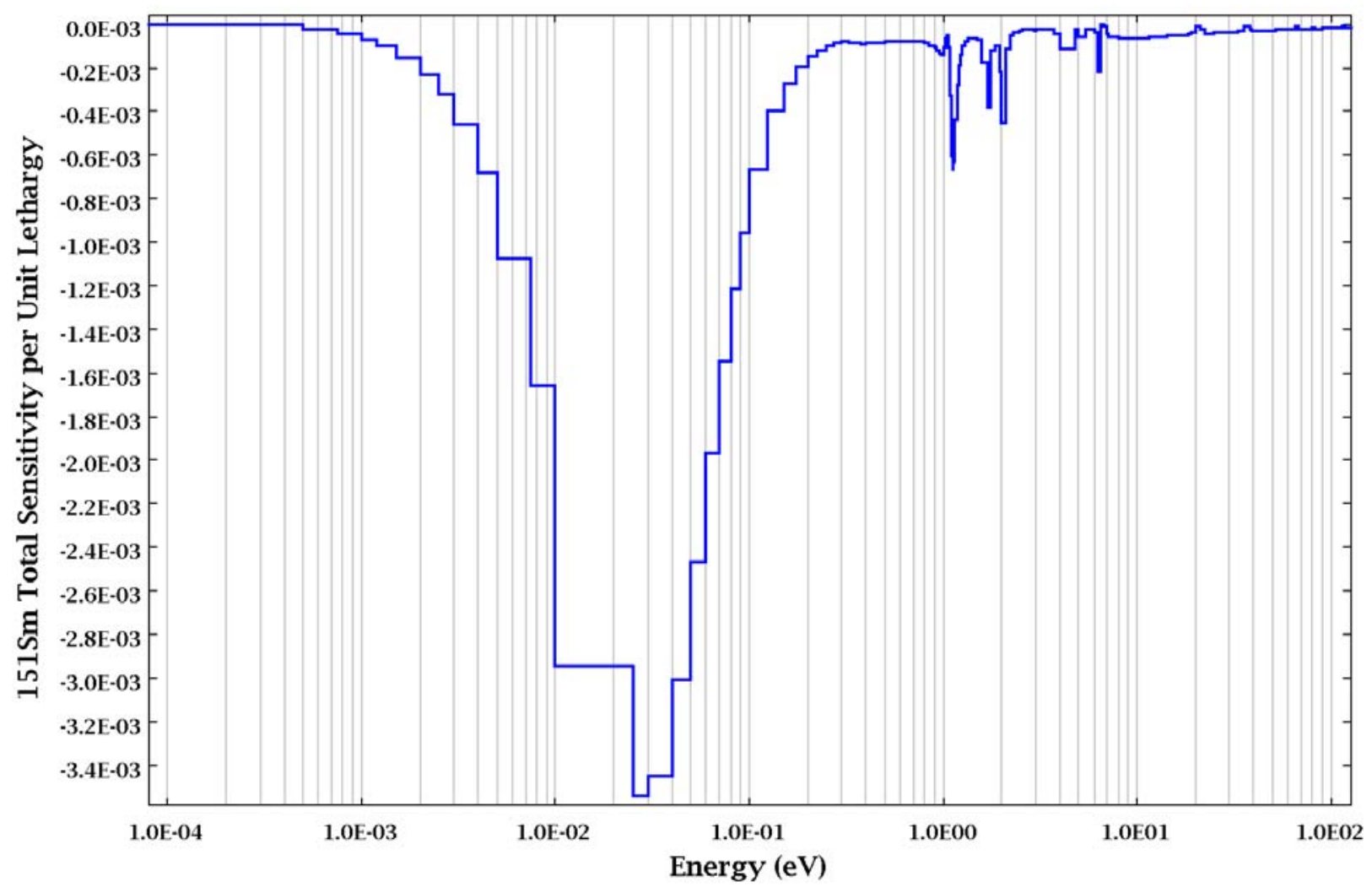

Fig. 36. Sensitivity of the $k_{\text {effective }}$ to the ${ }^{151} \mathrm{Sm}$ total cross section for the GBC-32 model.

\subsection{ASSESSMENT SUMMARY AND RECOMMENDATIONS FOR ${ }^{151} \mathrm{Sm}$}

For ${ }^{151} \mathrm{Sm}$, the latest ENDF, JEFF, and JENDL evaluations are essentially the same in the resolved resonance region; however, the upper energy limit of the unresolved range differs between the libraries. Because the evaluations are judged to be fairly similar, the three libraries are considered to be comparable in rigor. As a result, the ENDF evaluation was selected for further examination in the fission product assessment. When compared with the available measured cross-section database, evaluated ${ }^{151} \mathrm{Sm}$ total cross-section data agree with measured data up to $4 \mathrm{eV}$; however, the experimental database does not have measured total cross-section data above $4 \mathrm{eV}$. Moreover, measured ${ }^{151} \mathrm{Sm}$ capture cross-section data could not be located in the experimental database. Unfortunately, ${ }^{151} \mathrm{Sm}$ benchmark experiments could not be located in the open literature, and an assessment of the performance of ${ }^{151} \mathrm{Sm}$ in benchmark 
analyses could not be performed. Based on the cross-section evaluation assessment, total ${ }^{151} \mathrm{Sm}$ crosssection measurements are needed from $4 \mathrm{eV}$ and extending through the resonance region. Likewise ${ }^{151} \mathrm{Sm}$ capture cross-section measurements are needed from $10^{-5} \mathrm{eV}$ and extending through the resonance region. While there is a general need for cross-section measurements throughout this energy range, sensitivity analysis of a typical burnup credit application indicates that ${ }^{151} \mathrm{Sm}$ cross-section measurements for energies up to about $10 \mathrm{eV}$ are most important for burnup credit applications. In addition, the latest evaluated data files do not provide cross-section covariance information for ${ }^{151} \mathrm{Sm}$, and new measurement and evaluation efforts will provide cross-section covariance data in addition to improved cross-section data. At a minimum, providing covariance data will benefit burnup credit analyses by enabling the propagation of ${ }^{151} \mathrm{Sm}$ cross-section uncertainty to calculated $\mathrm{k}_{\text {effective }}$ values. Because there are no benchmark experiments involving ${ }^{151} \mathrm{Sm}$, there is also a need for ${ }^{151} \mathrm{Sm}$ benchmark critical experiments. 


\section{INVESTIGATION OF THE ${ }^{152}$ Sm EVALUATION}

\subsection{COMPARISON OF ${ }^{152} \mathrm{Sm}$ ENDF, JENDL, AND JEFF EVALUATIONS}

An outline of the energy limits for the resolved and unresolved resonance regions for the ${ }^{152} \mathrm{Sm}$ evaluation in ENDF, JEFF, and JENDL is presented in Table 13.

Table 13. Resonance energy regions in ENDF, JENDL, and JEFF libraries for ${ }^{152} \mathrm{Sm}$

\begin{tabular}{lccc}
\hline & \multicolumn{3}{c}{ Data library } \\
\cline { 2 - 4 } \multicolumn{1}{c}{ Energy range } & ENDF & JENDL & JEFF \\
\hline $\begin{array}{l}\text { Resolved resonance } \\
\text { region energy range }\end{array}$ & $10^{-5} \mathrm{eV}$ to $5.1012 \mathrm{keV}$ & $10^{-5} \mathrm{eV}$ to $5.029 \mathrm{keV}$ & $10^{-5} \mathrm{eV}$ to $3.6911 \mathrm{keV}$ \\
$\begin{array}{l}\text { Unresolved resonance } \\
\text { region energy range }\end{array}$ & $5.1012 \mathrm{keV}$ to $122.59 \mathrm{keV}$ & $5.029 \mathrm{keV}$ to $100 \mathrm{keV}$ & $3.6911 \mathrm{keV}$ to $70 \mathrm{keV}$ \\
\hline
\end{tabular}

\subsection{COMPARISONS OF THE ${ }^{152}$ Sm ENDF EVALUATION WITH EXPERIMENTAL DATA}

Limited experimental datasets are available for ${ }^{152} \mathrm{Sm}$ below $3 \mathrm{keV}$ in the EXFOR system. As a result, comparisons with measured cross-section data could not be performed with the cross-section evaluation.

\subsection{BENCHMARK CALCULATIONS}

Benchmark experiments that are sensitive to ${ }^{152} \mathrm{Sm}$ are available in the CERES experimental program involving the Minerve and Dimple reactors; however, these data are not available in the open literature. Based on the summary of C/E results from Ref. 37 using JEF 2.2 and ENDF/B-VI, the C/E is 0.928 for the CERES ${ }^{152} \mathrm{Sm}$ data. Although the authors note the discrepancy is within two standard deviations, the ${ }^{152} \mathrm{Sm}$ cross-section data underpredict the experimental results by $\sim 8 \%$. Because the integral benchmark testing data were not readily available for this work, no additional benchmark testing was performed for ${ }^{152} \mathrm{Sm}$.

\subsection{SENSITIVITY ANALYSIS FOR ${ }^{152}$ Sm IN A BURNUP CREDIT APPLICATION}

Sensitivity analyses of the ${ }^{152} \mathrm{Sm}$ in a typical burnup credit application were performed with the TSUNAMI sequence in SCALE 5.1 (Ref. 12). The sensitivity of $k_{\text {effective }}$ to the ${ }^{152} \mathrm{Sm}$ total cross section for the GBC-32 model is shown in Fig. 37. The burnup credit model is sensitive to the ${ }^{152} \mathrm{Sm}$ cross sections in the thermal energy region $(0.0253 \mathrm{eV})$ up to about $100 \mathrm{eV}$ and is relatively insensitive to cross-section data above $100 \mathrm{eV}$. 


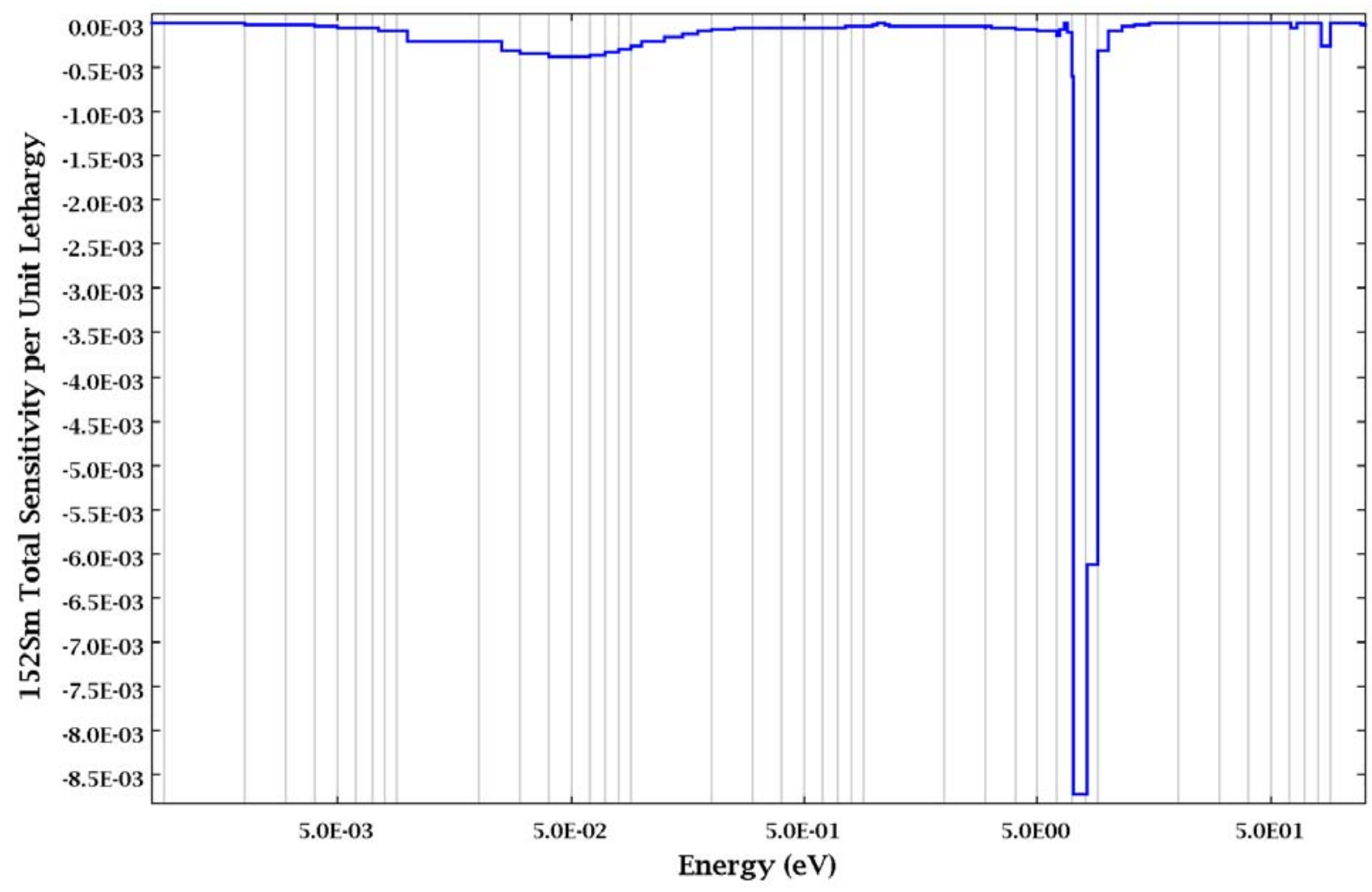

Fig. 37. Sensitivity of the $k_{\text {effective }}$ to the ${ }^{152} \mathrm{Sm}$ total cross section for the GBC-32 model.

\subsection{ASSESSMENT SUMMARY AND RECOMMENDATIONS FOR ${ }^{152} \mathrm{Sm}$}

While there is a general need for cross-section measurements throughout the resonance range, sensitivity analysis of a typical burnup credit application indicates that ${ }^{152} \mathrm{Sm}$ cross-section measurements for energies up to about $100 \mathrm{eV}$ are most important for burnup credit applications. In addition, the latest evaluated data files do not provide cross-section covariance information for ${ }^{152} \mathrm{Sm}$, and new measurement and evaluation efforts will provide cross-section covariance data in addition to improved cross-section data. At a minimum, providing covariance data will benefit burnup credit analyses by enabling the propagation of ${ }^{152} \mathrm{Sm}$ cross-section uncertainty to calculated $\mathrm{k}_{\text {effective }}$ values. Because of the paucity of benchmark experiments involving ${ }^{152} \mathrm{Sm}$, there is a need for ${ }^{152} \mathrm{Sm}$ benchmark critical experiments. 


\section{INVESTIGATION OF THE ${ }^{155}$ Gd EVALUATION}

\subsection{COMPARISON OF ${ }^{155}$ Gd ENDF, JENDL AND JEFF EVALUATIONS}

There are seven stable gadolinium isotopes, and the natural abundance for ${ }^{155} \mathrm{Gd}$ is $14.8 \%$. Because of its high capture cross section, approximately $60000 \mathrm{~b}$ at thermal, ${ }^{155} \mathrm{Gd}$ is very important in various nuclear fuel cycle applications. The latest evaluations for ${ }^{155} \mathrm{Gd}$ in the ENDF, JENDL, and JEFF libraries are very similar. The RRR and URR regions in the JEFF and JENDL evaluations are identical and only differ in the high-energy region. The energy limits for the RRR and URR in the ENDF, JENDL, and JEFF libraries are shown in Table 14.

Table 14. Resonance energy regions in ENDF, JENDL, and JEFF libraries for ${ }^{155}$ Gd

\begin{tabular}{lccc}
\hline & \multicolumn{3}{c}{ Data library } \\
\cline { 2 - 4 } \multicolumn{1}{c}{ Energy range } & $10^{-5} \mathrm{eV}$ to $183.3 \mathrm{eV}$ & $10^{-5} \mathrm{eV}$ to $181.8 \mathrm{eV}$ & $10^{-5} \mathrm{eV}$ to $181.8 \mathrm{eV}$ \\
\hline $\begin{array}{l}\text { Resolved resonance } \\
\text { region energy range }\end{array}$ & & & JEFF \\
$\begin{array}{l}\text { Unresolved resonance } \\
\text { region energy range }\end{array}$ & $183.3 \mathrm{eV}$ to $60.4 \mathrm{keV}$ & $181.8 \mathrm{eV}$ to $100 \mathrm{keV}$ & $181.8 \mathrm{eV}$ to $100 \mathrm{keV}$ \\
\hline
\end{tabular}

The cross-section representation in the RR region is based on the MLBW formalism. The resonance parameters were adopted from the Mughabghab compilation, and the bound level (negative resonance) was adjusted to reproduce the experimental total, capture, and scattering thermal cross sections. The average parameters used in the unresolved region representation of the cross section were based on experimental data. A comparison of the capture cross section in the ENDF and JENDL evaluations in the energy from $10^{-5}$ to $5 \mathrm{eV}$ is shown in Fig. 38. Both evaluations give identical results. The capture cross section is very large in the thermal region and the resonance region.

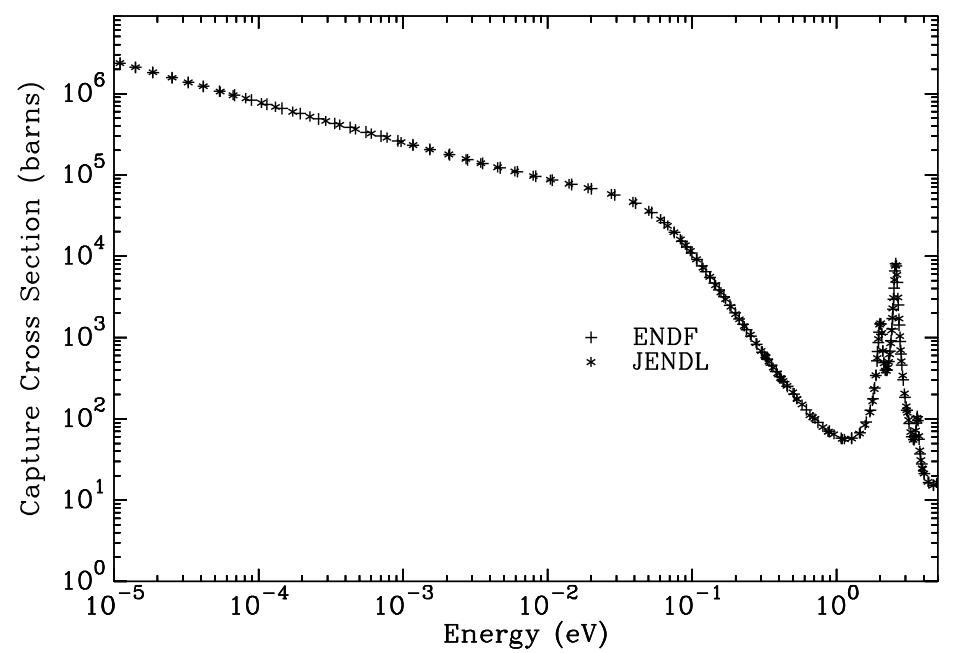

Fig. 38. Comparison of the capture cross sections for ${ }^{155} \mathrm{Gd}$ from $10^{-5}$ to $5 \mathrm{eV}$ for the ENDF (+) and JENDL (*). 


\subsection{COMPARISONS OF THE ${ }^{155}$ Gd ENDF EVALUATION WITH EXPERIMENTAL DATA}

In the resolved-resonance region, the only experimental data found in the EXFOR system is the total cross section of Moller et al. ${ }^{38}$ in the energy region from 0.0195 to $0.2793 \mathrm{eV}$. A comparison of the evaluation in the ENDF library with the experimental data is shown in Fig. 39. The ${ }^{155} \mathrm{Gd}$ evaluation in the ENDF library represents the total cross section of Moller below $0.3 \mathrm{eV}$. However, the lack of capture data in the EXFOR system precludes a complete assessment of the ${ }^{155} \mathrm{Gd}$ evaluation in the ENDF, JENDL, and JEFF cross-section libraries. The EXFOR file contains total and capture experimental data for the thermal energy. The thermal data are needed for a complete evaluation but are not sufficient for developing a complete evaluation. There exists average cross-section data in the kiloelectron volts region that were used in the evaluation of the URR region. Cross-section measurements are recommended for ${ }^{155} \mathrm{Gd}$ from thermal to $2 \mathrm{keV}$.

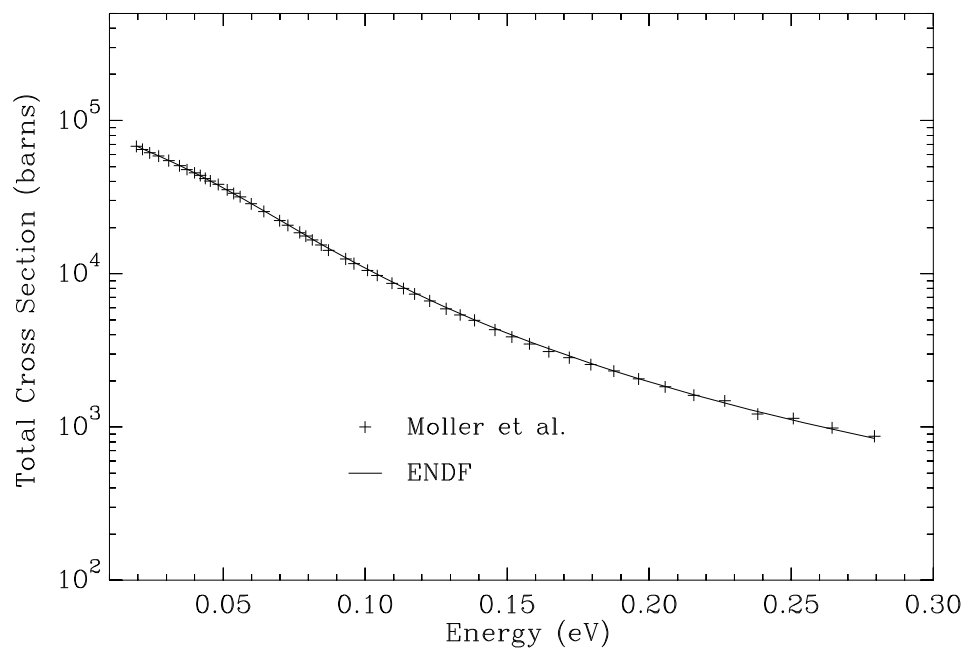

Fig. 39. Comparison of the experimental total cross section of Moller et al. with the ${ }^{155} \mathrm{Gd}$ ENDF evaluations.

\subsection{BENCHMARK CALCULATIONS}

In an effort to test the ${ }^{155} \mathrm{Gd}$ evaluation of the ENDF, JENDL, and JEFF libraries, a survey of available benchmark experiments sensitive to the ${ }^{155} \mathrm{Gd}$ cross sections was performed. The IHECSBE LEUCOMP-THERM-003 (Ref. 39) benchmark has a series of critical experiments with clusters of aluminum clad $\mathrm{U}(2.35) \mathrm{O}_{2}$ fuel rods in a large water-filled tank, and the benchmark includes gadolinium as impurity in the water. Sensitivity analyses revealed that the benchmark is not sensitive to ${ }^{155} \mathrm{Gd}$ and cannot be used to adequately assess the performance of the ${ }^{155} \mathrm{Gd}$ data. Additional Gd-poisoned experiments in the IHECSBE were investigated for sensitivity to ${ }^{155} \mathrm{Gd}$; however, the available benchmark experiments do not exhibit strong sensitivity to ${ }^{155} \mathrm{Gd}$. Benchmark experiments that are sensitive to ${ }^{155} \mathrm{Gd}$ are available in the CERES experimental program involving $\mathrm{UO}_{2}$ in the Minerve and Dimple reactors; however, these data are not available in the open literature. Based on the summary of C/E results from Ref. 37 using ENDF/B-VI, the C/E is 0.978 for ${ }^{155} \mathrm{Gd}$ data. Although the authors note the discrepancy is within two standard deviations, the ${ }^{155} \mathrm{Gd}$ cross-section data underpredict the experimental results by $2-3 \%$. 
Because the integral benchmark testing data were not readily available for this work, no additional benchmark testing was performed for ${ }^{155} \mathrm{Gd}$.

\subsection{SENSITIVITY ANALYSIS FOR ${ }^{155}$ Gd IN A BURNUP CREDIT APPLICATION}

Sensitivity analyses of the ${ }^{155} \mathrm{Gd}$ in a typical burnup credit application were performed with the TSUNAMI sequence in SCALE 5.1 (Ref. 12). The sensitivity of $\mathrm{k}_{\text {effective }}$ to the ${ }^{155} \mathrm{Gd}$ total cross section for the GBC-32 model is shown in Fig. 40. The burnup credit model is sensitive to the ${ }^{155} \mathrm{Gd}$ cross sections in the thermal energy region $(0.0253 \mathrm{eV})$ up to about $5 \mathrm{eV}$ and is relatively insensitive to cross-section data above $5 \mathrm{eV}$.

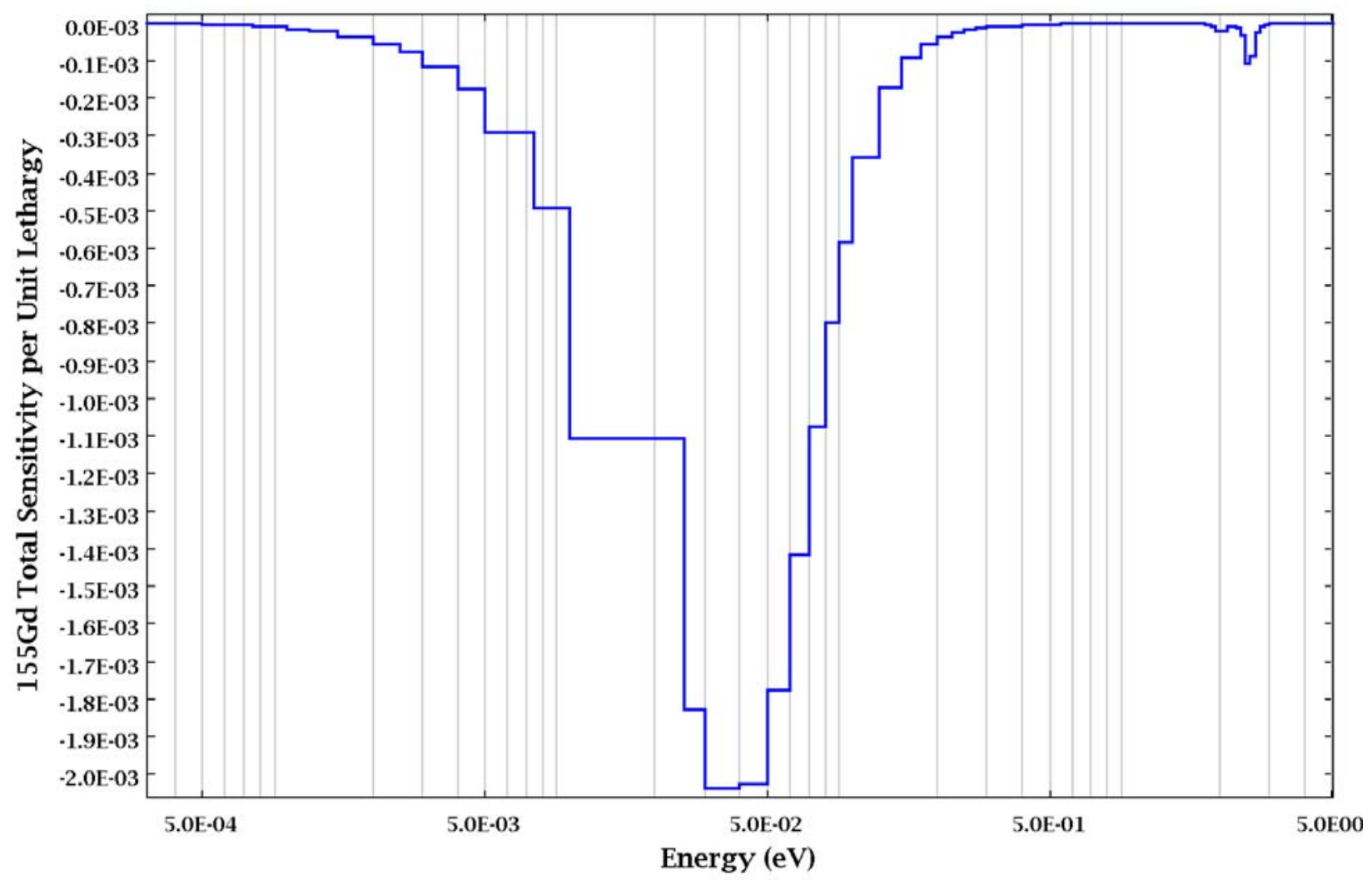

Fig. 40. Sensitivity of the $k_{\text {effective }}$ to the ${ }^{155} \mathrm{Gd}$ total cross section for the GBC-32 model.

\subsection{ASSESSMENT SUMMARY AND RECOMMENDATIONS FOR ${ }^{155}$ Gd}

The latest ENDF, JEFF, and JENDL evaluations for ${ }^{155} \mathrm{Gd}$ are similar. Moreover, the resolved resonance parameters are based on the Mughabghab ${ }^{14}$ compilation, and the unresolved resonance data are based on experimental data. Because the ENDF, JEFF, and JENDL evaluations are judged to be fairly similar, the three libraries are considered to be comparable in rigor. As a result, the ENDF evaluation was selected for further examination in the fission product assessment. When compared with the available measured cross-section database, the evaluated ${ }^{155} \mathrm{Gd}$ total cross-section data agree with measured data between $0.0195 \mathrm{eV}$ and $0.2793 \mathrm{eV}$; however, the experimental database does not have measured total cross-section 
data outside of the noted energy range. Except for a single measurement at $0.0253 \mathrm{eV}$, measured ${ }^{155} \mathrm{Gd}$ capture cross-section data could not be located in the experimental database (EXFOR). To assess the evaluation performance relative to critical benchmark data, the Gd-poisoned criticality experiments from IHECSBE were examined for sensitivity to ${ }^{155} \mathrm{Gd}$; however, benchmark experiments sensitive to ${ }^{155} \mathrm{Gd}$ are not available in the open literature. Unfortunately, ${ }^{155} \mathrm{Gd}$ reactivity worth benchmark experiments could not be located in the open literature, and an assessment of the performance of ${ }^{155} \mathrm{Gd}$ in reactivity worth benchmark analyses could not be performed. Based on the general cross-section data assessment, total and capture ${ }^{155} \mathrm{Gd}$ cross-section measurements are needed from $10^{-5} \mathrm{eV}$ and extending through the resonance region. While there is a general need for cross-section measurements throughout this energy range, sensitivity analysis of a typical burnup credit application indicates that ${ }^{155} \mathrm{Gd}$ cross-section measurements for energies up to about $5 \mathrm{eV}$ are most important for burnup credit applications. With the release of ENDF/B-VII, the gadolinium isotope evaluations have been updated to include cross-section covariance data. ${ }^{10}$ Relative to burnup credit, ENDF/B-VII includes improved ${ }^{155} \mathrm{Gd}$ resonance parameter covariance data that can benefit burnup credit analyses. However, new ${ }^{155} \mathrm{Gd}$ covariance data were not produced as part of a new resonance analysis; rather, the existing cross-section resonance parameters were preserved, and approximate methods were used to estimate the covariance information. Although the ENDF/B-VII ${ }^{155} \mathrm{Gd}$ covariance data may benefit sensitivity/uncertainty analyses with the existing cross-section files, improved ${ }^{155} \mathrm{Gd}$ cross-section data are needed to improve performance for criticality safety analyses.

Because of the limited amount of benchmark experiments having a significant sensitivity to ${ }^{155} \mathrm{Gd}$, there is a need for ${ }^{155} \mathrm{Gd}$ benchmark critical experiments. Note that benchmark experiments involving ${ }^{155} \mathrm{Gd}$ have been performed under the French burnup credit program, and these experiments are sensitive to the ${ }^{155} \mathrm{Gd}$ cross sections. Because the French benchmark data are not publicly available, these ${ }^{155} \mathrm{Gd}$-poisoned experiments are not included in the cross-section data assessment. 


\section{INVESTIGATION OF THE ${ }^{155}$ Eu EVALUATION}

\subsection{COMPARISON OF ${ }^{155}$ Eu ENDF, JENDL, AND JEFF EVALUATIONS}

${ }^{155} \mathrm{Eu}$ is an important precursor for the postshutdown production of ${ }^{155} \mathrm{Gd}$ through beta decay, and accurate ${ }^{155} \mathrm{Eu}$ data are needed to quantify the production of ${ }^{155} \mathrm{Gd}$. The buildup of ${ }^{155} \mathrm{Eu}$ in a nuclear reactor is predominantly due to sequential $(\mathrm{n}, \gamma)$ reactions in ${ }^{153} \mathrm{Eu}$ and ${ }^{154} \mathrm{Eu}$. The half-life of ${ }^{155} \mathrm{Eu}$ is 4.75 years. As noted previously, ${ }^{155} \mathrm{Gd}$ is important because of its high capture cross section. Additionally, ${ }^{155} \mathrm{Eu}$ has a high capture cross section. The latest ${ }^{155}$ Eu evaluations in the ENDF, JENDL, and JEFF libraries are very similar. Furthermore, the ENDF and JEFF evaluations are identical. The energy limits for the RRR and URR regions in the ENDF, JENDL, and JEFF libraries are shown in Table 15.

Table 15. Resonance energy regions in ENDF, JENDL, and JEFF libraries for ${ }^{155} \mathrm{Eu}$

\begin{tabular}{|c|c|c|c|}
\hline \multirow{2}{*}{ Energy range } & \multicolumn{3}{|c|}{ Data library } \\
\hline & ENDF & JENDL & JEFF \\
\hline $\begin{array}{l}\text { Resolved resonance } \\
\text { region energy range }\end{array}$ & $10^{-5} \mathrm{eV}$ to $37.5 \mathrm{eV}$ & $10^{-5} \mathrm{eV}$ to $29.7 \mathrm{eV}$ & $10^{-5} \mathrm{eV}$ to $37.5 \mathrm{eV}$ \\
\hline $\begin{array}{l}\text { Unresolved resonance } \\
\text { region energy range }\end{array}$ & $37.5 \mathrm{eV}$ to $10 \mathrm{keV}$ & $29.7 \mathrm{eV}$ to $100 \mathrm{keV}$ & $37.5 \mathrm{eV}$ to $10 \mathrm{keV}$ \\
\hline
\end{tabular}

The cross-section representation in the RR region for the three evaluations is based on the MLBW formalism with resonance parameters adopted from the Mughabghab compilation. ${ }^{14}$ In the JENDL evaluation, the bound level (negative resonance) was adjusted to reproduce the experimental total, capture, and scattering thermal cross sections. The average parameters used in the URR representation of the cross section were based on experimental data. A comparison of the capture cross section in the ENDF and JENDL evaluations in the energy from $10^{-5}$ to $5 \mathrm{eV}$ is shown in Fig. 41. Both evaluations give identical results.

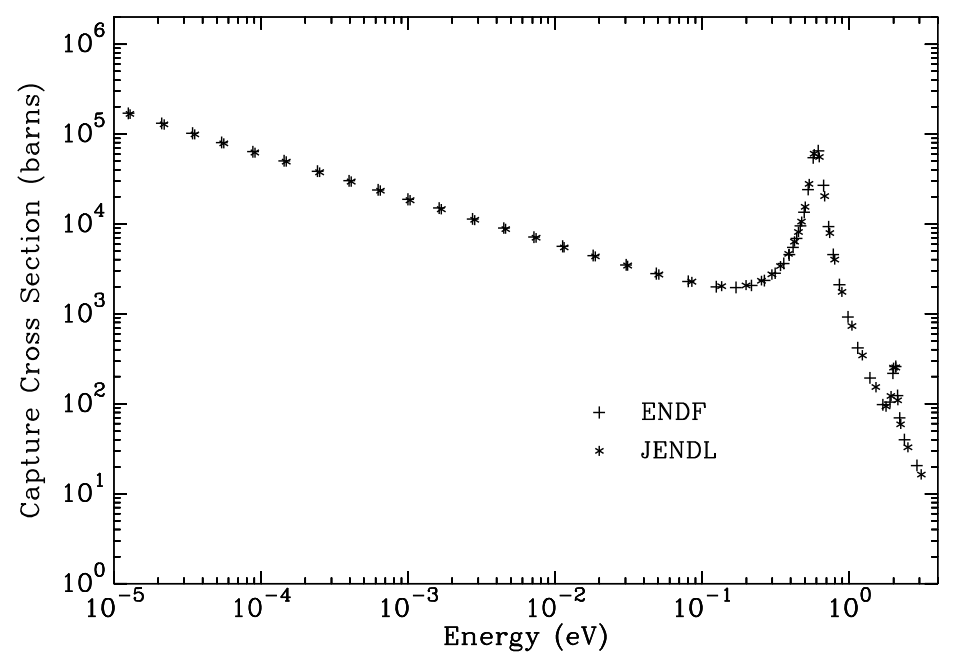

Fig. 41. Comparison of the capture cross sections for ${ }^{155} \mathrm{Eu}$ from $10^{-5}$ to $4 \mathrm{eV}$ for the ENDF (+) and JENDL (*). 


\subsection{EXPERIMENTAL DATA FOR ${ }^{155}$ Eu}

The only experimental data for ${ }^{155} \mathrm{Eu}$ available in the EXFOR system are the thermal capture cross-section data at $0.0253 \mathrm{eV}$ and average capture cross-section data in the energy region above the resonance region. It appears that the ${ }^{155} \mathrm{Eu}$ evaluation in the resonance region is based purely on nuclear model calculations. New cross-section measurements are needed to improve the ${ }^{155} \mathrm{Eu}$ data in the resonance region.

\subsection{BENCHMARK CALCULATIONS}

Benchmark experiments that are sensitive to ${ }^{155} \mathrm{Eu}$ are not available in the open literature. Integral benchmark data for ${ }^{155} \mathrm{Eu}$ may be available in the French experimental program; however, the authors were not aware of any ${ }^{155} \mathrm{Eu}$ integral data at the time of this work. Therefore, no additional benchmark testing was performed for ${ }^{155} \mathrm{Eu}$. As noted in Ref. 1, the ${ }^{155} \mathrm{Gd}$ concentration in SNF is most sensitive to the ${ }^{155}$ Eu cross section; persistent discrepancies in the prediction of ${ }^{155} \mathrm{Gd}$ in SNF suggest problems may exist in the current ${ }^{155} \mathrm{Eu}$ cross-section data.

\subsection{SENSITIVITY ANALYSIS FOR ${ }^{155}$ Eu IN A BURNUP CREDIT APPLICATION}

Sensitivity analyses of the ${ }^{155} \mathrm{Eu}$ in a typical burnup credit application were performed with the TSUNAMI sequence in SCALE 5.1 (Ref. 12). The sensitivity of $\mathrm{k}_{\text {effective }}$ to the ${ }^{155} \mathrm{Eu}$ total cross section for the GBC-32 model is shown in Fig. 42. The burnup credit model is sensitive to the ${ }^{155} \mathrm{Eu}$ cross sections in the thermal energy region $(0.0253 \mathrm{eV})$ up to about $1 \mathrm{eV}$ and is relatively insensitive to cross-section data above $1 \mathrm{eV}$. 


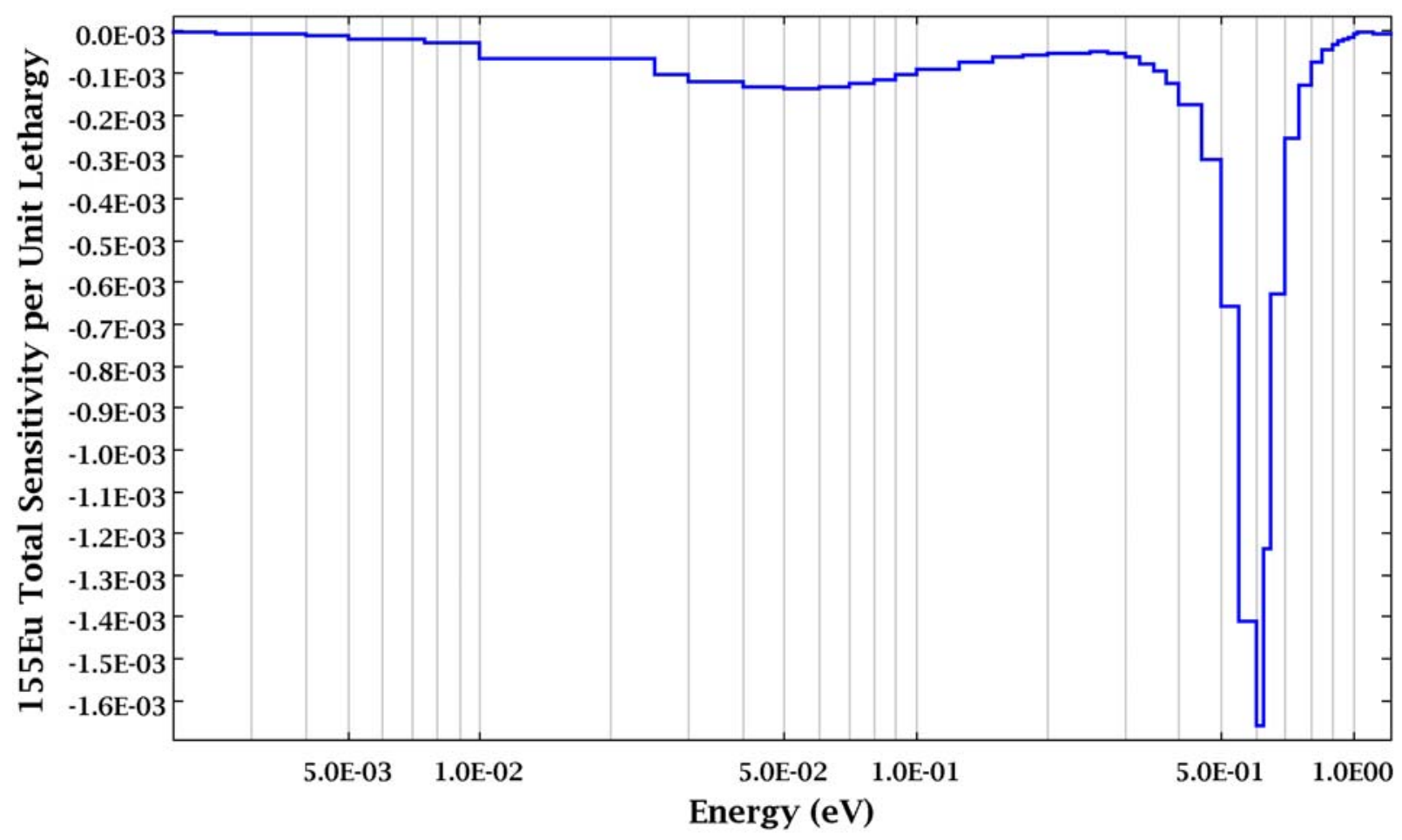

Fig. 42. Sensitivity of the $\mathbf{k}_{\text {effective }}$ to the ${ }^{155}$ Eu total cross section for the GBC-32 model.

\subsection{ASSESSMENT SUMMARY AND RECOMMENDATIONS FOR ${ }^{155}$ Eu}

Because the ENDF, JEFF, and JENDL evaluations for ${ }^{155} \mathrm{Eu}$ are judged to be fairly similar, the three libraries are considered to be comparable in rigor. As a result, the ENDF evaluation for ${ }^{155} \mathrm{Eu}$ is used in the FP assessment. An investigation of the ${ }^{155}$ Eu resonance evaluation revealed that the resolved resonance parameters are based on the Mughabghab ${ }^{14}$ compilation, and the unresolved resonance parameters were obtained from cross-section measurements. When compared with available experimental data listed in EXFOR, the only measured cross-section data for ${ }^{155} \mathrm{Eu}$ are a thermal capture cross-section measurements at $0.0253 \mathrm{eV}$. With regard to benchmark performance, ${ }^{155} \mathrm{Eu}$ benchmark experiments are not available in the open literature. Based on the cross-section evaluation assessment, total and capture ${ }^{155} \mathrm{Eu}$ cross-section measurements are needed from $10^{-5} \mathrm{eV}$ and extending through the resonance region. While there is a general need for cross-section measurements throughout this energy range, sensitivity analysis of a typical burnup credit application indicates that ${ }^{155} \mathrm{Eu}$ cross-section measurements for energies up to about $1 \mathrm{eV}$ are most important for burnup credit applications.

In addition, the latest evaluated data files do not provide cross-section covariance information for ${ }^{155} \mathrm{Eu}$, and new measurement and evaluation efforts will provide cross-section covariance data in addition to improved cross-section data. At a minimum, providing covariance data will benefit burnup credit analyses by enabling the propagation of ${ }^{155}$ Eu cross-section uncertainty to calculated $k_{\text {effective }}$ values. 


\section{CONCLUSION AND RECOMMENDATIONS}

This work provides an assessment of the latest cross-section data for several FPs with the highest worth to burnup credit: ${ }^{149} \mathrm{Sm},{ }^{143} \mathrm{Nd},{ }^{103} \mathrm{Rh},{ }^{151} \mathrm{Sm},{ }^{133} \mathrm{Cs},{ }^{155} \mathrm{Gd}$, and ${ }^{152} \mathrm{Sm}$. In addition, ${ }^{153} \mathrm{Eu}$, and ${ }^{155} \mathrm{Eu}$ are included in this assessment because the ${ }^{155} \mathrm{Gd}$ concentration in SNF is highly dependent on ${ }^{155} \mathrm{Eu}$ and to a lesser extent ${ }^{153} \mathrm{Eu}$, and calculated isotopic predictions for ${ }^{155} \mathrm{Gd}$ often show significant differences when compared to measured results. The assessment focused on the latest FP cross-section evaluations that are available in the ENDF, JEFF, and JENDL libraries as of March 2005. The latest evaluations used in the report correspond to ENDF/B-VI.8, JEFF3.0, and JENDL3.3.

The accuracy of the data was investigated by using differential and integral data. Measured differential data were retrieved from the EXFOR system and compared with continuous-energy cross sections obtained from the evaluated nuclear data libraries processed with the NJOY and AMPX code systems. To verify the adequacy of the evaluated data in integral benchmark calculations, MCNP and SCALE were used to investigate the performance of the FP data in benchmark calculations. Integral benchmark experiments were used to assess the cross sections for ${ }^{103} \mathrm{Rh}$ and ${ }^{149} \mathrm{Sm}$. Reactivity worth measurements carried out at the French Atomic Energy Commission at Cadarache were used to assess the cross sections for ${ }^{103} \mathrm{Rh},{ }^{133} \mathrm{Cs}$, ${ }^{153} \mathrm{Eu},{ }^{143} \mathrm{Nd}$, and ${ }^{149} \mathrm{Sm}$. With regard to ${ }^{155} \mathrm{Gd}$, critical benchmark experiments involving gadolinium are available in the open literature; however, the available benchmarks do not exhibit strong sensitivity to ${ }^{155} \mathrm{Gd}$. Benchmark experiments that are sensitive to ${ }^{155} \mathrm{Gd}$ are available in the CERES experimental program involving $\mathrm{UO}_{2}$ in the Minerve and Dimple reactors; however, these data are not available in the open literature. Based on the summary of C/E results, ${ }^{37}$ the ${ }^{155} \mathrm{Gd}$ cross-section data under predict the experimental capture rate by 2-3\%. With regard to the remaining fission products, integral benchmark data sensitive to the ${ }^{151} \mathrm{Sm},{ }^{152} \mathrm{Sm}$ and ${ }^{155} \mathrm{Eu}$ cross sections are not available. The resonance parameters for ${ }^{151} \mathrm{Sm},{ }^{152} \mathrm{Sm},{ }^{155} \mathrm{Gd}$, and ${ }^{155} \mathrm{Eu}$ in the existing cross-section libraries are basically the parameters listed in the Mughabghab compilation with minor modifications. Resonance parameters listed in the Mughabghab compilation are a collection of evaluations used to investigate issues related to nuclear physics. Moreover, these parameters do not represent a R-matrix analysis of all resonances that are measured throughout the resonance region. The Mughabghab parameters are typically used as a starting point for a resonance analysis of measured cross-section data. Therefore, the authors recommend that measured cross-section data with a corresponding R-matrix analysis be used to improve evaluations that are based solely on the compilation of Mughabghab resonance parameters. The conclusion is that there is a definite need for total and capture cross-section measurements for the nine FPs assessed in this work.

The recommended FP measurements are provided in Table 16 with a tabulated summary of the FP assessment in Table 17. The basis for the recommendations in Table 16 is documented in the body of the report, and Table 17 provides a "quick-reference" summary of the cross-section data assessment. For the FPs noted in Table 16, new cross-section measurements and corresponding cross-section evaluations would improve confidence in reactivity predictions in burnup credit applications. In Tables 16 and 17 , each FP is identified according to the priority of importance for burnup credit. In addition, Tables 16 and 17 provide a proposed ordering for addressing each FP, and this order does not exactly match the priority for burnup credit. Primarily, the "Proposed order to address" column was determined based on the opportunity to leverage current international work activities to produce improved cross-section data evaluations as quickly as possible. Additional details about international work activities are provided in the later part of this section. In addition to current international work efforts, the top three FPs in the "Proposed order to address" column are also stable isotopes. The task of procuring samples and performing measurements with these stable isotopes is straightforward and provides the best opportunity 
for success (i.e., completed cross-section measurement with corresponding evaluation) in a relatively short period of time (i.e., 1 to 2 years).

Table 16. Recommended FP cross-section measurements

\begin{tabular}{|c|c|c|c|c|c|c|}
\hline $\begin{array}{l}\text { Priority for } \\
\text { burnup } \\
\text { credit }\end{array}$ & $\begin{array}{l}\text { Proposed } \\
\text { order to } \\
\text { address }\end{array}$ & $\begin{array}{l}\text { Fission } \\
\text { product }\end{array}$ & $\begin{array}{c}\text { Applicable } \\
\text { energy range for } \\
\text { burnup credit }\end{array}$ & Total & Capture & $\begin{array}{c}\text { Evaluated } \\
\text { covariance } \\
\text { data currently } \\
\text { available }\end{array}$ \\
\hline 1 & 5 & ${ }^{149} \mathrm{Sm}$ & $0.0253-1 \mathrm{eV}$ & $\begin{array}{l}10^{-5} \mathrm{eV} \text { through } \\
\text { RRR }\end{array}$ & $\begin{array}{l}10^{-5} \mathrm{eV} \text { through } \\
\text { RRR }\end{array}$ & No \\
\hline 2 & 4 & ${ }^{143} \mathrm{Nd}$ & $0.0253-600 \mathrm{eV}$ & $\begin{array}{l}10 \mathrm{eV} \text { through } \\
\text { RRR }\end{array}$ & $\begin{array}{l}10 \mathrm{eV} \text { through } \\
\text { RRR }\end{array}$ & No \\
\hline 3 & 1 & ${ }^{103} \mathrm{Rh}$ & $0.0253-3 \mathrm{eV}$ & $10^{-5} \mathrm{eV}-1 \mathrm{eV}$ & $\begin{array}{l}10^{-5} \mathrm{eV} \text { through } \\
\text { RRR }\end{array}$ & No \\
\hline 4 & 6 & ${ }^{151} \mathrm{Sm}$ & $0.0253-10 \mathrm{eV}$ & $\begin{array}{l}4 \mathrm{eV} \text { through } \\
\text { RRR }\end{array}$ & $\begin{array}{l}10^{-5} \mathrm{eV} \text { through } \\
\text { RRR }\end{array}$ & No \\
\hline 5 & 2 & ${ }^{133} \mathrm{Cs}$ & $0.0253-1 \mathrm{keV}$ & $\begin{array}{l}10 \mathrm{eV} \text { through } \\
\text { RRR }\end{array}$ & $\begin{array}{l}10^{-5} \mathrm{eV} \text { through } \\
\text { RRR }\end{array}$ & No \\
\hline 6 & 3 & ${ }^{155} \mathrm{Gd}$ & $0.0253-5 \mathrm{eV}$ & $\begin{array}{l}10^{-5} \mathrm{eV} \text { through } \\
\text { RRR }\end{array}$ & $\begin{array}{l}10^{-5} \mathrm{eV} \text { through } \\
\text { RRR }\end{array}$ & Yes \\
\hline 7 & 7 & ${ }^{152} \mathrm{Sm}$ & $0.0253-100 \mathrm{eV}$ & $\begin{array}{l}10^{-5} \mathrm{eV} \text { through } \\
\text { RRR }\end{array}$ & $\begin{array}{l}10^{-5} \mathrm{eV} \text { through } \\
\text { RRR }\end{array}$ & No \\
\hline 8 & 8 & ${ }^{153} \mathrm{Eu}$ & $0.0253-1 \mathrm{keV}$ & $\begin{array}{l}10^{-5} \mathrm{eV} \text { through } \\
\text { RRR }\end{array}$ & $\begin{array}{l}10^{-5} \mathrm{eV} \text { through } \\
\text { RRR }\end{array}$ & No \\
\hline 9 & 9 & ${ }^{155} \mathrm{Eu}$ & $0.0253-1 \mathrm{eV}$ & $\begin{array}{l}10^{-5} \mathrm{eV} \text { through } \\
\text { RRR }\end{array}$ & $\begin{array}{l}10^{-5} \mathrm{eV} \text { through } \\
\mathrm{RRR}\end{array}$ & No \\
\hline
\end{tabular}


Table 17. FP assessment summary

\begin{tabular}{|c|c|c|c|c|c|c|c|}
\hline \multirow{2}{*}{$\begin{array}{l}\text { Priority } \\
\text { for } \\
\text { burnup } \\
\text { credit }\end{array}$} & \multirow{2}{*}{$\begin{array}{c}\text { Proposed } \\
\text { order to } \\
\text { address }\end{array}$} & \multirow{2}{*}{$\begin{array}{l}\text { Fission } \\
\text { product }\end{array}$} & \multicolumn{2}{|c|}{$\begin{array}{l}\text { Measured data available in } \\
\text { EXFOR }\end{array}$} & \multirow{2}{*}{$\begin{array}{c}\text { Findings from } \\
\text { comparisons } \\
\text { with } \\
\text { benchmark } \\
\text { criticality } \\
\text { experiments }\end{array}$} & \multirow{2}{*}{$\begin{array}{l}\text { Findings from } \\
\text { reactivity worth } \\
\text { experiments }\end{array}$} & \multirow{2}{*}{$\begin{array}{c}\text { GBC-32 } \\
\text { cask } \\
\% \Delta \mathbf{k} / \mathbf{k}\end{array}$} \\
\hline & & & Total & Capture & & & \\
\hline 1 & 5 & ${ }^{149} \mathrm{Sm}$ & $\begin{array}{c}6.47 \times 10^{-4} \mathrm{eV} \\
\text { to } 0.028 \mathrm{eV}\end{array}$ & N/A & $\begin{array}{c}\text { capture worth } \\
\text { underestimated }\end{array}$ & $\begin{array}{c}\text { capture rate } \\
\text { underestimated by } \\
4.8 \%\end{array}$ & 0.023 \\
\hline 2 & 4 & ${ }^{143} \mathrm{Nd}$ & $\begin{array}{l}10^{-2} \text { to } 10 \mathrm{eV} \\
60 \mathrm{eV} \text { to } 30 \mathrm{keV}\end{array}$ & $10^{-2}$ to $10 \mathrm{eV}$ & N/A & $\begin{array}{c}\text { capture rate } \\
\text { underestimated by } \\
0.7 \%-8.5 \%\end{array}$ & 0.037 \\
\hline 3 & 1 & ${ }^{103} \mathrm{Rh}$ & $18 \mathrm{eV}$ to $4.2 \mathrm{keV}$ & $\begin{array}{l}100 \mathrm{eV} \text { to } \\
20 \mathrm{Mev}\end{array}$ & not conclusive & $\begin{array}{c}\text { capture rate } \\
\text { overestimated by } 8 \%- \\
12.9 \%\end{array}$ & 0.022 \\
\hline 4 & 6 & ${ }^{151} \mathrm{Sm}$ & $10^{-5}$ to $4 \mathrm{eV}$ & $\begin{array}{l}0.39 \text { to } \\
34 \mathrm{keV} \\
\text { N/A }\end{array}$ & N/A & N/A & 0.015 \\
\hline 5 & 2 & ${ }^{133} \mathrm{Cs}$ & $\begin{array}{c}0.6 \text { to } 20 \mathrm{eV} \\
0.016 \text { to } 4.4 \mathrm{eV}\end{array}$ & N/A & N/A & $\begin{array}{c}\text { capture rate } \\
\text { overestimated by } \\
5.5 \%\end{array}$ & 0.015 \\
\hline 6 & 3 & ${ }^{155} \mathrm{Gd}$ & $\begin{array}{c}11 \text { to } 570 \mathrm{eV} \\
0.0195 \text { to } \\
0.2793 \mathrm{eV}\end{array}$ & $0.0253 \mathrm{eV}$ & not conclusive & $\begin{array}{c}\text { capture rate } \\
\text { underestimated } \\
\text { by } 2-3 \%\end{array}$ & 0.003 \\
\hline 7 & 7 & ${ }^{152} \mathrm{Sm}$ & N/A & N/A & N/A & $\begin{array}{c}\text { capture rate } \\
\text { underestimated by } \\
\sim 8 \%\end{array}$ & 0.007 \\
\hline 8 & 8 & ${ }^{153} \mathrm{Eu}$ & $10^{-3}$ to $1 \mathrm{eV}$ & $10^{-2}$ to $1 \mathrm{eV}$ & N/A & not conclusive & 0.007 \\
\hline 9 & 9 & ${ }^{155} \mathrm{Eu}$ & N/A & $\begin{array}{l}1 \text { to } 10 \mathrm{eV} \\
0.0253 \mathrm{eV}\end{array}$ & N/A & N/A & 0.008 \\
\hline
\end{tabular}


The burnup credit program developed by the European Community has expressed concerns regarding FP isotopes with high capture cross sections. The program identified a series of FPs for which nuclear data are deficient for reproducing integral benchmark experiment results. ${ }^{40}$ In CY 2005, the Institute for Reference Materials and Measurements (IRMM) of the Joint Research Center located in Geel, Belgium, initiated low-energy (i.e., up to 500-eV) cross-section measurements at the GELINA (Geel Electron Linear Accelerator) facility for ${ }^{103} \mathrm{Rh}$. In addition, IRMM has initiated cross-section measurements for ${ }^{133} \mathrm{Cs}$, and the opportunity exists to build upon the measurement work completed by IRMM. The GELINA facility is comparable to the ORELA (Oak Ridge Electron Linear Accelerator) measurement facility at ORNL, and ORELA has the capability to both confirm the existing GELINA measurements and extend the measurements to higher energies, thereby improving the cross-section evaluations. Because of the work already completed by IRMM and the availability of ${ }^{103} \mathrm{Rh}$ and ${ }^{133} \mathrm{Cs}$ measurement samples, ${ }^{103} \mathrm{Rh}$ and ${ }^{133}$ Cs cross-section measurements and evaluations should be completed initially. In addition, ORNL currently has measurement samples for ${ }^{155} \mathrm{Gd}$ readily available. Therefore, ${ }^{155} \mathrm{Gd}$ should be addressed following ${ }^{103} \mathrm{Rh}$ and ${ }^{133} \mathrm{Cs}$. Once ${ }^{103} \mathrm{Rh},{ }^{133} \mathrm{Cs}$, and ${ }^{155} \mathrm{Gd}$ measurements are completed, cross-section measurements should be performed for ${ }^{149,151,152} \mathrm{Sm}$, and ${ }^{143} \mathrm{Nd}$. Although ${ }^{143} \mathrm{Nd}$ has higher worth relative to ${ }^{151} \mathrm{Sm}$ and ${ }^{152} \mathrm{Sm},{ }^{149} \mathrm{Sm}$ has more worth than ${ }^{143} \mathrm{Nd}$ for burnup credit; however, it is more efficient and practical to procure samples and perform measurements for all three samarium isotopes simultaneously. As new cross-section measurements are completed, resonance analysis work can be initiated to develop new FP cross-section evaluations. As a result, FP measurements and evaluation work can be performed in parallel to improve the FP cross-section database. Once the seven "high-priority" FPs are addressed, additional efforts should focus on improving cross-section data for ${ }^{153} \mathrm{Eu}$ and ${ }^{155} \mathrm{Eu}$ in an effort to improve ${ }^{155} \mathrm{Gd}$ isotopic predictions. Reevaluations of cross-section data should include a more rigorous and complete evaluation of cross-section uncertainty information. Note that recent measurement and analysis work has been completed by Rensselaer Polytechnic Institute (RPI) for natural Sm, Nd, and Gd.41, 42, 43 Note that the recent measurements for Sm, Nd, and Gd were performed on natural samples. Measurements for enriched isotopic samples would improve the resonance analyses for ${ }^{149,151,152} \mathrm{Sm}$, ${ }^{143} \mathrm{Nd}$, and ${ }^{155} \mathrm{Gd}$. Therefore, the recent work by RPI for natural Sm, Nd, and Gd should be used in conjunction with the cross-section measurements and analyses that are recommended in this report.

Finally, integral experiments and differential data measurements and evaluations provide the foundation for improving nuclear data accuracy. Therefore, it is recommended that critical benchmark experiments involving ${ }^{133} \mathrm{Cs},{ }^{143} \mathrm{Nd},{ }^{151} \mathrm{Sm},{ }^{155} \mathrm{Gd},{ }^{153} \mathrm{Eu}$, and ${ }^{155} \mathrm{Eu}$ be performed. The recommended FP critical experiments can be used together with the recommended FP cross-section measurement and evaluation program to develop improved FP cross-section evaluations for supporting nuclear fuel cycle safety applications. 


\section{REFERENCES}

1. I. C. Gauld and D. E. Mueller, Evaluation of Cross-Section Sensitivities in Computing Burnup Credit Fission Product Concentrations, ORNL/TM-2005/48, UT-Battelle, LLC, Oak Ridge National Laboratory, August 2005.

2. J. C. Wagner, Computational Benchmark for Estimation of Reactivity Margin from Fission Products and Minor Actinides in PWR Burnup Credit, NUREG/CR-6747 (ORNL/TM-2000/306), U.S. Nuclear Regulatory Commission, Oak Ridge National Laboratory, October 2001.

3. "Evaluated Nuclear Data File (ENDF)," Database Version of February 9, 2004, URL http://www.nndc.bnl.gov/endf/index.html National Nuclear Data Center, Brookhaven National Laboratory Associated Universities, INC., Upton, Long Island, New York.

4. K. Shibata, "Descriptive Data of JENDL-3.3” Japan Atomic Energy Research Institute-Data/Code 2002-026 (January 2003).

5. “The JEFF-3.0 Nuclear Data Library,” JEFF Report 19, OECD/NEA Data Bank ISBN 92-6401046-7 (April 2005).

6. "Experimental Nuclear Reaction Data (EXFOR/CSISRS)," Database Version of January 21, 2005, URL http://www.nndc.bnl.gov/exfor/index.html National Nuclear Data Center, Brookhaven National Laboratory Associated Universities, Inc., Upton, Long Island, New York.

7. M. E. Dunn and N. M. Greene, "AMPX-2000: A Cross-Section Processing System for Generating Nuclear Data for Criticality Safety Applications,” Trans. Am. Nucl. Soc., 86, 118-119 (2002).

8. R. E. MacFarlane and D. W. Muir, NJOY99.0 Code System for Producing Pointwise and Multigroup Neutron and Photon Cross Sections from ENDF/B-VI Data, PSR 480/NJOY99.0, Los Alamos National Laboratory, March 2000.

9. K. H. Guber, L. C. Leal, R. O. Sayer, P. E. Koehler, T. E. Valentine, H. Derrien, and J. A. Harvey, "New Neutron Cross-Section Measurements at ORELA for Improved Nuclear Data Calculations," International Conference on Nuclear Data for Science and Technology (ND2004), 1706-1711, Santa Fe, NM (September 26-October 1, 2004).

10. M. B. Chadwick et al., "ENDF/B-VII.0 Next Generation Evaluated Nuclear Data Library for Nuclear Science and Technology,” Special Issue on Evaluated Nuclear Data File ENDF/B-VII.0 Nuclear Data Sheets, 107(12), 2931-3059 (December 2006).

11. SCALE: A Modular Code System for Performing Standardized Computer Analyses for Licensing Evaluation, ORNL/TM-2005/39, Version 5, Vols. I-III, "STARBUCS: A SCALE Control Module for Automated Criticality Safety Analyses Using Burnup Credit,” Vol. I, Sect. C10 (April 2005). Available from Radiation Safety Information Computational Center at Oak Ridge National Laboratory as CCC-732.

12. SCALE: A Modular Code System for Performing Standardized Computer Analyses for Licensing Evaluation, ORNL/TM-2005/39, Version 5.1, Vols. 1-III, “TSUNAMI-3D: Control Module for Three-Dimensional Cross-Section Sensitivity and Uncertainty Analysis for Criticality,” Vol. I, Book 2, Sect. C9 (November 2006). Available from Radiation Safety Information Computational Center at Oak Ridge National Laboratory as CCC-732.

13. D. G. Bowen and S. P. Monahan ENDF/B Information Review in Support of the Yucca Mountain Criticality Safety Methodology, Los Alamos National Laboratory Report HSR-6-04-029 LA-UR04-3482, May 2004.

14. S. F. Mughabghab, Neutron Resonance Parameters and Thermal Cross Sections, Part B, Z=61100, Vol. 1, National Nuclear Data Center, Brookhaven National Laboratory, Upton, New York, 1984.

15. Ribon et al., ${ }^{103} \mathrm{Rh}$ total cross-section data available in the EXFOR system with accession number 20148. 
16. Moxon et al., ${ }^{103} \mathrm{Rh}$ capture cross-section data available in the EXFOR system with accession number 20914.

17. Popov et al., ${ }^{103} \mathrm{Rh}$ capture cross-section data available in the EXFOR system with accession number 40797.

18. G. A. Harms, P. H. Helmick, J. T. Ford, S. A. Walker, D. T. Berry, and P. S. Pickard, Experimental Investigation of Burnup Credit for Safe Transport, Storage, and Disposal of Spent Nuclear Fuel, Sandia National Laboratories SAND2004-0912, April 2004.

19. LEU-COMP-THERM-079, International Handbook of Evaluated Criticality Safety Benchmark Experiments, NEA/NSC/DOC(95)03, Organization for Economic Co-operation and Development Nuclear Energy Agency, Nuclear Science Committee, September 2006.

20. MCNP4C Monte Carlo N-Particle Transport Code System, CCC-700/MCNP4C, Los Alamos National Laboratory (April 2000).

21. SCALE: A Modular Code System for Performing Standardized Computer Analyses for Licensing Evaluations, NUREG/CR-0200, Rev. 7 (ORNL/NUREG/CSD-2/R7), Version 4.4a, Vols. I, II, and III, May 2004 (DRAFT). Available from Radiation Safety Information Computational Center at Oak Ridge National Laboratory as CCC-725. See also, B. T. Rearden, C. M. Hopper, K. R. Elam, S. Goluoglu, and C. V. Parks, "Applications of the TSUNAMI Sensitivity and Uncertainty Analysis Methodology," pp. 61-66 in Proc. of The 7th International Conference on Nuclear Criticality Safety (ICNC2003), October 20-24, 2003, Tokai-mura, Japan.

22. A. Santamarina, N. Thiollay, and C. Chabert, "JEF2 Fission Product Qualification Based on French Integral Experiments,” JEFF-Meeting, 12-14 April, 1999. JEFDOC-784.

23. R. Sanchez and J. Mondot, “APOLLO2: A User-Friendly Code for Multigroup Transport Calculations," Topical Meeting on Advances in Nuclear Engineering Computation and Radiation Shielding,” Santa Fe, April 9-13, 1989.

24. J. P. Both and Y. Pénéliau, "The Monte Carlo Code TRIPOLI-4 and Its First Benchmark Interpretation,” Physor 96 Conference, September 1996.

25. Landon et al., ${ }^{133}$ Cs total cross-section data available in the EXFOR system with accession number 12029.

26. Hickman, ${ }^{133}$ Cs total cross-section data available in the EXFOR system with accession number 12004.

27. Harvey et al., ${ }^{133} \mathrm{Cs}$ total cross-section data available in the EXFOR system with accession number 11912.

28. Garg et al., ${ }^{133}$ Cs total cross-section data available in the EXFOR system with accession number 11905.

29. Adib et al., ${ }^{153}$ Eu total cross-section data available in the EXFOR system with accession number 30560.

30. Widder, ${ }^{153}$ Eu total cross-section data available in the EXFOR system with accession number 20437.

31. Vertebny, ${ }^{143} \mathrm{Nd}$ total, capture, and scattering cross-section data available in the EXFOR system with accession number 40290.

32. Tellier, ${ }^{143} \mathrm{Nd}$ total cross-section data available in the EXFOR system with accession number 20118.

33. G. Rohr et al., Proceedings of the Third Conference on Neutron Cross Sections and Technology, Knoxville, Tenn. Vol. 2, 743, 1971.

34. Ohno et al., ${ }^{149} \mathrm{Sm}$ total cross-section data available in the EXFOR system with accession number 20327

35. ICSBEP LEU-COMP-THERM-050, International Handbook of Evaluated Criticality Safety Benchmark Experiments, NEA/NSC/DOC(95)03, Organization for Economic Co-operation and Development, Nuclear Energy Agency, Nuclear Science Committee, September 2006.

36. Kirouac et al., ${ }^{151} \mathrm{Sm}$ total cross-section data available in the EXFOR system with accession number 10503. 
37. P. J. Finck, R. N. Blomquist, C. G. Stenberg, and C. Jammes, "Evaluation of Fission Product Worth Margins in PWR Spent Nuclear Fuel Burnup Credit Calculations,” Argonne National Laboratory, ANL-FRA-1998-1 (1998).

38. Moller et al., ${ }^{155} \mathrm{Gd}$ total cross-section data available in the EXFOR system with accession number 12097.

39. LEU-COMP-THERM-003, International Handbook of Evaluated Criticality Safety Benchmark Experiments, NEA/NSC/DOC(95)03, Organization for Economic Co-operation and Development, Nuclear Energy Agency, Nuclear Science Committee, September 2006.

40. The United States Department of Energy (DOE) and The European Atomic Energy Community (EURATOM) Action Sheet EC-16 "Production of Evaluated Neutron Data File for Fission Products Important for Spent Fuel Burnup Credit Applications,” September 2005.

41. G. Leinweber, J. A. Burke, H. D. Knox, N. J. Drindak, D. W. Mesh, W. T. Haines, R. V. Ballad, R. C. Block, R. E. Slovacek, C. J. Werner, M. J. Trbovich, D. P. Barry, and T. Sato, "Neutron Capture and Transmission Measurements and Resonance Parameter Analysis of Samarium,” Nuclear Science and Engineering, 142, 1-21 (2002).

42. D. P. Barry, M. J. Trbovich, Y. Danon, R. C. Block, R. E. Slovacek, G. Leinweber, J. A. Burke, and N. J. Drindak, "Neutron Transmission and Capture Measurements and Resonance Parameter Analysis of Neodymium from 1 to 500 eV," Nuclear Science and Engineering, 153, 8-25 (2006).

43. G. Leinweber, D. P. Barry, M. J. Trbovich, J. A. Burke, N. J. Drindak, H. D. Knox, R. V. Ballad, R. C. Block, Y. Danon, and L. I. Severnyak, "Neutron Capture and Total Cross-Section Measurements and Resonance Parameters of Gadolinium," Nuclear Science and Engineering, 154, 261-279 (2006). 
ORNL/TM-2005/65

\section{INTERNAL DISTRIBUTION}

\author{
1. G. Arbanas \\ 2. S. M. Bowman \\ 3. B. L. Broadhead \\ 4. M. D. DeHart \\ 5. H. Derrien \\ 6. M. E. Dunn \\ 7. I. C. Gauld \\ 8. J. C. Gehin \\ 9. K. H. Guber \\ 10. J. O. Johnson \\ 11. B. L. Kirk \\ 12. L. M. Larson \\ 13. L. C. Leal \\ 14. D. E. Mueller
}

\author{
15. C. V. Parks \\ 16. J. E. Rushton \\ 17. R. O. Sayer \\ 18. J. C. Wagner \\ 19. R. M. Westfall \\ 20. D. A. Wiarda \\ 21. M. L. Williams \\ 22. Central Research Library \\ 23. OTIC-RC, OSTI, CR
}

\section{EXTERNAL DISTRIBUTION}

24. A. Courcelle, Comissariat a l'Energie Atomique, CEA/Cadarache DEN/DER/SPRC/LEPh, Bat230 13108 Saint Paul Lez Durance, Cedex, France

25. D. E. Carlson, U.S. Nuclear Regulatory Commission, RES/DSARE/REAHFB, MS T10-F13A, Washington, DC 20555-0001

26. R Y. Lee, U.S. Nuclear Regulatory Commission, RES/DSARE/SMSAB, MS T10-K8, Washington, DC 20555-0001

27. Harold H. Scott, U.S. Nuclear Regulatory Commission, RES/DSARE/SMSAB, MS T10-K8, Washington, DC 20555-0001

28. N. S. Thompson, RW-31E/Forrestal Building, U.S. Department of Energy, 1000 Independence Avenue, S.W., Washington, DC 20585

29. C. J. Withee, U.S. Nuclear Regulatory Commission, NMSS/SFPO/TRB, MS O13-D13, Washington, DC 20555-0001

30. M. L. Anderson, Bechtel SAIC Company, LLC, 1261 Town Center Drive, Las Vegas, NV 89134

31. S. Anton, Holtec International, 555 Lincoln Drive West, Marlton, NJ 08503

32. M. C. Brady Raap, Battelle, Pacific Northwest National Laboratory, P.O. Box 999/ MS K8-34, Richard, WA 99352

33. J. M. Conde López, Consejo de Seguridad Nuclear, Jefe de Area de Ingeniería Nuclear, Subdirección General de Technologia Nuclear, Justo Dorado, 11, 28040 Madrid, SPAIN

34. P. Cousinou, Institut de Protection et de Sûreté Nucleaire, Départment de Recherches en Sécurité, CECI B.P. 6 - 92265 Fontenzy-Aux-Roses, Cedex, FRANCE

35. J. N. Gulliford, BNFL, R101, Rutherford House, Risley, Warrington, Cheshire WA3 6AS

36. W. H. Lake, 23 Thomas Dr., Silver Spring, MD 20904-2930

37. D. B. Lancaster, Nuclear Consultants.com, 320 South Corl Street, State College, PA 16801

38. R. Y. Lee, U.S. Nuclear Regulatory Commission, RES/DSARE/SMSAB, MS T10-K8, Washington, DC 20555-0001

39. Holger Pfeifer, NAC International, 655 Engineering Drive, Norcross, GA 30092

40. M. Mason, Transnuclear, Two Skyline Drive, Hawthorne, NY 10532-2120 
41. A. J. Machiels, Electric Power Research Institute, Advanced Nuclear Technology, Energy Conservation Division, 3412 Hillview Ave., Palo Alto, CA 94304-1395

42. C. W. Mays, Framatome ANP, 3315 Old Forest Road, P.O. Box 10935, Lynchburg, VA 24506-0935

43. J. C. Neuber, SIEMENS AG, KWU NS-B, Berliner Str. 295-303, D-63067 OFFENBACH AM MAIN, GERMANY

44. H. Okuno, Japan Atomic Energy Research Institute, Department of Fuel Cycle, Safety Research, 2-4 Shirakata-Shirane, 319-1195 Tokai-mura, Naka-Gun, Ibaraki-ken, JAPAN

45. M. Rahimi, U.S. Nuclear Regulatory Commission, NMSS/DWM/HLWB, MS T7-F3, Washington, DC 20555-0001

46. E. Sartori, OECD/NEA Data Bank, Le Seine-Saint Germain, 12 Boulevard des Iles, F-92130 Issy-lesMoulineaux, FRANCE

47. D. A. Thomas, Bechtel SAIC Company, LLC, 1261 Town Center Drive, Las Vegas, NV 89134

48. A. Wells, 2846 Peachtree Walk, Duluth, GA 30136

49. D. E. Dei, Naval Reactors, 1240 Isaac Hull Avenue SE, Stop 8011, Washington Navy Yard, D.C. 20376-8011

50. Arjan Plompen, EC-JRC-IRMM, Retieseweg 111, B 2440 Geel, Belgium

51. Peter Rullhusen, EC-JRC-IRMM Retieseweg 111, B 2440 Geel, Belgium 